\title{
Firm Dynamics and Residual Inequality in Open Economies*
}

\author{
Gabriel Felbermayr ${ }^{\dagger}{ }^{\dagger}$ Giammario Impullitti, ${ }^{\ddagger}$ and Julien Prat $^{\S}$
}

August 21, 2017

\begin{abstract}
Wage inequality between similar workers has been on the rise in many rich countries. Recent empirical research suggests that heterogeneity in firm characteristics is crucial to understand wage dispersion. Lower trade costs as well as labor and product market reforms are considered critical drivers of inequality dynamics. We ask how these factors affect wage dispersion and how much of their effect on inequality is attributable to changes in wage dispersion between and within firms. To tackle these questions, we incorporate directed job search into a dynamic model of international trade where wage inequality results from the interplay of convex adjustment costs with firms' different hiring needs along their life cycles. Fitting the model to German linked employer-employee data for the years 1996-2009, we find that firm heterogeneity explains about half of the surge in inequality. The most important mechanism is tougher product market competition driven by domestic product market deregulation and, indirectly, by international trade.
\end{abstract}

JEL-Codes: F12, F16, E24.

Keywords: Wage Inequality, International Trade, Directed Search, Firm Dynamics, Product and Labor Market Regulation.

${ }^{*}$ We are grateful to four anonymous referees and to the editor for extremely helpful suggestions and corrections. We also with to than seminar participants at the Universities of Barcelona, Bayreuth, Copenhagen, Edinburgh, Innsbruck, LSE, Mainz, Munich, Nottingham, Salzburg, Tilburg, Warsaw, Warwick, Uppsala, Zurich, CREST, IESE, OFCE as well as the NBER Summer Institute (ITI) and MWIE meeting at the University of Michigan for discussion and insightful comments. We are particularly indebted to Gonzague Vanoorenberghe, Harry Huizinga, Manuel Oechslin, Josef Zweimüller, and Joel Rodrigue. Special thanks goes to Andreas Hauptmann, Karoline Kuchenbaecker, Sybille Lehwald, Pontus Rendahl and Hans-Jörg Schmerer for their invaluable help and advice with data and numerical methods. Felbermayr thanks the German Science Foundation for support under CRC TRR 190. Prat acknowledges the support of the Investissements d'Avenir grant (ANR-11-IDEX-0003/Labex Ecodec/ANR-11-LABX-0047).

${ }^{\dagger}$ Ifo Institute-Leibniz Institute for Economic Research at the University of Munich, CESifo, Munich, Germany; felbermayr@ifo.de.

${ }^{\ddagger}$ University of Nottingham, UK, CESifo Munich, Germany; Giammario.Impullitti@nottingham.ac.uk.

${ }^{\S}$ CNRS (CREST), Paris, France; Institute for Economic Analysis (CSIC), BGSE, Barcelona; julien.prat@ensae.fr. 


\section{Introduction}

Wage inequality has been on the rise in many industrialized countries. According to a recent OECD study, since the mid-1980s, inequality increased in 17 out of 22 OECD member states for which data are available (OECD, 2011). This trend has been particularly pronounced in post unification Western Germany where, measured by the standard deviation of log gross wages, inequality has increased by about $70 \%$ from 1975 to 2009. Most of the adjustment has taken place since the mid 1990s, after formerly communist Middle and Eastern European countries signed free trade agreements with the EU, the so called Europe Agreements, leading to a remarkable increase in Germany's international trade. In the early 2000s, the country also undertook substantial reforms aimed at deregulating its product and labor markets: the Hartz reforms produced a radical restructuring of the labor market, and the European Union's Single Market Program led to ambitious reforms of the product market. The conjunction of these changes makes it difficult to assess their relative contributions to the observed inequality dynamics.

In Germany, less than $10 \%$ of wage inequality is attributable to between-sector effects. Similarly, only a small fraction of wage inequality is attributable to observed worker characteristics (Baumgarten, 2013). In contrast, plant characteristics are much more important, either directly or through their interactions with unobserved worker effects (Card et al., 2013). Using a rich linked employer-employee data set provided by the Institute for Labor Market Research (the so called LIAB data set) we find that about half of the increase in residual inequality between 1996 and 2009 can be attributed to the between-firm component, the dispersion of average pay across firms. Unobserved worker effects are about as important as plant effects, but their link to wage inequality is relatively straight-forward and not in the focus of our work. Traditionally, the literature has stressed changes in the relative returns to education and/or capital. However, these explanations, epitomized by the Stolper-Samuelson theorem, cannot account for the increase in wage dispersion within narrowly defined skill classes, occupations, or industries. Moreover, assuming perfectly competitive markets, the literature often has no means to analyze many labor and product market reforms.

In order to address these shortcomings, we propose a theoretical model of trade with frictional labor markets that generates wage dispersion among similar workers between and within firms. Then, we calibrate the model to German linked employer-employee data and provide a quantitative assessment of the role of international trade, domestic labor and product market

reforms in explaining inequality dynamics. The model introduces directed labor market search 
and convex adjustment costs into a general equilibrium model where firms enjoy different levels of productivity and commit to wage contracts. The model provides a fairly tractable theory of wage dispersion amongst homogeneous workers based on differences in firm sizes and growth rates. Due to convex adjustment costs, firms find it optimal to add employment gradually. More productive firms have higher optimal sizes and, thus, grow faster than less productive firms. These different adjustment needs translate into different wage policies: firms undertaking larger adjustments find it optimal to offer higher wages in order to attract more applicants, which enables them to reduce their total recruitment costs. Since revenue functions are concave, adjustment is fastest in earlier stages. This generates wage dispersion within firms because workers hired at earlier stages of a firm's life cycle are offered contracts with higher present values.

We show that hiring schedules are governed by non-linear second order ordinary differential equations. In general, they cannot be solved analytically and the equilibrium has to be characterized numerically. For this reason, we explain the model properties in a simplified one-period setup, where the standard Melitz (2003) model emerges in the limit case without search frictions. The model generates a positive correlation between wages and firm productivity. It predicts that inequality is higher in open economies, but that it is hump-shaped in the degree of openness. If adjustment costs are strongly convex, growing firms resort to very aggressive hiring policies that guarantee high job filling probabilities but lead to low job finding rates. Consequently, frictional unemployment may increase as trade costs fall.

Firm dynamics are important for our quantitative exercise. In our dynamic economy, firms spread their adjustment needs across time and this tends to relax the effect of trade on inequality. Compressing adjustment into one period would exaggerate the trade-inequality nexus. Moreover, the dynamic model is consistent with a new stylized fact according to which firms grow by filling their vacancies faster. Davis et al. (2013) use US establishment-level data and find that vacancy filling rates rise steeply with firm employment growth rates. We also show that these predictions are consistent with the relationship between plant size, growth, and wages found in the LIAB data. Our framework generates both within and between firm wage dispersion as in the data. The reason is that young firms have steeper growth profiles, hence workers hired by firms in their early stages are offered higher wages compared to those offered to workers hired in more mature stages of the firm life cycle. Finally, in our model, there is always a measure of young but productive firms that would at some point in their lifetime become exporters but have not yet reached the required critical size.

We calibrate the dynamic model to German data, using firm and worker information from 
the LIAB data set. We fit the parameters to salient cross-sectional and aggregate statistics for the year 1996. The model generates a good fit of several key statistics, such as average firm size, the share of exporting firms, the tenure profile of wages, the export wage premium and the between-firm component of residual wage dispersion. Moreover, the link between firm growth and wages reproduces about $40 \%$ of total residual wage inequality observed in the data. Hence the model generates a quite large wage dispersion, considering that the firm growth-wage link is the only engine of inequality and that frictional labor market models notoriously struggle to generate large wage inequality (Hornstein et al. 2010).

In our comparative statics exercises we evaluate the effects of recent trade, product and labor market reforms in Germany. We adjust trade costs such that the model replicates the change of German trade shares observed between 1996 and 2009. We also analyze the effect of lower unemployment benefits and of higher job search efficiency associated with the Hartz reforms. Moreover, in our data, the median markup of firm revenues over variable costs fell from $30 \%$ to $24 \%$ between 1996 and 2009. We relate this increase in product market competition to a higher elasticity of demand. We find that the observed reduction in markups is associated with an increase in overall inequality by a factor of about 1.5 (while the data features an increase by 1.8), and that it explains most dynamics of the relative importance of the between-firm component of inequality. In contrast, lower trade costs (at constant markups) and the Hartz reforms have only minor effects on wage inequality while they matter for the (natural) rate of unemployment. Our key result linking markups and wage dispersion can be explained as follows: an increase in demand elasticity raises the size premium for more productive firms, hence for a given distribution of productivity firm size distribution becomes more dispersed. Since the process of firm growth in our economy links firm size to wages, increases in demand elasticity leads to more dispersion in firm size and ultimately to higher wage inequality.

Our benchmark economy assumes that countries as well as reforms are symmetric. While this is a plausible exercise for the trade and product market reforms which were undertaken simultaneously by the major German trade partners, Germany was rather isolated in its push towards labor market deregulation. For this reason, as a robustness check we develop a small open economy version of the model and compare all the relevant comparative statics of this economy to those obtained in the symmetric-country model. In order to make the results comparable we calibrate the small open economy to replicate the same moments for Germany as in the benchmark symmetric case. We study the effects of labor market reforms taking place only in Germany first, in a scenario where we do not allow for size differences between the two countries and where trade is balanced. Second, we repeat the exercise allowing Germany to 
have the trade surplus we observe in the data. Finally, we perform the same exercise allowing countries to differ in size. In all these scenario we also analyze the effects of multilateral trade liberalization. We show that the key results of the baseline model are robust to the small open economy extension.

Related literature. A number of recent papers have investigated how changes in the distribution of firm revenues brought about by trade liberalization map into changes in the distribution of individual wages of observationally identical workers. ${ }^{1}$ We go beyond the literature by broadening the focus to a wider range of possible drivers of inequality.

Our frictional labor market with directed search and large firms builds on work by Kaas and Kircher (2015). ${ }^{2}$ In contrast to this paper, we allow for general equilibrium feedbacks through firms' revenues, introduce international trade along the lines of Melitz (2003), and focus on wage inequality. Coşar et al. (2016) have also introduced search and convex adjustment costs into the Melitz model. However, their assumptions of random search and continuous renegotiation of wages implies that firms grow by posting more vacancies and not by recruiting faster, and that there is no within-firm wage dispersion. Smooth firm growth and export dynamics is also generated in Fajgelbaum (2013), where search frictions in job-to-job transitions slow down firm growth and entry into export markets with implications for aggregate income and welfare. However, his paper does not study inequality.

Helpman et al. (2010) use a random search model with two-sided heterogeneity and assortative matching. ${ }^{3}$ Workers have different abilities that can be detected through a costly screening process. As more productive firms can put ability to better use, they invest more in screening, hire more able workers, and pay higher wages. This mechanism generates a non-degenerate wage distribution. It is strengthened when trade costs fall. The key difference between the two models is that we present a theory of wage dispersion based on firm characteristics only, whereas wage inequality in Helpman et al. (2010) is produced by assortative matching between unobserved

\footnotetext{
${ }^{1}$ Another literature focuses on the role of trade in affecting the skill premium in representative firms economies (e.g., Acemoglu, 2003; and Epifani and Gancia, 2008), and in models of firm heterogeneity (e.g., Yeaple, 2005; Harrigan and Reshef, 2012)

${ }^{2}$ Kaas and Kircher (2015) extend Moen's (1997) seminal model to an environment where firms employ multiple workers. In related work, Garibaldi and Moen (2010) characterize a directed search model with convex vacancy costs and on-the-job search.

${ }^{3}$ The papers by Helpman and Itskhoki (2010) and Felbermayr and Prat (2011) feature random search, bargaining, and linear adjustment costs. This implies constant wages amongst homogeneous workers. Egger and Kreickemeier (2009) and Amiti and Davis (2012) assume that more productive firms must pay 'fair' wages linked to productivity or operating profits; else, workers do not exert effort. Davis and Harrigan (2012) present a trade model in which firms pay efficiency wages to induce worker effort. Firms with higher labor productivity pay higher wages if they possess an inferior monitoring technology.
} 
workers' abilities and firms. Recently, Card et al. (2013) have used German social security data to show that assortative matching and firm characteristics account for up to $16 \%$ and up to $21 \%$ of the overall dispersion of wages, respectively. Hence, our papers offer two complementary theories of wage dispersion; each accounting for a source of inequality that proves to be substantial in the data.

A number of papers offer quantitative perspectives. Helpman et al. (2017) structurally estimate the Helpman et al. (2010) model on Brazilian data; Egger et al. (2013) and Hauptmann and Schmerer (2013) apply fair wage models to data from France and Balkan countries and to Germany, respectively; Amiti and Davis (2011) provide reduced form evidence for their model from Indonesian data. All these papers find that trade has a non-negligible impact on the distribution of wages. By contrast, Cosar et al. (2016) take their model to the Colombian data and do not find quantitatively important effects of trade on inequality. Similarly, our quantitative analysis suggests that trade was not decisive in shaping German wage dispersion in recent decades. Interestingly, a common feature distinguishing Cosar et al. (2016) and our paper from the rest of the literature, is the use of a dynamic model with convex adjustment costs. This weakens the response of wages to trade liberalization as firms optimally spread their adjustments over time. A recent paper by Bellon (2016) also indicates that the effect of trade crucially depends on the time horizon. Calibrating a model of directed search with large firms and heterogeneous workers, Bellon (2016) finds that trade liberalization has little impact in the long-run although inequality overshoots on the path to the new steady state.

A concurrent line of empirical research focuses on how within-firm inequality shapes the dynamics of wage dispersion. Mueller et al. (2015) show that pay differentials between high and low skilled jobs in the UK correlate with firm size. Barth et al. (2014) find that much of the increase in inequality in the US in the period 1992-2007 comes from increased dispersion of earnings among establishments. Bloom et al. (2015) use a rich US employer-employee data set to show that within-firm inequality is fairly stable and that most of the increase in topincomes is due to the average pay of the firm rather than the within firm pay structure. We provide evidence that a similar dynamics is at work in Germany in recent decades. Given this evidence, our paper appears to be among the first to provide a quantitative perspective on the determinants of within and between firm inequality in general equilibrium. ${ }^{4}$

So far, the recent evolution of wage dispersion in Germany has been analyzed using reducedform econometrics only; see Dustman et al. (2008) and Card et al. (2013). Dauth et al. (2014)

\footnotetext{
${ }^{4}$ One other noteworthy paper is the one by Bagger and Lentz (2015) who do not focus on trade or on firm dynamics.
} 
present reduced form empirical evidence on the role of trade with Eastern Europe and China for employment in Germany. Recent papers by Launov and Waelde $(2013,2016)$ and Krebs and Scheffel (2013) provide a quantitative analysis of the Hartz reforms. However, they focus on unemployment and not on wage dispersion, and they do not contrast institutional reform to product market liberalization.

Outline of the paper. Section 2 provides a set of stylized facts on the evolution of inequality, trade, and institutions in Germany in recent decades. Section 3 lays out the baseline dynamic model. Section 4 sketches a simple one-period model and presents analytical results on the effect of trade liberalization. Section 5 uses the evidence documented in Section 2 to calibrate the dynamic model and explores its properties numerically. The quantitative analysis assesses the role of trade and institutional reforms in shaping the recent dynamics of German wage inequality. Section 6 concludes. Technical details and proofs are relegated to the Appendix.

\section{Germany After the Fall of the Iron Curtain}

\subsection{Rising gross wage inequality}

From 1985 to today, gross wages inequality has sharply increased in Germany, with a substantial acceleration around the year 1993. We use administrative worker-level data based on social security records to document these facts. More precisely, we work with a $2 \%$ random sample of the universe of employed persons under social security (i.e., excluding the self-insured). These data are provided by the Institute for Labor Market Research, the official research body of the Federal Employment Agency. ${ }^{5}$

Following common practice, we focus on male full-time workers aged 20 to 60 with work places in Western Germany for the years 1975 to 2009. Figure 1 plots the variance of log daily wages. It shows that this measure of inequality has doubled from 0.14 in 1985 to 0.28 in 2009 . Strikingly, more than $90 \%$ of this increase has taken place since $1993 .^{6}$

Observable worker characteristics are only of limited help in explaining the rise of wage

\footnotetext{
${ }^{5}$ German social security data covers the whole workforce subject to unemployment insurance. The data is deemed of very high quality. Wage income is censored at the annual Social Security earnings maximum. This affects at most the $14 \%$ highest incomes. We use well-established imputation algorithms to deal with this problem; see Dustmann et al. (2009) for a discussion. The $2 \%$ sample is known as the SIAB data base; a matched employeremployee data set is also available (LIAB data). See Appendix B for details.

${ }^{6} \mathrm{~A}$ similar finding, based on variants of the same data set, is reported by Dustmann et al. (2009) and Card et al. (2013). These authors document that the overall trend and its break in the mid 90s is robust to using alternative inequality measures such as interquartile comparisons of the wage distribution. Fuchs-Schuendeln et al. (2010) confirm the findings using census and survey data.
} 
Figure 1: The variance of raw and residual wages over time in Germany

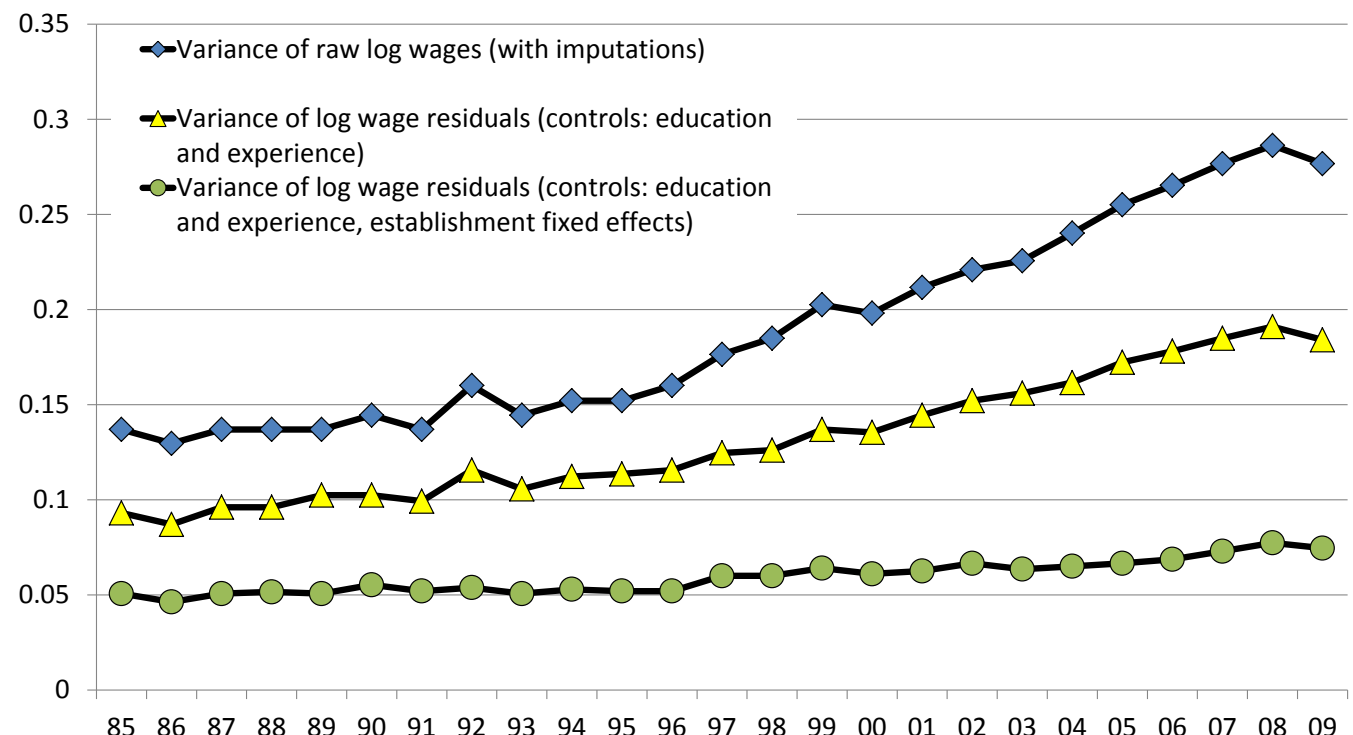

Notes. Variances of log raw daily wages for male, full-time workers in Western Germany using the $2 \%$ sample of German social security data (SIAB). Residual wages from yearly Mincer regression controlling for education and experience, including dummies for region and industry.

inequality. To show this, we run yearly Mincerian wage regressions of the form $\ln w_{i t}=\boldsymbol{\beta} \mathbf{X}_{i t}+\omega_{i t}$ where the vector $\mathbf{X}_{i t}$ contains dummy variables capturing four educational categories as well as a cubic experience term. We find that, from 1985 to 2009, the variance of log residual wages $\omega_{i t}$ has increased by 0.09 points from about 0.09 to 0.18 (see Figure 1). It exhibits a very similar trend as raw inequality. ${ }^{7}$ Also, there is evidence for a break in the series around the year 1993. The evidence suggests that worker observables such as education and experience explain only about one third of the increase in wage inequality since 1985. So, traditional theories based on observational differences between groups of workers, such as the Stolper-Samuelson theorem or mechanisms based on skill-biased technical change, explain only a fraction of the increase in inequality in Germany.

By contrast, adding firm fixed effects to the Mincer regression leads to a different picture: the variance of the residuals from such a regression is almost flat over time, moving from 0.05 in 1985 to 0.06 in 1996 to 0.07 in $2009 .^{8}$ This analysis suggests that establishment fixed effects

\footnotetext{
${ }^{7}$ Similar evidence is found by Violante et al. (2011) for the US, by Jappelli and Pistaferri (2011) for Italy, and by Blundell and Etheridge (2011) for the UK. Evidence for emerging countries is provided by Helpman et al. (2012) for Brazil; or by Xing and Li (2011) for China.

${ }^{8}$ To be perfectly precise: our data identify the establishment (the plant) at which a worker is employed, not a firm (we use the firm identifier betnr in the SIAB data set). In the sequel, we treat plants and firms as
} 
Table 1: Decomposition of log wage variance

\begin{tabular}{lcccccccccc}
\hline \hline & $\mathbf{1 9 8 5 - 1 9 9 1}$ & $\mathbf{1 9 9 0 - 1 9 9 6}$ & \multicolumn{1}{c}{$\mathbf{1 9 9 6 - 2 0 0 2}$} & \multicolumn{2}{c}{$\mathbf{2 0 0 2 - 2 0 0 9}$} & \multicolumn{2}{c}{ Change } \\
& Contrib. & $\%$ & Contrib. & $\%$ & Contrib. & $\%$ & Contrib. & $\%$ & Abs. & $\%$ \\
\hline Worker effects & 0.084 & 61 & 0.093 & 63 & 0.107 & 58 & 0.127 & 51 & 0.043 & 39 \\
Plant effects & 0.025 & 19 & 0.029 & 20 & 0.038 & 21 & 0.053 & 21 & 0.028 & 25 \\
Covariate index & 0.015 & 11 & 0.007 & 5 & 0.008 & 4 & 0.007 & 3 & -0.008 & -7 \\
Cov(worker, plant) & 0.003 & 2 & 0.006 & 4 & 0.018 & 10 & 0.041 & 16 & 0.038 & 34 \\
Sum & $\mathbf{0 . 1 3 7}$ & & $\mathbf{0 . 1 4 7}$ & & $\mathbf{0 . 1 8 4}$ & & $\mathbf{0 . 2 4 9}$ & & $\mathbf{0 . 1 1 2}$ & \\
\hline \hline
\end{tabular}

Notes. Table based on variance decomposition in Card et al. (2013) using log daily wage data for West German, male, full-time workers, aged 20-60, as reported in German social security data (the same data as used in Figure 1); covariates include year dummies, a quadratic and cubic term in age, all fully interacted with educational attainment.

(together with the standard Mincer controls) explain more than $80 \%$ of the total increase in inequality in Germany. ${ }^{9}$

While this last finding suggests an important role for plant-specific effects in explaining total wage inequality in Germany, it is based on a regression design that does not control for unobserved worker abilities and which may therefore be spurious. Card et al. (2013) go beyond this analysis by imposing a log-linear structure such as in Abowd et al. (1999) and assuming that the movement of workers across firms is conditionally exogenous. They decompose the overall variance of observed wages into its components: the variance of an index of worker observables, the variance of the worker effect, the variance of the plant effect, and the covariances between pairs of these objects. Card et al. (2013) employ a regression design that identifies worker and plant effects over 6 year intervals. They work with the same data that underlies our Figure $1 .{ }^{10}$

Table 1 shows that, in any cross-section, the variance of the worker effects provides the largest contribution to the variance of individual wages, ranging between 63 and $51 \%$. The second most important contribution to the overall variance comes from plant effects, with a variance of 0.029 in the $1990-96$ period and of 0.053 in the 2002-09 period. ${ }^{11}$ Our work tries to rationalize the existence of such plant effects and how they are affected by trade liberalization or institutional reform. Notice, however, that the specification applied by Card et al. (2013) implies that worker and firm effects are additively separable; this rules out match effects arising synonymous.

${ }^{9}$ Woodcock (2008) documents the important role of firm effects for the US while Torres et al. (2013) ascribe about $30 \%$ of the overall wage variance in Portugal to firm effects.

${ }^{10}$ Card et al. (2013) use the full population rather than the $2 \%$ sample, which enables them to identify worker effects. Their regression model is given by $\ln w_{i t}=\alpha_{i}+\psi_{j(i, t)}+\beta X_{i t}+r_{i t}$, where $\alpha_{i}$ is a worker effect, $\psi_{j(i, t)}$ is the establishment component, $X_{i t}$ is an index of time-varying worker observables and $r_{i t}$ is a random disturbance.

${ }^{11}$ The variance components missing in Table 1 (the variance of the residual, the covariances between plant or worker effects with the covariate index) make up less than $8 \%$ and do not show any significant trend. 
from log supermodularity between unobserved worker and firm characteristics. So, the variance attributed to firm effects in Table 1 may be inflated by match-effects. As a consequence, we use the Card et al. (2013) results as a reference point against which to evaluate the decomposition predicted by our model, but we do not directly target any of the moments displayed in Table 1.

Table 2: Decomposition of log residual wage variance into a within and a between plant component

\begin{tabular}{lcccccc}
\hline \hline & \multicolumn{2}{c}{$\mathbf{1 9 9 6}$} & \multicolumn{2}{c}{$\mathbf{2 0 0 9}$} & \multicolumn{2}{c}{ Change } \\
& Contrib. & $\%$ & Contrib. & $\%$ & Contrib. & $\%$ \\
\hline Within & 0.06 & 50 & 0.08 & 43 & 0.02 & 35 \\
Between & 0.06 & 50 & 0.10 & 57 & 0.04 & 65 \\
Sum & $\mathbf{0 . 1 2}$ & $\mathbf{1 0 0}$ & $\mathbf{0 . 1 8}$ & $\mathbf{1 0 0}$ & $\mathbf{0 . 0 6}$ & $\mathbf{1 0 0}$ \\
\hline \hline
\end{tabular}

Notes. Decomposition using log daily wage data for West German, male, full-time workers, aged 20-60, as reported in German social security data (LIAB data).

Finally, we decompose the variance of log residual wages into a within-plant and a betweenplant component. ${ }^{12}$ We do so using the LIAB data set, and report the years 1996 and 2009. We find that, in 1996, both components were of similar importance for total wage inequality; in 2009, the relative weight of the within component has decreased to about $43 \%$. Thus, about two thirds of the total increase in inequality is due to the between component. This is in line with the recent findings by Bloom et al. (2015) for the US. Both in 1996 and in 2009 slightly less than $10 \%$ of the between-firm variance shown in the table is between industries; $90 \%$ of it is within industries. ${ }^{13}$ We take this as support for our single-sector modeling strategy.

The evidence suggests an important role for firm effects. It also shows that a non-trivial share of the increase in wage inequality is driven by the between-firm component. While Helpman et al. (2010) analyze the link between trade and the extent of assortative matching, our model focuses on the role of firm effects for both between and within firm components of wage inequality.

\subsection{Increasing competition and institutional reform}

There is an open debate as to the relative roles of labor market reform, technological change, product market deregulation, and international trade in explaining the facts described above.

\footnotetext{
${ }^{12}$ We use the formula $\sigma^{2}=\sum_{z} p_{z} \sigma_{z}^{2}+\sum_{z} p_{z}\left(\bar{w}_{z}-\bar{w}\right)^{2}$, where $z$ indexes a firm, $p_{z}$ is the employment share of firm $z, \bar{w}_{z}$ is the mean wage within a firm $z$, and $\sigma_{z}$ is the standard deviation of wages within a firm $z$. Elements without firm indices refer to the full sample.

${ }^{13}$ Table 1 in Baumgarten (2013) reports a share of within-industry variance of almost $92 \%$ in Germany (as of 1996).
} 
In their empirical work, Autor et al. $(2013,2014)$ have forcefully argued that exposure to competition from China has led to higher wage inequality in the US; Dauth et al. (2014) use similar econometric techniques to show that increased trade with Eastern Europe and China has also boosted earnings dispersion in Germany. Others such as Dustmann et al. (2014) stress the role of institutional changes, in particular labor market reforms. These papers cannot always fully control for other drivers of inequality. Our strategy is to employ a structural equilibrium model where we have full control over counterfactuals.

The upper-left diagram in Figure 2 shows that trade openness has moved very much in tandem with inequality, so that increasing trade integration appears as a potential explanatory variable. The figure plots the ratio of total trade over GDP on the right-side axis. While that measure did not exhibit any positive trend from 1985 to 1993 , it rose from $22 \%$ to $39 \%$ over the 1993-2009 period.

After the end of communism in Middle and Eastern Europe, German firms gained access to markets in its neighborhood with more than 100 million potential consumers. Already in 1991, the European Community had signed a free trade and association agreement with Poland, agreements with other Eastern European countries followed. This led to a massive expansion of trade which is clearly evidenced by the aggregate trade share plotted in Figure 2. A second boost to German trade openness occurred following China's accession to the World Trade Organization (WTO) in late 2001. The strong increase in openness is confirmed with alternative openness measures. Table 3 shows a measure of the German value added content in foreign demand over total German value added (GDP). That measure has increased by less than the overall trade share (due to the increased importance of foreign inputs in German exports). Nevertheless, the approximately 30\% increase in openness registered between 1995 and 2008 still represents a substantial change. ${ }^{14}$ The table also shows that export growth was driven by both the extensive and the intensive margins: the share of manufacturing firms that engage in exporting has risen from 18 to $30 \%$, while the share of exports in the total sales of these firms increased from 20 to $29 \%$. Interestingly, this increase in trade openness is not only associated with rising wage inequality but also with a substantial fall in the unemployment rate, which drops from close to $10 \%$ in 1996 to $7.8 \%$ in 2009 .

Besides ever deeper global integration, Germany enacted an ambitious overhaul of its labor market institutions. The so called Hartz reforms aimed at accelerating labor market flows and reducing unemployment duration. The first two of these reforms, Hartz I and II, active from January 2003, implemented new training programs, new forms of employment for elderly

\footnotetext{
${ }^{14}$ These are the years for which the OECD provides the data.
} 
Figure 2: Residual inequality, trade, and labor market reform
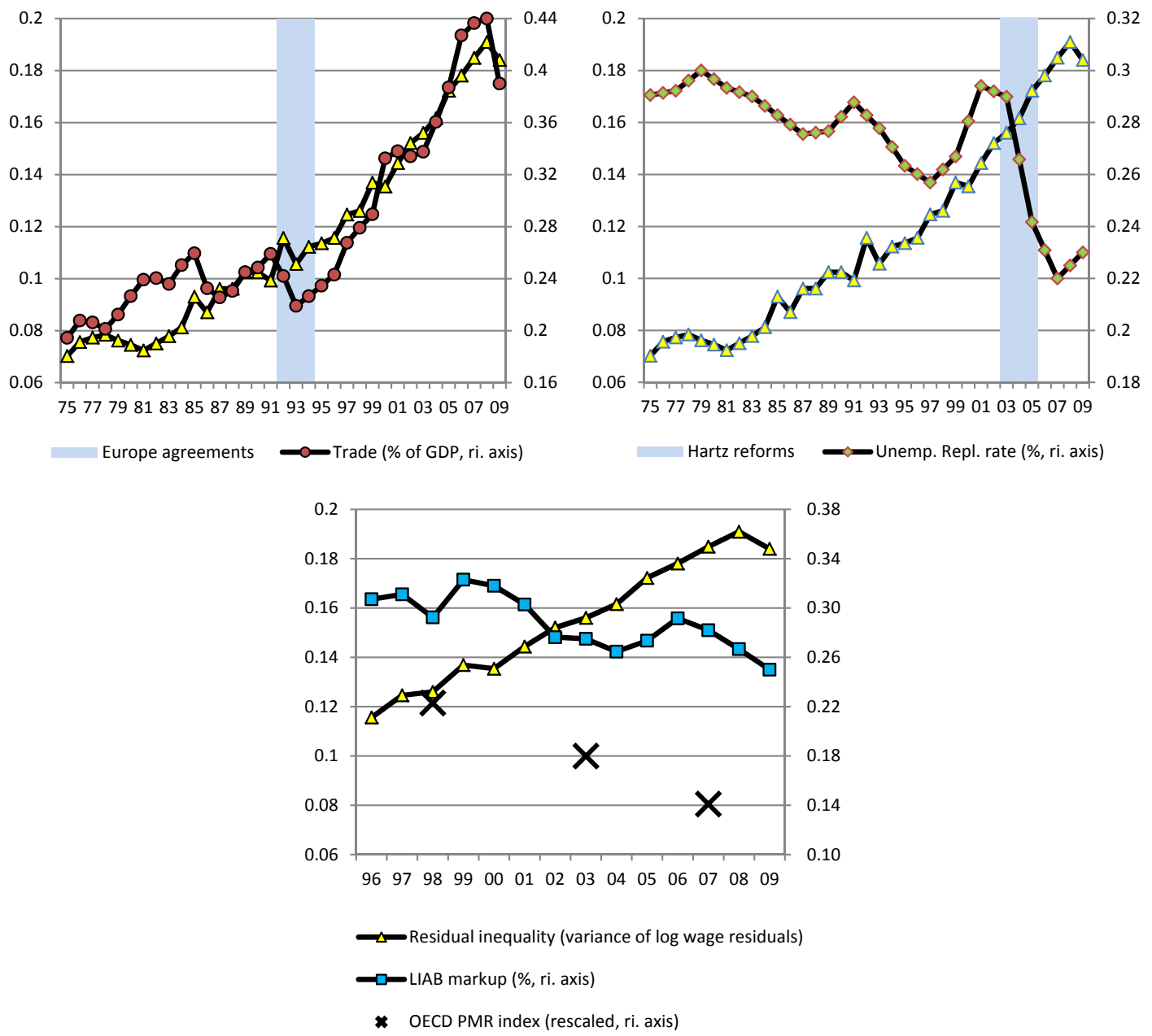

Notes. Inequality data as in Figure 2. Trade refers to exports plus imports over two times GDP. Data from German Federal Statistical Office (Destatis). Gross unemployment replacement rates from OECD (www.oecd.org/els/social/workincentives). Markups computed based on LIAB data. Product market regulation (PMR) index from Koske et al. (2015).

workers and introduced the so called 'mini-jobs', mainly consisting in tax deductions for low-paid or part-time workers. Hartz III, operative from January 2004, consisted in a substantial reform of the federal employment agency which led to the creation of 'job centers' aimed at improving assistance and providing efficient advice to job seekers. ${ }^{15}$ While the first three reforms focused on promoting new forms of employment and improving the job search process, Hartz IV, effective from January 2005 modified the rules for eligibility of unemployment assistance, leading to a reduction in average levels and duration of unemployment benefits.

\footnotetext{
${ }^{15}$ See Jacobi and Kluve (2007) for a detailed description of the Hartz reforms.
} 
Table 3: Aggregate statistics for Germany

\begin{tabular}{|c|c|c|c|}
\hline & 1996 & 2009 & Source \\
\hline \multicolumn{4}{|l|}{ Openness } \\
\hline \multirow{2}{*}{$\begin{array}{l}\text { Agg. export openness (VA based })^{1)} \\
\text { Share of plants with exports }\end{array}$} & $16.69 \%$ & $27.75 \%$ & OECD-WTO TiVA data base \\
\hline & $18.00 \%$ & $30.00 \%$ & LIAB data base \\
\hline $\begin{array}{r}\text { Share of plants with exports }{ }^{2)} \\
\text { Share of exports in exporter sales }{ }^{2}\end{array}$ & $20.00 \%$ & $29.00 \%$ & LIAB database \\
\hline \multicolumn{4}{|l|}{ Institutions } \\
\hline & $26.00 \%$ & $23.00 \%$ & OECD, tax benefits models \\
\hline Product market regulation (index) ${ }^{4}$ & 0.22 & 0.14 & OECD, Koske et al. (2015) \\
\hline Markup ${ }^{2)}$ & $30 \%$ & $24 \%$ & LIAB data base \\
\hline \multicolumn{4}{|l|}{ Labor market outcomes } \\
\hline Variance of raw log wages & 0.16 & 0.28 & SIAB data base \\
\hline Variance of residual log wages & 0.12 & 0.18 & SIAB data base \\
\hline Unemployment rate & $9.90 \%$ & $7.80 \%$ & Destatis \\
\hline \multicolumn{4}{|l|}{ Firm-level average employment levels ${ }^{2}$} \\
\hline non-exporter plants & 12.74 & 13.89 & LIAB data base \\
\hline exporter plants & 96.61 & 89.56 & LIAB data base \\
\hline all plants & 27.56 & 35.12 & LIAB data base \\
\hline
\end{tabular}

Notes. ${ }^{1)}$ Domestic value added embodied in foreign final demand as \% of total value added (GDP); data refer to 1995 and 2008. ${ }^{2)}$ based on information from LIAB data base, manufacturing sector. ${ }^{3)}$ first year refers to $1995 .{ }^{4)}$ years refer to 1998 and 2008.

In order to evaluate the effects of the first three reforms, Fahr and Sunde (2009) and Hertweck and Sigrist (2012) provide an estimation of the matching function and of its changes after the reforms. Their main result shows that the reforms, especially Hartz III, produced a substantial improvement of the efficiency of the matching process in Germany. Fahr and Sunde (2009) find that the flows from unemployment to employment accelerated by $5-10 \%$, corresponding to a reduction in the average unemployment duration of the same order of magnitude. In the upperright diagram in Figure 2, we report OECD estimates of gross unemployment replacement rates for Germany, which document a decline from a level of $29 \%$ in 2001 to $23 \%$ in $2009 .{ }^{16}$ However, the generosity of unemployment benefits has been on a downward trend even before. ${ }^{17}$

Finally, like many other OECD countries, Germany has substantially deregulated its product market. According to information from the OECD's product market regulation (PMR) data

\footnotetext{
${ }^{16}$ See the data on www.oecd.org/els/social/workincentives.

${ }^{17}$ Another important change in labor market institutions in those years is the reduction in collective bargaining coverage which followed German reunification. The German LIAB data show that about $80 \%$ of all firms were covered by industry agreements in 1996; this share declined to about $60 \%$ in 2009 , with most of the decline occurring prior to 2005. We do not study this institutional change here; for an empirical analysis of the links between the fall in collective bargaining and wage inequality in Germany see Dustmann et al. (2009) and Card et al. (2013).
} 
base, from 1998 to 2008 the index of PMR intensity has fallen from 0.22 to $0.14 ;^{18}$ about three quarters of this decline happened from 1998 to 2003 (Koske et al., 2015). The lower diagram in Figure 2 provides an illustration. This index is based on several measures of product market regulations broadly grouped in state control indicators (e.g. scope of public enterprises, price controls), barriers to entrepreneurship (e.g. administrative and legal burdens, barriers to entry), and barriers to trade (e.g. barriers to FDI, discriminatory procedures against foreign firms). Decomposing the sources of regulatory reforms for Germany shows that the liberalization push came mostly from the reduction of state controls and of barriers to entrepreneurship. ${ }^{19}$ The deregulation of the product markets and increased foreign competition may have lowered profit margins of German firms. The lower diagram in Figure 2 plots proxies for markups derived from the LIAB data set. Operating profits are calculated as revenues minus total costs, where total costs are made up of the wage bill plus material inputs. Markups are defined as the share of operating profits in revenues. Quite strikingly, some volatility notwithstanding, markups have trended downwards from about $31 \%$ in 1996 to about $25 \%$ in 2009 .

\section{Model}

We propose a continuous time framework that brings together the Melitz (2003) trade model with the directed search approach of Kaas and Kircher (2015). Trade between two symmetric countries is subject to variable and fixed costs, while the labor market is characterized by searchand-matching frictions and convex adjustment costs. ${ }^{20}$ Workers are homogenous but firms are heterogenous with respect to their productivity.

\subsection{Model setup}

Final output producers. Consumer preferences are linear over a single final output good $Y$ that is produced, under perfect competition, according to an aggregate CES production function

$$
Y=M^{-\frac{1}{\sigma-1}}\left[\int_{\omega \in \Omega} y(\omega)^{\frac{\sigma-1}{\sigma}} d \omega\right]^{\frac{\sigma}{\sigma-1}}, \sigma>1,
$$

\footnotetext{
${ }^{18}$ To ease the presentation, the original OECD index was rescaled using the factor 0.1 .

${ }^{19}$ See Wolf et al. (2015) Table 2. Importantly, that measure is much wider in scope than any index of trade openness.

${ }^{20}$ We opt for a symmetric framework, mostly for the sake of tractability and to avoid simplifying but problematic assumptions (such as the introduction of a linear outside sector). Trade costs have fallen symetrically; hence, our setup comes with little loss of generality.
} 
where the measure of the set $\Omega$ is the mass $M$ of available varieties of intermediate inputs, $\omega$ denotes such an input, $y(\omega)$ is the quantity of the input used, and $\sigma$ is the elasticity of substitution across varieties. The term $M^{-1 /(\sigma-1)}$ neutralizes the scale effect due to love of variety otherwise present in CES aggregator functions. ${ }^{21}$ The price index dual to (1) is given by

$$
P \triangleq\left[\frac{1}{M} \int_{\omega \in \Omega} p(\omega)^{1-\sigma} d \omega\right]^{\frac{1}{1-\sigma}},
$$

and is used as the numeraire, i.e., $P=1$. Then aggregate income is simply equal to $Y$. With these assumptions, demand for an intermediate good $\omega$ is given by the isoelastic inverse demand function

$$
y(\omega)=\frac{Y}{M} p(\omega)^{-\sigma}
$$

Intermediate input producers. Producers of intermediate goods operate under monopolistic competition. Payment of an entry fee of $f_{E} /(r+\delta)$ allow firms to draw their time-invariant productivity levels $z(\omega)$ from a sampling distribution with c.d.f. $G(z)$. Productivity remains constant over a firm's lifetime, but employment $\ell_{a}(\omega)$ is a function of firm age $a$. Output is given by a linear production function

$$
y\left(\ell_{a} ; \omega\right)=z(\omega) \ell_{a}(\omega) .
$$

Due to monopolistic competition, each firm produces a unique variety; the dependence of $z$ and optimal $\ell$ on $\omega$ is understood and suppressed in the present section.

Firms need to pay a flow fixed cost $f$ in order to operate domestically and another flow fixed cost $f_{X}$ if they are present on the export market. Each unit of production shipped abroad is subject to an iceberg-type variable trade cost $\tau \geq 1$. As will be shown later, due to the presence of fixed market access costs in equilibrium only firms with sufficiently high productivity levels $z \geq z_{D}^{*}$ find it profitable to operate, and only the most productive firms featuring $z \geq z_{X}^{*}>z_{D}^{*}$ will also decide to export.

Revenues from exporting are $p_{X} y_{X} / \tau$ and producers face the same demand (3) for domestic and foreign sales. Thus prices and quantities in the domestic and foreign markets satisfy:

\footnotetext{
${ }^{21}$ This avoids a counterfactual negative correlation between the unemployment rate in autarky and the size of the country (labor supply). With trade and symmetric countries, this counterfactual implication is maintained on the world level. See Felbermayr, Prat, and Schmerer (2011) for a discussion of the case of positive gains from variety.
} 
$p_{X}(z)=\tau p_{D}(z)$ and $y_{X}(z)=\tau^{1-\sigma} y_{D}(z)$. Total revenues are therefore given by

$$
R\left(\ell_{a}, \mathbb{I}_{a} ; z\right)=\left[\frac{Y}{M}\left(1+\mathbb{I}_{a} \tau^{1-\sigma}\right)\right]^{\frac{1}{\sigma}}\left(z \ell_{a}\right)^{\frac{\sigma-1}{\sigma}}
$$

where $\mathbb{I}_{a}$ is an indicator function that takes value 1 when the firms serves the foreign market and 0 otherwise.

Directed job search. Labor is the only factor of production. Transactions in the labor market are segmented over a continuum of submarkets, each indexed by its ratio of open vacancies to job seekers $\theta=V(\theta) / S(\theta){ }^{22}$ The matching function in each submarket features constant returns to scale. Thus, if we let $q(\theta)$ denote the vacancy filling rate (with $\partial q(\theta) / \partial \theta<0$ ), $\theta q(\theta)$ is the rate of finding a job (with $\partial[q(\theta) \theta] / \partial \theta>0$ ). We use $\eta \triangleq-q^{\prime}(\theta) \theta / q(\theta)$ to denote the constant elasticity of the filling rate with respect to $\theta$.

Firms are destroyed at the time-invariant Poisson rate $\delta$. Workers and firms separate at the natural attrition rate $\chi$. Both $\delta$ and $\chi$ are treated as exogenous. New firms are continuously created. They differ with respect to their innate productivity levels but start their lives equally small. They grow smoothly over time due the presence of convex adjustment costs, with growth rates depending on productivity. This leads to a cross-section of firms whose employment levels depend on both age and productivity.

We assume that search is directed and that firms have the ability to commit. They post contracts which stipulate wage rates $w$ for any point in time at which the firm operates. Since workers are risk neutral, they do not have preferences over the timing of payments as long as they yield the same discounted sum. Thus we simplify matters by considering that workers are offered a constant income stream. This choice of wage profile is also without loss of generality from the firm's standpoint: it does not affect its optimization problem because promised wages are sunk and, as such, do not affect future decisions. By committing to a wage, firms decide in which submarket $\theta$ they want to recruit and how many vacancies they want to create. Workers have information about each submarket prior to their search and use it to select the submarket in which they apply. Hence conditions across submarkets must be such that workers are indifferent.

It is convenient to derive first the reservation wage as well as the indifference condition

\footnotetext{
${ }^{22} V(\theta)$ and $S(\theta)$ denote the number of open vacancies and job seekers in the submarket with tightness $\theta$. When we refer to 'labor market tightness', we take the perspective of searching workers. A lower value of $\theta$, thus, reflects a tighter labor market.
} 
relating wages across submarkets. Workers' asset values satisfy the following conditions

$$
\begin{gathered}
r E(w)=w+(\delta+\chi)[U-E(w)], \\
r U=b+\theta q(\theta)[E(w)-U],
\end{gathered}
$$

where the interest rate is denoted by $r$ and unemployment benefits (the value of leisure) by $b$. With risk-neutral households the steady state Euler equation yields an interest rate equal to the intertemporal discount factor. The flow value of employment is $r E(w)$. By definition, the reservation wage $w_{r}$ is such that $r U=w_{r}$.

Substituting $E(w)$ out of the above system and using $w_{r}=r U$, we obtain

$$
w_{r}=b+\underbrace{\theta q(\theta)\left[\frac{w(\theta)-w_{r}}{r+\delta+\chi}\right]}_{\triangleq \rho} .
$$

The variable $\rho$ denotes the premium commended by workers over the flow value $b$ of being unemployed. The expression can be rearranged so as to define the indifference condition for workers across submarkets $w(\theta)=w_{r}+\rho(r+\delta+\chi) / \theta q(\theta)$. The condition above shows the positive relationship between wages and the vacancy filling rate typical of directed search models (e.g., Moen, 1997; Acemoglu and Shimer, 1999). Conversely, wages and the job finding rate are negatively related: workers search in submarkets with low wages only if they have a higher probability to find a job. As wages approach the value of leisure, the gains derived from being employed vanish and the arrival rate of jobs diverges to infinity.

\section{$3.2 \quad$ Firm policies}

Consider a firm of age a. Its value $\Pi$ depends on two state variables: the current level of employment $\ell_{a}$ and the cumulated wage bill $W_{a} \triangleq \int_{0}^{a} e^{-\chi(a-s)} q\left(\theta_{s}\right) v_{s} w\left(\theta_{s}\right) d s$. Firms face the adjustment cost function $C(v)$, which is an increasing and strictly positive function of the number of vacancies posted. They solve the following problem:

$$
\begin{aligned}
\Pi\left(\ell_{a}, W_{a} ; z\right) & \triangleq \max _{\left\{\theta_{s}, v_{s}, \mathbb{I}_{s}\right\}} \int_{a}^{\infty} e^{-(r+\delta)(s-a)}\left[R\left(\ell_{s}, \mathbb{I}_{s} ; z\right)-W_{s}-C\left(v_{s}\right)-f-\mathbb{I}_{s} f_{X}\right] d s \\
\text { s.t. } \dot{\ell}_{s} & =q\left(\theta_{s}\right) v_{s}-\chi \ell_{s} ; \\
\dot{W}_{s} & =q\left(\theta_{s}\right) v_{s} w\left(\theta_{s}\right)-\chi W_{s} ; \\
w\left(\theta_{s}\right) & =w_{r}+\frac{\rho}{\theta_{s} q\left(\theta_{s}\right)}(r+\delta+\chi) .
\end{aligned}
$$


The firm chooses the labor market segment $\theta_{s}$ in which it wishes to recruit, and the mass $v_{s}$ of new vacancies to be created at age $s$. It also makes an export decision, i.e., it sets the export dummy $\mathbb{I}_{s}$ to either zero or one. The firm's problem is subject to three constraints. The first constraint (equation (7)) represents the law of motion of firm size: vacancies are filled at the rate $q\left(\theta_{s}\right)$ and jobs are destroyed at the attrition rate $\chi$. Equation (8) describes the law of motion of the cumulated wage bill: at each instant, random separation shocks lower the wage bill by the amount $\chi W_{s}$, while new hires $q\left(\theta_{s}\right) v_{s}$, who are paid the wage $w\left(\theta_{s}\right)$, add to the total wage bill. Equation (9) is a reformulation of the indifference condition (6) derived above.

As explained before, the cumulated wage bill $W$ does not affect future decisions because it is sunk. Expected profits can therefore be decomposed as follows

$$
\Pi\left(\ell_{a}, W_{a} ; z\right)=\Psi\left(\ell_{a} ; z\right)-\frac{W_{a}}{r+\delta+\chi}-\frac{f}{r+\delta},
$$

which allows us to write the value of the firm as the solution of the following Hamilton-JacobiBellman (HJB) equation

$(r+\delta) \Pi\left(\ell_{a}, W_{a} ; z\right)=\max _{\left\{v_{a}, \theta_{a}, \mathbb{I}_{a}\right\}}\left\{R\left(\ell_{a}, \mathbb{I}_{a} ; z\right)-W_{a}-C\left(v_{a}\right)-f-\mathbb{I}_{a} f_{X}+\frac{\partial \Psi\left(\ell_{a}, \mathbb{I}_{a} ; z\right)}{\partial \ell_{a}} \dot{\ell}_{a}-\frac{\dot{W}_{a}}{r+\delta+\chi}\right\}$

Eliminating the terms including $W$ and replacing the law of motions (7) and (8) yields

$$
(r+\delta) \Psi\left(\ell_{a} ; z\right)=\max _{\left\{v_{a}, \theta_{a}, \mathbb{I}_{a}\right\}}\left\{\begin{array}{c}
R\left(\ell_{a}, \mathbb{I}_{a} ; z\right)-C\left(v_{a}\right)-\mathbb{I}_{a} f_{X} \\
+\frac{\partial \Psi\left(\ell_{a}, \mathbb{I}_{a} ; z\right)}{\partial \ell_{a}}\left[q\left(\theta_{a}\right) v_{a}-\chi \ell_{a}\right]-\frac{w\left(\theta_{a}\right)}{r+\delta+\chi} q\left(\theta_{a}\right) v_{a}
\end{array}\right\} .
$$

Recruitment policy. The policy functions are derived by maximizing the simplified Bellman equation (11). Remember that, in each period, a firm chooses the tightness of the submarket in which it recruits along with the number of vacancies. The first order condition with respect to $v$ reads

$$
\frac{C^{\prime}\left(v_{a}\right)}{q\left(\theta_{a}\right)}=\frac{\partial \Psi\left(\ell_{a}, \mathbb{I}_{a} ; z\right)}{\partial \ell_{a}}-\frac{w\left(\theta_{a}\right)}{r+\delta+\chi}
$$

Quite intuitively, the expected marginal cost of hiring an additional worker, $C^{\prime}\left(v_{a}\right) / q\left(\theta_{a}\right)$, should be equal to the worker's shadow value, $\partial \Psi\left(\ell_{a} ; z\right) / \partial \ell_{a}$, minus the discounted wage bill, $w\left(\theta_{a}\right) /(r+\delta+\chi)$.

Maximizing the objective function with respect to $\theta$ yields

$$
\frac{\partial \Psi\left(\ell_{a}, \mathbb{I}_{a} ; z\right)}{\partial \ell_{a}} q^{\prime}\left(\theta_{a}\right)=w^{\prime}\left(\theta_{a}\right) \frac{q\left(\theta_{a}\right)}{r+\delta+\chi}+w\left(\theta_{a}\right) \frac{q^{\prime}\left(\theta_{a}\right)}{r+\delta+\chi}
$$


By varying $\theta$, the firm affects the vacancy filling rate and thus the extent to which it can benefit from the shadow value of a filled vacancy. At the same time, changing $\theta$ also changes expected wage costs, both because a different choice of labor market segment $\theta$ requires the posting of a different wage and because variation in the job fill rate implies variation in the likelihood that the posted wage actually needs to be paid. In equilibrium, the two marginal effects must be identical. Combining (12) and (13), we obtain

$$
\theta_{a}=\frac{1-\eta}{\eta} \frac{\rho}{C^{\prime}\left(v_{a}\right)}
$$

where $\eta$ denotes the elasticity of the matching function.

The relationship between $\theta_{a}$ and $v_{a}$ does not depend on the (endogenous) export status $\mathbb{I}_{a}$. The sign of the relationship is determined by the curvature of the recruitment cost function. When vacancy costs are convex, i.e., $C^{\prime \prime}\left(v_{a}\right)>0$, firms wishing to post more vacancies search in labor markets characterized by higher tightness (lower $\theta_{a}$ ). Since wages are decreasing in market tightness, we can conclude that firms with larger adjustment needs (higher $v_{a}$ ) pay higher wages. Thus, if vacancy costs are convex, the model replicates the positive empirical correlation between firm growth and wages paid to new hires. This result is intuitive: given that recruitment costs increase over-proportionately, firms that wish to hire many workers find it profitable to post higher wages in order to raise their job filling rates.

Proposition 1 (Wage-Size Link) If recruitment costs are strictly convex, firms wishing to expand employment faster post higher wages. If, additionally, recruitment costs are isoelastic, firms with larger steady state employment levels create more vacancies and post higher wages. These effects are bigger, the greater the degree of convexity. Conversely, if recruitment costs are strictly concave, faster growing and larger firms post lower wages.

Proof. The first part of the Proposition is shown in the text. To prove the second part, note that steady state employment of the firm is given by $\bar{\ell}=q(\bar{\theta}) \bar{v} / \chi$ and, hence, $(\partial \bar{\ell} / \partial \bar{v})(\bar{v} / \bar{\ell})=$ $-\eta(\partial \bar{\theta} / \partial \bar{v})(\bar{v} / \bar{\theta})+1$. When the cost function has a constant elasticity $C^{\prime}(v) v / C(v) \equiv \alpha,(14)$ implies $(\partial \bar{\theta} / \partial \bar{v})(\bar{v} / \bar{\theta})=1-\alpha$, and so $(\partial \bar{\ell} / \partial \bar{v})(\bar{v} / \bar{\ell})=1-\eta(1-\alpha)>0$. The sign follows when $C(v)$ is convex, i.e., $\alpha>1$.

In order to capture the well documented correlation between firm size and wages, we will hereafter restrict our attention to convex cost functions. ${ }^{23}$ The empirical literature supports this

\footnotetext{
${ }^{23}$ If $C^{\prime \prime}\left(v_{a}\right)=0$, there is no link between the number of vacancies that a firm wishes to post and the labor market it selects, and, by (6), there would not be any wage dispersion.
} 
assumption. Direct empirical evidence is provided by Merz and Yashiv (2007), who estimate a structural model using US data and show that both labor and capital adjustment costs are strongly convex. Similarly Manning (2006) using UK data finds evidence of convex labor adjustment costs. Besides these findings providing direct support to the convexity assumption, ${ }^{24}$ Davis et al. (2013) find that US firms grow through a smooth process and that, as predicted by our model, faster growing firms fill their vacancies quicker. ${ }^{25}$

Export status. The decision to export depends not only on the productivity, but also on the size (and, thus, on the age) of the firm. Young productive firms start small but gradually build up their work force until exporting a share of their output covers the fixed costs required to access the foreign market. They choose the exporting status that maximizes current revenues net of fixed costs,

$$
\mathbb{I}_{a}(z)=\arg \max _{\mathbb{I}_{a} \in\{0,1\}}\left\{R\left(\ell, \mathbb{I}_{a} ; z\right)-\mathbb{I}_{a} f_{X}\right\} .
$$

The solution to this problem implies that there exists a size threshold $\ell^{X}(z)$, which makes firms indifferent between exporting and not exporting

$$
\ell^{X}(z)=\frac{1}{z}\left(\frac{f_{X}}{\left(\frac{Y}{M}\right)^{\frac{1}{\sigma}}\left[\left(1+\tau^{1-\sigma}\right)^{\frac{1}{\sigma}}-1\right]}\right)^{\frac{\sigma}{\sigma-1}}
$$

so that firms featuring $\ell_{a}(z)>\ell^{X}(z)$ will be exporters. Forward-looking future exporters build up employment before they reach the age $a_{X}(z) \triangleq \inf \left\{a: \mathbb{I}_{a}(z)=1\right\}$ at which they enter the foreign market. Optimal hiring ensures that employment grows smoothly over time. In particular, recruitment intensity does not jump when a firm starts exporting. By contrast, the share of domestic sales in total sales falls discretely at age $a_{X}$ to make room for exports.

Note that the critical size $\ell^{X}(z)$ is decreasing in the firm's productivity level $z$. As we will see below, firms with higher productivity have higher employment growth rates at all ages. This means that they start exporting earlier than less efficient firms. The property of our model, that export status is a function of productivity $z$ and age $a$ rationalizes the overlap in the productivity distribution of exporters and non-exporters observed in the data (e.g. Roberts and

\footnotetext{
${ }^{24}$ Shimer (2010) proposes a theoretical microfundation of convexity in labor adjustment costs. With concave revenues functions, the opportunity cost of reallocating workers from production tasks to recruitment tasks is convex in the size of the adjustment.

${ }^{25}$ The relationship between vacancy filling rates and wages is standard in the competitive search literature (e.g. Moen, 1997, and Acemoglu and Shimer, 1999). Kaas and Kircher (2015) derive a relationship between firm growth and wages similar to that in Proposition 1.
} 
Tybout, 1997; Bernard et al., 2003).

Dynamic conditions. We now derive the dynamic conditions governing the evolution of firm size. The following parametric assumptions provide tractability:

Assumption 1 Vacancy costs are isoelastic, $C(v)=v^{\alpha}$, with $\alpha>1$.

Assumption 2 The matching function is Cobb-Douglas, $q(\theta)=A \theta^{-\eta}$, with $\eta \in(0,1)$.

Solving the HJB equation (11), we obtain the equilibrium employment path and the dynamics of firm sizes and wages.

Proposition 2 (Firm Employment Growth) Under Assumptions 1 and 2, the optimal employment schedule of any given firm satisfies

$$
\left(\frac{\dot{\ell}_{a}+\chi \ell_{a}}{\xi_{0}}\right)^{\xi_{1}}\left(r+\delta+\chi-\xi_{1} \frac{\ddot{\ell}_{a}+\chi \dot{\ell}_{a}}{\dot{\ell}_{a}+\chi \ell_{a}}\right)=\frac{\eta}{\rho}\left[R_{1}\left(\ell_{a}, \mathbb{I}_{a} ; z\right)-w_{r}\right],
$$

with $\xi_{0} \triangleq A^{1+1 / \xi_{1}}\left[\left(\frac{1}{\eta}-1\right) \frac{\rho}{\alpha}\right]^{\frac{1}{\alpha-1}}>0$ and $\xi_{1} \triangleq \frac{1-\eta}{\eta+1 /(\alpha-1)}>0$. The optimal solution to (16) is pinned down by the boundary conditions $(i) \ell_{0}=0$, and (ii) $\lim _{a \rightarrow \infty} \ell_{a}(z)=\bar{\ell}(z)$ with ${ }^{26}$

$$
\left(\frac{\chi \bar{\ell}(z)}{\xi_{0}}\right)^{\xi_{1}}=\frac{\eta}{\rho}\left[\frac{R_{1}[\bar{\ell}(z), \mathbb{I}(\bar{\ell}(z), z) ; z]-w_{r}}{r+\delta+\chi}\right]
$$

The boundary condition for firms that eventually become exporters is given by the smooth pasting condition: $\lim _{\ell_{a} \rightarrow \ell_{z}^{X_{-}}} \dot{\ell}_{a}(z)=\lim _{\ell_{a} \rightarrow \ell_{z}^{X_{+}}} \dot{\ell}_{a}(z)$.

Proof. See Appendix A.1.

According to (17), marginal revenues $R_{1}(\cdot)$ converge to a limit that is higher than the reservation wage $w_{r}$. This is because workers have a strictly positive turnover rate $\chi>0$ and so need to be replaced through costly recruitment. This drives a wedge between the opportunity cost of employment and the productivity of the marginal worker.

Equation (17) also shows that more productive firms converge to larger sizes (since $R_{1}($.$) is$ increasing in $z$ ). Moreover, firms that will end up being exporters have larger size conditional on age than non exporters. Hence, while the firm size distribution is continuous in firm age $a$, it exhibits a discontinuity in the productivity space, as firms with $z \geq z_{X}^{*}$ will be larger at all ages.

\footnotetext{
${ }^{26} \mathrm{~A}$ solution always exists and is unique since the LHS is increasing in $\bar{\ell}$ and has function values in $(0, \infty)$, while the RHS is decreasing and takes values in $\left[-w_{r} \eta /[\rho(r+\delta+\chi)], \infty\right)$.
} 
Ceteris paribus, asymptotic firm sizes are lower the higher the value of unemployment benefits, or the less efficient the matching process. Finally, firms converge to larger sizes the bigger $\sigma$ is, since this reduces monopoly power.

To characterize the equilibrium wage policy for each firm, notice that the equilibrium job finding rate $\theta q(\theta)$ can be expressed as $\left(\left[\dot{\ell}_{a}(z)+\chi \ell_{a}(z)\right] / \xi_{0}\right)^{-\xi_{1}} \cdot{ }^{27}$ Then, the worker indifference condition (9) implies that

$$
w_{a}(z)=w_{r}+\left(\frac{\dot{\ell}_{a}(z)+\chi \ell_{a}(z)}{\xi_{0}}\right)^{\xi_{1}}(r+\delta+\chi)\left(w_{r}-b\right)
$$

By equation (7), this expression shows that search frictions lead to a markup of wages above the reservation wage and that this markup is proportional to the adjustment needs of a firm since $q_{a}(z) v_{a}(z)=\dot{\ell}_{a}(z)+\chi \ell_{a}(z)$. Equation (18) displays a growth and a size premium. A higher efficiency of the search technology lowers those premia, as higher $A$ implies high $\xi_{0}$. A higher degree of convexity $\alpha$ in the adjustment cost function leads to a higher value of $\xi_{1}$ and makes wages more responsive to firms' adjustment needs. The higher the effective discount rate $r+\delta+\chi$, the higher the premium as firms find it even more worthwhile to post higher wages to fill vacancies faster. International trade affects the distribution of wages by affecting the distribution of firm-level adjustment needs. As we will see below, lower trade costs lead to a more skewed distribution of firm sizes and growth rates, thereby altering the distribution of $\dot{\ell}_{a}(z)+\chi \ell_{a}(z)$ and hence that of wages.

Note that (18) describes wages of workers hired at a firm of age $a$. However, the firm employs workers hired throughout its history, possibly at different wages. This generates within-firm wage inequality: as adjustment needs change over time so do wages paid to new hires.

\subsection{General Equilibrium}

Having characterized firms' policies, we now close the model. We need to determine the equilibrium productivity cutoffs $z_{D}^{*}$ and $z_{X}^{*}$, along with aggregate output and the unemployment rate. Recalling that new firms draw their productivity from the distribution $G(z)$, the equilibrium density of the productivity distribution is $\mu(z) \triangleq g(z) /\left[1-G\left(z_{D}^{*}\right)\right]$ for all $z \geq z_{D}^{*}$; and the share of exporting firms is given by $\varrho<1$. Average output per firm $Y / M$ is given by the

\footnotetext{
${ }^{27}$ See equation (45) in the Appendix.
} 
accounting identity

$$
\frac{Y}{M}=\left[\frac{1}{1+\varrho} \int_{z_{D}^{*}}^{\infty}\left(\int_{0}^{\infty}\left(1+\mathbb{I}_{\{a ; z\}} \tau^{1-\sigma}\right)^{\frac{1}{\sigma}}\left(z \ell_{a}(z)\right)^{\frac{\sigma-1}{\sigma}} \delta e^{-\delta a} d a\right) \mu(z) d z\right]^{\frac{\sigma}{\sigma-1}},
$$

where employment $\ell_{a}(z)$ of a firm of age $a$ and productivity $z$ is consistent with the optimality conditions described in Proposition 2. ${ }^{28}$ Average output $Y / M$ is a shifter of the revenue function (5), and thus a key equilibrium object driving firm behavior.

In contrast to Melitz (2003) (or to the one-period model discussed below), profits are not $\log$-linear in productivity. Thus, the usual result that the two cutoffs $z_{X}^{*}$ and $z_{D}^{*}$ are multiples of each other does not hold anymore. Instead, we have to directly compute revenues and verify that the zero cutoff profit (ZCP) conditions, which ensure that the marginal domestic and exporting firms exactly break even, are satisfied. The same holds for the free entry (FE) condition which ensures that entry of new firms occurs until expected profits are exactly identical to the entry $\operatorname{costs} f_{E} /(r+\delta)$.

For given recruitment policies, discounted profits are easily computed reinserting equations (11) and (12) into the definition of $\Pi(\cdot)$ to obtain

$$
\begin{aligned}
\Pi(0,0 ; z) & =\frac{1}{r+\delta}\left[\frac{C^{\prime}\left(v_{0}(z)\right)}{q\left(\theta_{0}(z)\right)} \dot{\ell}_{0}(z)-C\left(v_{0}(z)\right)-f-e^{-(r+\delta) a_{X}(z)} f_{X}\right] \\
& =\frac{1}{r+\delta}\left[(\alpha-1) v_{0}(z)^{\alpha}-f-e^{-(r+\delta) a_{X}(z)} f_{X}\right] .
\end{aligned}
$$

where $a_{X}(z) \triangleq \inf \left\{a: \mathbb{I}_{a}(z)=1\right\}$ is the age at which firm $z$ enters the foreign market. ${ }^{29}$ Equation (20) enables us to solve for the domestic cutoff $z_{D}^{*}$ as the zero cutoff profit condition (ZCP) reads $\Pi\left(0,0 ; z_{D}^{*}\right)=0$ : startups have zero employment and thus no promised wage, i.e., $\ell_{0}=$ $W_{0}=0$. In turn, the export productivity cutoff $z_{x}^{*}$ is determined by the condition, $z_{X}^{*}=$ $\inf \left\{z: \bar{\ell}(z) \geq \ell^{X}(z)\right\}$, according to which the marginal exporter is the least productive firm reaching the export threshold size $\ell^{X}(z)$ defined in (15). The free entry condition is satisfied when $\left(1-G\left(z_{D}^{*}\right)\right) \int_{z_{D}^{*}}^{\infty} \Pi(0,0 ; z) \mu(z) d z=f_{E} /(r+\delta)$. Since $\rho=w_{r}-b$, the ZCP and the free entry condition along with (19) provide us with three equations for the three unknowns $\left\{Y / M, w_{r}, z_{D}^{*}\right\}$. The final closure of the model requires the determination of the mass of firms $M$ and the unemployment level. Since $v(\omega) / \theta(\omega)$ job seekers are needed to meet the recruitment

\footnotetext{
${ }^{28}$ The expression for aggregate employment takes into account that firms are destroyed each period at the Poisson rate $\delta$.

${ }^{29}$ When the firm always remains a domestic producer, $a_{x}=+\infty$ and the last term in (20) vanishes.
} 
needs of firm $\omega$, aggregating over all firms we find that the aggregate number of job seekers reads

$$
S=\frac{M}{1+\varrho} \int_{z_{D}^{*}}^{\infty}\left(\int_{0}^{\infty} \frac{v_{a}(z)}{\theta_{a}(z)} \delta e^{-\delta a} d a\right) \mu(z) d z .
$$

Aggregate employment $L$ can be computed in a similar way to obtain the equilibrium rate of unemployment $U=S /(S+L)$ and, assuming an inelastic labor supply, the mass of firms such that $S+L$ equals the size of the population.

\section{A One-Period Variant of the Model}

We have seen that the effect of international trade on the distribution of wages is driven by the distribution of firms' hiring needs. With convex adjustment costs, firms smooth their recruitment over time. Thus, a dynamic perspective is crucial for a quantitative assessment of the model. However, many qualitative insights can be gathered studying a framework in which firm adjustment happens within one single period.

\subsection{Problem of the firm}

Besides assuming that firms adjust within one period, the other deviations from the setup of Section 3 is to set the value of leisure $b$ to zero. The timing is such that at the beginning of the periods all workers look for a job. Search is as described in the previous section. Thus, at the end of the period, a fraction $\theta q(\theta)$ of workers in a given submarket is employed and produces output. There is no discounting within the period. The expected wage income of a job seeker in market $\theta$ is given by $W=\theta q(\theta) w(\theta)$ so that we obtain the indifference condition

$$
w(\theta)=\frac{W}{\theta q(\theta)},
$$

which is the counterpart of (9). As in the dynamic model, wages are a negative function of tightness as workers trade off a higher employment probability against a lower wage.

Firms post vacancies and wages at the beginning of the period; they fill the share $q(\theta)$ of the announced jobs, and their end of period employment is $\ell=q(\theta) v$. Firm revenues are again given by (5). Inserting the worker indifference condition and substituting for $\ell$, the problem of the firm reads

$$
\pi(z)=\max _{\{\theta, v, \mathbb{I}\}} R(q(\theta) v, \mathbb{I} ; z)-\frac{W}{\theta} v-C(v)-f-\mathbb{I} f_{X}
$$

The first-order condition with respect to $v$ yields $R_{\ell}(\cdot) q(\theta)=W / \theta+C^{\prime}(v)$ and the one with 
respect to $\theta$ yields $R_{\ell}(\cdot) q^{\prime}(\theta)=-W / \theta^{2}$. Together these first order conditions imply

$$
\theta=\frac{1-\eta}{\alpha \eta} v^{1-\alpha} W
$$

which is identical to condition (14) in the dynamic model (with $W$ being replaced by $\rho=w_{r}-b$ ). Firms posting more vacancies choose lower levels of $\theta$ (i.e., higher market tightness) and therefore post higher wages. Since $\ell=q(\theta) v$, larger firms pay higher wages.

\subsection{Distribution of wages across firms}

Keeping Assumptions 1 and replacing Assumption 2 by $q(\theta)=\min \left\{A \theta^{-\eta}, 1\right\}$ with $\eta \in(0,1)$, we now characterize the distributions of wages, employment and profits. ${ }^{30}$ We relate variables across submarkets with the help of a representative firm whose productivity $\tilde{z}$ is such that its optimal price in the non-exporting sate equals one, i.e., $p_{D}(\tilde{z})=1$. Notice that firms with

productivity $\tilde{z}$ can actually be exporters. Hence, the associated variables $\tilde{\ell}, \tilde{\theta}$ and profits $\tilde{\pi}$ are constructs which are not necessarily observed in equilibrium. We will alternatively refer to $\tilde{z}$ as the productivity of the representative firm or average productivity. As shown in Appendix A.2, this normalization allows us to derive the following wage schedule:

$$
\ln w(z)=\ln \left(\frac{\eta(\sigma-1)}{\sigma}\right)+\underbrace{\left(\frac{\sigma-1-\beta}{\sigma-1}\right) \ln z}_{\text {Productivity effect }}+\underbrace{\frac{\beta}{\sigma-1} \ln \tilde{z}}_{\text {Avg. efficiency }}+\underbrace{(\sigma-1-\beta) \ln \left(1+\mathbb{I}(z) \tau^{1-\sigma}\right)}_{\text {Export status effect }},
$$

where $\beta$ is a combination of parameters defined in (53). Since $\beta \in(0, \sigma-1)$, log-wages are increasing in firm productivity. The elasticity of wages with respect to $z$ is constant and equal to $1-\beta /(\sigma-1)$. That elasticity is declining in $\alpha$, the degree of convexity of the adjustment cost function. In the absence of search frictions, $\eta=1$, or with linear adjustment costs, $\alpha=1$, we have $\beta=\sigma-1$. Then the wage schedule collapses to $\ln w(z)=\ln ([\sigma-1] / \sigma)+\ln \tilde{z}$ and wage dispersion disappears.

The wage schedule has two other components. First, when the efficiency of the representative firm $\tilde{z}$ increases, the labor market becomes more competitive, and all firms must pay higher wages. Second, in order to serve the export market, exporting firms are required to reach a higher equilibrium size. This gives rise to an export wage premium as firms grow to a larger size by posting higher wages.

\footnotetext{
${ }^{30}$ We will focus on equilibria where $\theta q(\theta)<1$ in all submarkets.
} 


\subsection{Equilibrium}

Domestic and export market entry. Profits net of fixed costs are log-linear in $z$; see Appendix A.3 for a proof. More precisely, taking the ratio of operating profits of firm $z$ and of firm $\tilde{z}$ yields

$$
\pi(z)+f+\mathbb{I}(z) f_{X}=\left(1+\mathbb{I}(z) \tau^{1-\sigma}\right)^{\beta /(\sigma-1)}\left(\frac{z}{\tilde{z}}\right)^{\beta}[\tilde{\pi}+f] .
$$

Evaluating (26) for the marginal domestic producer $z_{D}^{*}$ yields the zero cutoff profit (ZCP) condition

$$
(Z C P): \tilde{\pi}=f\left[\left(\tilde{z}\left(z_{D}^{*}\right) / z_{D}^{*}\right)^{\beta}-1\right]
$$

where we account for the dependence of $\tilde{z}$ on $z_{D}^{*}$ through

$$
\tilde{z}\left(z_{D}^{*}\right)=\left[\frac{1}{1+\varrho} \int_{z_{D}^{*}}^{\infty} z^{\beta}\left[1+\mathbb{I}(z) \tau^{1-\sigma}\right]^{\beta /(\sigma-1)} \mu(z) d z\right]^{1 / \beta}
$$

see Appendix A.3 for details. In the absence of search frictions, we would have $\beta=\sigma-1$ and our ZCP would be identical to that in Melitz (2003). By contrast, in our model there is no ZCP for exporters. We identify the export cutoff $z_{X}^{*}$ by using the indifference condition $\pi\left(z_{X}^{*}, \mathbb{I}=0\right)=$ $\pi\left(z_{X}^{*}, \mathbb{I}=1\right)$. Without loss of generality, one can view the indifferent firm $z_{X}^{*}$ as serving the domestic market only. Using (26), we obtain

$$
\frac{z_{X}^{*}}{z_{D}^{*}}=\left(\frac{f_{X}}{f}\right)^{1 / \beta}\left[\left(1+\tau^{1-\sigma}\right)^{\beta /(\sigma-1)}-1\right]^{-1 / \beta} \geq 1 .
$$

The two cutoffs are positively related in equilibrium and, as one might expect, the productivity premium of the marginal exporter $z_{X}^{*} / z_{D}^{*}$ is increasing in export fixed costs $f_{X}$ relative to domestic fixed costs $f$, and in the iceberg trade factor $\tau .{ }^{31}$

Free entry condition. The free entry condition ensures that entry occurs until expected profits are exactly identical to the entry costs $f_{E}$, hence $E[\pi(z)]=f_{E} /\left[1-G\left(z_{D}^{*}\right)\right]$. In equation (65) of Appendix A.4, we show how expected profits $E[\pi(z)]$ and profits of the representative firm $\tilde{\pi}$ are connected. This allows us to write the following free entry (FE) condition,

$$
(F E): \tilde{\pi}=\frac{f_{E}+\left\{1-G\left[z_{X}^{*}\left(z_{D}^{*}\right)\right]\right\}\left(f_{X}-f\right)}{2-G\left(z_{D}^{*}\right)-G\left[z_{X}^{*}\left(z_{D}^{*}\right)\right]} .
$$

\footnotetext{
${ }^{31}$ In the absence of labor market frictions or convex adjustment costs (i.e., $\eta=1$ or $\alpha=1$, which both imply $\beta=\sigma-1)$, the relationship collapses to $z_{X}^{*} / z_{D}^{*}=\left(f / f_{X}\right)^{-1 /(\sigma-1)} \tau$ as in the standard Melitz (2003) model.
} 
Product market equilibrium. Using the ZCP condition and the free entry condition (30), we can now determine product market equilibrium in the $\left(\tilde{\pi}, z_{D}^{*}\right)$-space. Existence of an equilibrium is guaranteed if $f_{X}<f_{E}$ and $\sigma>1+\alpha$.

Proposition 3 (Equilibrium) If $f_{X}<f_{E}$ and $\sigma>1+\alpha$, the ZCP condition (27) and the free entry $(F E)$ condition (30) uniquely determine the domestic cutoff $z_{D}^{*}$. The export cutoff $z_{X}^{*}$ and the productivity of the representative firm $\tilde{z}$ follow from equations (29) and (28).

Proof. See Appendix A.5.

Value of search and welfare. Since $W$ is average labor income and we have normalized the price index $P=1$, the value of search $W$ is a measure of welfare. Using the profit function and the ZCP condition (27), one obtains

$$
W=\left[\frac{K}{f} \tilde{z}^{\gamma}\left(z_{D}^{*}\right)^{\beta}\right]^{\frac{1-\eta}{\eta} \frac{\alpha-1}{\alpha}},
$$

where $\gamma, \beta$, and $K$ are all positive constants. ${ }^{32}$ So, an increase in the productivity of the marginal domestic producer and/or of the representative firm raises the value of search. Quite intuitively, as firms become more efficient, the zero cutoff profit and free entry conditions are reestablished through an increase in labor costs.

\subsection{The impact of trade liberalization}

The selection effect. In a first step, we study the effect of lower $\tau$ on the productivity of the representative firm, $\tilde{z}$. Under the conditions stated in Proposition 3, the FE locus shifts down. To pin down the shift of the ZCP curve, however, a parameter restriction is needed since the effect of $\tau$ on $\tilde{z}$ is generally ambiguous.

Proposition 4 (Selection) Under the assumptions that firms draw their productivity from a Pareto distribution and that $f_{X}>f$, trade liberalization has an unambiguously positive effect on the domestic cutoff $z_{D}^{*}$ and $\tilde{z}$.

Proof. See Appendix A.8.

Trade liberalization expands the market size of productive firms who can take advantage from easier access to the foreign market. It also hurts less productive firms, whose revenues

\footnotetext{
${ }^{32}$ See equations (53), (61) and (62) in the Appendix.
} 
may fall due to increased competition by efficient foreign competitors. As a consequence, less efficient firms shut down, while more efficient firms expand. In line with Melitz (2003), this selection effect drives up the productivity $\tilde{z}$ of the representative firm as long as the additional output share lost in iceberg costs does not outweigh the productivity gains at the factory gate.

The reallocation of labor towards more efficient firms increases the value of search. This is easily established considering the ZCP condition $\pi\left(z_{D}^{*} ; \tilde{z}, W\right)=0$. Equation (54) in the appendix implies that $\pi\left(z_{D}^{*}\right)$ is strictly decreasing in $W$ and strictly increasing in both $\tilde{z}$ and $z_{D}^{*}$. Since a reduction in $\tau$ raises the productivity of the representative and marginal firms, $W$ has to increase until the ZCP is satisfied again.

Effects on wage dispersion and employment. Since lowering $\tau$ increases $\tilde{z}$, the wage profile (25) suggests that all wages rise with trade liberalization. Moreover, lowering $\tau$ has a direct positive effect on the exporter wage premium. To see the effect of lower $\tau$ on wage inequality, we examine the variance of wages

$\operatorname{var}[\ln w(z)]=(\sigma-1-\beta)^{2}\left\{\frac{\operatorname{var}[\ln z]}{(\sigma-1)^{2}}+\operatorname{var}\left[\ln \left(1+\mathbb{I}(z) \tau^{1-\sigma}\right)\right]+\frac{2 \operatorname{cov}\left[\ln z, \ln \left(1+\mathbb{I}(z) \tau^{1-\sigma}\right)\right]}{\sigma-1}\right\}$.

If either all firms export (i.e., $\mathbb{I}(z)=1$ for all $z$ ), or no firm exports (i.e., $\mathbb{I}(z)=0$ for all $z$ ), then $\operatorname{var}[\ln w(z)]=(\sigma-1-\beta)^{2}\left\{\operatorname{var}[\ln z] /(\sigma-1)^{2}\right\}$, which is lower than the expression in (32). Clearly, the term var $\left[\ln \left(1+\mathbb{I}(z) \tau^{1-\sigma}\right)\right]$ increases with the share of exporters when that share is low, but decreases when the share of exporters is high. Hence, wage dispersion reaches its maximum at some intermediate level of openness. The export wage premium generates an inverted U-shape relationship between inequality and trade. A similar result is derived by Helpman et al. (2010) with a different model where inequality arises because of assortative matching. In the next section we assess whether the inverted U-shape relationship continues to hold in a dynamic version of our model.

Finally, we turn to the effect of trade liberalization on employment. We show in Appendix A.6 that equilibrium employment can be written as

$$
L=\tilde{\theta} q(\tilde{\theta})\left(\frac{\bar{z}}{\tilde{z}}\right)^{\beta \frac{\sigma}{\sigma-1}-1},
$$

where $\bar{z}$ is a weighted average of productivity levels constructed similarly to the productivity of the representative firm $\tilde{z}$ (see equation (69)). ${ }^{33}$ The expression of $L$ is made of two components.

\footnotetext{
${ }^{33}$ In Appendix A.9, we show that, with Pareto productivity, (33) becomes $L=\tilde{\theta} q(\tilde{\theta}) \Lambda$, where $\Lambda$ is a constant
} 
The first one, $\tilde{\theta} q(\tilde{\theta})$, is the job finding rate in the submarket chosen by the representative firm. It would be equal to the aggregate level of employment if all workers were applying to jobs with posted wages $\tilde{w}$. The second component is due to the allocation of workers across submarkets with different levels of tightness; this 'composition' feature is captured by the ratio of two different weighted means for $z$.

The relationship between trade and unemployment cannot be signed analytically, since it depends on two opposite forces. A negative composition effect: trade-induced selection increases the average efficiency and size of firms; in order for firms to serve a larger market they offer higher wages and a longer queue (lower $\theta$ ), thus potentially increasing unemployment. A positive efficiency effect due to the increase in the value of search $W$ : as trade increases average efficiency $\tilde{z}$, workers' outside option $W$ increases, thereby raising the indifference condition (22). In other words, for each contract $w$ firms need to offer a higher job finding rate $\theta q(\theta)$ in order to attract workers, and thus $\tilde{\theta} q(\tilde{\theta})$ increases. In the particular cases where all or no firms export, the ambiguity resolves as the composition effect disappears and, due to the efficiency effect, all firms offer a higher job finding rate when trade costs fall. In the general case where only a subset of firms export, the composition effect is operative and the impact of trade on employment is ambiguous. Notice that, since a reduction in trade cost increases the share of exporters, the extensive margin produces an additional composition effect similar to the one discussed above. New exporters grow and serve the foreign market by offering higher wages and longer queues. The degree of convexity of the adjustment cost function plays a key role in shaping the employment effect of trade. If $\alpha=1$, the composition effect vanishes since there is no dispersion of wages and queues. Then, trade liberalization leads to lower unemployment. If $\alpha>1$, the more heterogeneous firms are, the stronger is the negative composition effect of trade on jobs.

\section{Quantitative Analysis}

We start by showing that the model can replicate key moments of the German economy in 1996. We analyze the outcome of the calibration and explain why it is qualitatively consistent with the following facts: (i) rapidly expanding firms fill their vacancies at a faster rate and pay higher wages; ${ }^{34}$ (ii) the productivity distributions of exporters and non-exporters overlap; (iii) within-firm wage inequality contributes to overall inequality. Then, performing a number of comparative statics exercises, we characterize the impact of trade liberalization as well as labor

that depends solely on the exogenous parameters of the model.

${ }^{34}$ This fact has been only established for the U.S. economy. 
and product market reforms on residual inequality and unemployment. ${ }^{35}$

Before taking the model to the data, we generalize it by allowing wages to vary with tenure. As already explained in Section 3, neither firms nor workers have specific preferences over the timing of payments because they are both risk neutral. Thus their decisions are unaffected by the introduction of a wage-tenure profile as long as expected labor earnings for new hires remain the same across specifications. ${ }^{36}$ This flexibility enables us to match the returns to tenure observed in the data. We follow a standard Mincerian approach and assume that log-wages are a function of tenure $T$ through a linear and a quadratic term. Note, however, that this is a shortcut; the model as such does not endogenize wage profiles. ${ }^{37}$

We start with a symmetric setup and then show an asymmetric version of our model where Germany is understood as a small open economy. Interestingly, this extension has no significant bearing on the insights obtained in the symmetric framework.

\subsection{Calibration to German data}

We fix a number of parameters using external sources, normalize those that determine levels only, and set others to match empirical counterparts. We choose the values of the remaining parameters to minimize the sum of squared differences between the model's prediction and actual moments. ${ }^{38}$ The calibration of the asymmetric model is close in spirit and will be explained in Section 5.4.

The four externally calibrated parameters are $\{\eta, \delta, \chi, r\}$. Where applicable, the estimates producing those parameter values are based on data provided by the Institute of Labour Market Research (IAB) in Germany and are, therefore, naturally compatible with the SIAB and LIAB data bases provided by the same agency and used for other moments in our quantitative exercise. For the elasticity of the matching function, we refer to Kohlbrecher et al. (2014) who estimate $\eta=0.65 .^{39}$ The firm and job destruction rates are taken from Fuchs and Weyh (2010). These authors use the Establishment History Panel of the IAB for the period 2000 to 2006. The data

\footnotetext{
${ }^{35}$ We focus on comparison between steady states and this is a limitation of our analysis, since in the real world the effects of these reforms play out slowly across time. The analysis of the transitional path in trade models with firm heterogeneity and labor market frictions is quite demanding, therefore the literature focuses on the steady state. See Helpman and Itskhoki (2015) for a recent first take analysing the transition.

${ }^{36}$ In the working paper version of this article, Felbermayr et al (2014), we have assumed flat wages in he quantitative analysis. Aggregate results do not depend on this assumption.

${ }^{37}$ This is a general shortcoming of directed search models like ours; research has yet to come up with credible mechanisms generating endogenous wage profiles.

${ }^{38}$ The algorithm for the numerical solution of the model is discussed in the Technical Appendix.

${ }^{39}$ Kohlbrecher et al. (2013) present estimates of $\eta$ based on the SIAB data base (which contains information about unemployment spells of workers) for the period 1993 to 2007. Controlling for workforce heterogeneity, they do not reject a constant returns to scale specification of the matching function.
} 
base includes all plants in Germany with at least one employee subject to social security. We use their empirical estimates to set the yearly plant exit rate $\delta=5 \%$ per year, and the yearly job destruction rate due to match dissolutions $\chi=7 \%$. We choose a yearly interest rate of $4 \%$.

Table 4: Calibration: Baseline Equilibrium for 1996

\begin{tabular}{|c|c|c|c|c|}
\hline \multirow{2}{*}{\multicolumn{3}{|c|}{ External Parameters }} & \multirow{2}{*}{\multicolumn{2}{|c|}{ Source }} \\
\hline & & & & \\
\hline$\eta$ & 0.65 & Elasticity matching function & \multicolumn{2}{|c|}{ Kohlbrecher et al. $(2014)^{*}$} \\
\hline$\delta$ & 0.05 & Firm destruction rate & \multicolumn{2}{|c|}{ Fuchs and Weyh $(2010)^{*}$} \\
\hline$\chi$ & 0.07 & Match destruction rate & \multicolumn{2}{|c|}{ Fuchs and Weyh $(2010)^{*}$} \\
\hline$r$ & 0.04 & Annual interest rate & \multicolumn{2}{|c|}{ Standard } \\
\hline Parameters & Value & $\begin{array}{l}\text { Estimated Parameters } \\
\text { Interpretation }\end{array}$ & \multicolumn{2}{|l|}{ Source } \\
\hline$\psi_{1}$ & $1.900 \%$ & Tenure profile, linear term & \multirow{2}{*}{\multicolumn{2}{|c|}{$\begin{array}{l}\text { LIAB data, Mincer regression } \\
\text { LIAB data, Mincer regression }\end{array}$}} \\
\hline$\psi_{2}$ & $-0.037 \%$ & Tenure profile, quadratic term & & \\
\hline \multicolumn{5}{|c|}{ Calibrated Parameters } \\
\hline Parameters & Value & Moment & Model & Data \\
\hline Elasticity of substitution, $\sigma$ & 4.25 & Median markup & $30 \%$ & $30 \%$ \\
\hline Iceberg Costs, $\tau$ & 1.53 & Exports share among exporters & $20 \%$ & $20 \%$ \\
\hline Unemployment benefits, $b$ & 0.35 & Replacement rate & $32.7 \%$ & $35 \%$ \\
\hline Fixed costs, $f$ & 1.64 & Average firm size & 26.8 & 27.5 \\
\hline Fixed export costs, $f_{x}$ & 0.70 & Share of exporting firms & $18.7 \%$ & $18.7 \%$ \\
\hline Fixed entry costs, $f_{E}$ & 5.46 & Within-firm wage variance, $\%$ total & $56 \%$ & $50 \%$ \\
\hline Shape parameter, $\kappa$ & 3.80 & Average exporter size & 99.7 & 96.6 \\
\hline Vacancy costs, $\alpha$ & 3.62 & Exporter wage premium & $7.6 \%$ & $10 \%$ \\
\hline Matching function, $A$ & 3.46 & Unemployment rate & $9.9 \%$ & $9.9 \%$ \\
\hline
\end{tabular}

Notes. When applicable, data refer to annual periodicity.

* Parameter estimates are based on German social security data provided by the IAB.

To introduce a data-disciplined wage-tenure profile, we estimate a standard Mincerian wage regression

$$
\ln w_{i, j, t}=\psi_{1} T_{i, j, t}+\psi_{2} T_{i, j, t}^{2}+\gamma \mathbf{X}_{i, t}+\boldsymbol{\delta} \mathbf{Z}_{j, t}+\varepsilon_{i, j, t}
$$

where $w_{i, j, t}$ is the wage of worker $i$ employed at some plant $j$ at year $t$. The vector $\mathbf{X}_{i, t}$ collects worker-level controls such as dummy variables for 4 educational categories, ${ }^{40} 5$ age groups, ${ }^{41}$ a gender dummy, an indicator for German nationality, and indicator variables for more than 300 occupations. The vector $\mathbf{Z}_{j, t}$ contains firm-level variables such as an exporter dummy, log employment, and a full array of plant fixed effects. ${ }^{42}$ Here, we are interested in the tenure

\footnotetext{
${ }^{40}$ These categories are: (i) no vocational training, no high school; (ii) high school and/or vocational training; (iii) university or technical college; (iv) missing educational information.

${ }^{41}$ These groups are defined over the age intervals 18-25, 26-35, 36-45, 46-55, and 56-65 years.

${ }^{42}$ The OLS regression draws on yearly linked employer-employee data (LIAB) for full-time male workers in the Western German manufacturing sector from 1996 to 2007. Observations are weighted using officially provided analytical weights such that the sample is fully representative. The number of observations is $N=9497283$. Standard errors are robust and clustered at the plant-level. This regression yields an adjusted $R^{2}$ statistic of
} 
profile. We obtain $\hat{\psi}_{1}=0.019$ and $\hat{\psi}_{2}=-0.00037$, with both coefficients different from zero at the $0.1 \%$ level of significance. We use these coefficients to simulate the theoretical wage profiles. To compare the empirical estimates of column (4) to those implied by our model, we create 230 samples of simulated data, each comprising 5,000 firms and about 120,000 workers. We run regression (34) on our simulated data, and find the coefficients $\psi \prime_{1}=0.02, \psi_{2}=-0.00036$, both highly significant, and almost identical to the empirical estimates. ${ }^{43}$

We calibrate the remaining nine parameters $\left\{\sigma, \tau, b ; \alpha, \kappa, A, f, f_{X}, f_{E}\right\}$ to match important moments of the German economy for the year 1996. Three of them, $\tau, \sigma, b$ have natural counterparts in the data so they can be directly calibrated, each one matching a single relevant moment. As shown in Section 2, the median markup in 1996 is 30\%, which allows us to calibrate the elasticity of substitution $\sigma$. Exporters' export sales as a share of their total sales is $\tau^{1-\sigma} /\left(1+\tau^{1-\sigma}\right)$ in the model. ${ }^{44}$ Thus matching the average share of exports in total revenues of exporters of $20 \%$ observed in the data, we obtain the benchmark $\tau=1.53$. For the parameter $b$, we use the replacement rate of 0.33 computed by the OECD. ${ }^{45}$ Setting $b=0.35$, we calibrate its ratio to the average wage and set it as close as possible to 0.33. Finally, we assume that the productivity distribution is Pareto with shape parameter $\kappa$ and normalize, without loss of generality, the expected productivity to one by setting the minimum possible productivity $z_{\min }=(\kappa-1) / \kappa$.

We simultaneously choose the remaining parameters, $v \equiv\left\{\alpha, \kappa, A, f, f_{X}, f_{E}\right\}$ so that the numerical steady-state solution of the model matches relevant statistics. The parameters are calibrated in order to minimize a loss function defined by the quadratic distance between the moments in the model and the targeted statistics. We define $\mathbf{m}=\left[m_{1}, \ldots, m_{6}\right]$ as the vector of the empirical moments described above, and $y(\boldsymbol{v})$ as the vector of equilibrium model moments generated by some vector of parameters $\boldsymbol{v}$. Our calibrated parameter vector is obtained solving numerically

$$
\hat{\boldsymbol{v}}=\underset{v \in \Xi}{\arg \min }\left[(y(v)-\mathbf{m}) \cdot W \cdot(y(v)-\mathbf{m})^{\prime}\right],
$$

where $W$ is the weighting matrix, a diagonal matrix with the squares of the data targets on the diagonal, $W_{i i}=1 / m_{i}^{2}$, and zero for all other entries. We calculate the following empirical moments from plant-level data (see the Data Appendix $B$ for further details): (i) the average firm size is 27.5 employees; (ii) the share of exporting firms is $18.7 \%$; (iii) the average size of exporting $75.23 \%$.

${ }^{43}$ The averaging procedure is required to deal with sampling error.

${ }^{44}$ Note that the link between $\tau$ and the share of revenues realized in foreign countries is particularly straightforward. Since $R_{X}=\left(p_{X} q_{X}\right) / \tau=p_{D} q_{D} \tau^{1-\sigma}=R_{D} \tau^{1-\sigma}$, we have $R_{X} /\left(R_{D}+R_{X}\right)=\tau^{1-\sigma} /\left(1+\tau^{1-\sigma}\right)$.

${ }^{45}$ The OECD summary measure is defined as the average of the gross unemployment benefit replacement rates for two earnings levels, three family situations and three durations of unemployment. For further details, see OECD (1994), The OECD Jobs Study (chapter 8) and Martin J. (1996). 
firms equals 96.6 employees; (iv) the difference between average wages paid by exporters to those paid by non-exporters (the exporter wage premium) is $10.1 \%{ }^{46}(\mathrm{v})$ the aggregate unemployment rate provided by the Federal Employment Agency is equal to 9.9\% in 1996; (vi) the share of total wage variance attributable to the within-firm component is about $56 \%$.

As shown in Table 4, our model is able to replicate these moments rather well. It is worth stressing that the original feature of our model, within-firm wage inequality generated by directed search, accurately matches its data counterpart. The only noticeable tension is with respect to the distribution of firm sizes, as the model slightly overestimates the average size of exporters. This suggests that the right-tail of the model's distribution is somewhat thicker than the one in the data, a well known feature of the Pareto distribution (see, e.g., Head et al., 2014). The implied parameter values are plausible. The ad valorem tariff equivalent of trade costs (approximately 60\%), is well in line with numbers discussed in Anderson and van Wincoop (2004). The shape parameter of the Pareto distribution, $\kappa$, is close to the value found by Bernard et al. (2007) for the US.

\subsection{Validation tests}

Dynamic moments Our theory generates a positive link between worker turnover at the establishment level and the wages of new hires. While limitations of the LIAB data set make a direct test of this prediction difficult, ${ }^{47}$ we can still obtain tentative estimates of the role of plant size and growth on hiring wages. Moreover, as an out of sample test, we show that the calibrated model produces firm level wage-growth correlations consistent with these estimates.

We define as a 'new hire' a worker $i$ employed at some plant $j$ at year $t$ who has not been employed at that plant in year $t-1$. We run a variant of the Mincer regression (34), but focus on the wages of newly hired workers $\tilde{w}_{i, j, t}$

$$
\ln \tilde{w}_{i, j, t}=\iota_{1} \ln E_{j, t}+\iota_{2} \ln E_{j, t-1}+\gamma \mathbf{X}_{i, t}+\boldsymbol{\delta} \mathbf{Z}_{j, t}+\varepsilon_{i, j, t} .
$$

$E_{j, t}$ is total employment at establishment $j$ that employs worker $i$ at date $t$, vectors $\mathbf{X}_{i, t}$ and $\mathbf{Z}_{j, t}$ are defined as above. The estimates $\hat{\iota}_{1}$ and $\hat{\iota}_{2}$ are to be interpreted as conditional correlations and have no causal meaning. Next to (35), we also run regressions in which we suppress the

\footnotetext{
${ }^{46}$ The exporter wage premium is estimated in Mincer regressions without controlling for firm productivity or size. It captures the average residual wage premium paid by exporters (i.e., controlling for observed worker characteristics). Therefore, it confounds the export status effect and the productivity effect highlighted in equation (25).

${ }^{47}$ The panel suffers from substantial attrition so that the number of continuing firms available is rather low.
} 
lagged employment level, or in which we add establishment dummies $D_{j(i)}$.

Table 5: Mincer moments: Data versus model

\begin{tabular}{|c|c|c|c|c|c|c|}
\hline \multirow[t]{3}{*}{ Dependent variable: } & \multicolumn{4}{|c|}{ log wage of new hires } & \multicolumn{2}{|c|}{ log wages } \\
\hline & Data & Model & Data & Model & Data & Model \\
\hline & $(1)$ & $\left(1^{\prime}\right)$ & $(2)$ & $\left(2^{\prime}\right)$ & $(3)$ & $\left(3^{\prime}\right)$ \\
\hline \multirow[t]{2}{*}{$\ln E_{j(i), t}$} & 0.057 & 0.004 & 0.014 & 0.014 & & \\
\hline & $(0.025)$ & $(0.001)$ & $(0.021)$ & $(0.001)$ & & \\
\hline \multirow[t]{2}{*}{$\ln E_{j(i), t-1}$} & & & -0.003 & -0.006 & & \\
\hline & & & $(0.009)$ & $(0.000)$ & & \\
\hline \multirow[t]{2}{*}{ Exporter status $(0,1)$} & & & & & 0.021 & 0.022 \\
\hline & & & & & $(0.004)$ & $(0.002)$ \\
\hline \multicolumn{7}{|l|}{ Additional controls } \\
\hline$\overline{\text { Establishment effects }}$ & YES & & YES & & YES & \\
\hline Firm productivity & $\mathrm{NO}$ & $\mathrm{NO}$ & $\mathrm{NO}$ & YES & NO & YES \\
\hline Worker observables & YES & n.a. & YES & n.a. & YES & n.a. \\
\hline $\operatorname{adj} . R^{2}$ & 0.85 & n.a. & 0.87 & n.a. & 0.82 & n.a. \\
\hline
\end{tabular}

Notes. Columns (1) to (2') report regression results for newly hired workers; columns (3) and (3') report results for all workers (new and incumbent). All regressions based on real data use an unbalanced panel of establishments covering the years 1996 to 2009. Regressions based on simulated data refer to the calibration targeting the 1996 moments. Robust standard errors in parentheses. All models include worker observables, region-year and industry-year effects as in (35). Columns marked with primes (') report averages (standard deviations in brackets) of estimated effects from 230 regressions on simulated residual wages, conditional on productivity (coefficients suppressed).

Regression model (1) in Table 5 yields a statistically significant size effect. ${ }^{48}$ We then use the simulated dataset described above to assess whether this finding is consistent with our calibrated model. We regress simulated log residual wages of newly hired workers on simulated current and lagged log employment levels (as well as on the level of productivity, the only time-invariant establishment characteristic in our model), and report the averages and standard deviations of the obtained coefficients in column (1'). Indeed, the simulated data show a positive correlation between wages of new hires and size, too, albeit at a substantially smaller degree.

Column (2) returns to real data and shows that neither the contemporaneous nor the lagged employment levels are statistically significant when both included. The coefficients are very close to zero but they have the expected signs: a higher contemporaneous employment level increases wages, while a higher lagged level lowers them as adjustment needs are smaller. ${ }^{49}$ These

\footnotetext{
${ }^{48}$ Without adding establishment effects, the measured coefficient would be about twice as large. Starting with Schmidt and Zimmermann (1991), the role of firm size for wages has been well-documented in German data, albeit usually in samples comprising both new and incumbent workers.

${ }^{49}$ This pattern remains broadly robust if we vary the array of controls included in (35). Presumably, this
} 
results imply that the wages of new hires increase in plant growth and in plant size. Using the simulated data, we find that contemporaneous and lagged employment levels affect wage offers with elasticities of 0.014 and -0.006 , respectively, both very close to their (insignificant) empirical counterparts. In light of the limitations of our data set, it should not be surprising that such small correlations are difficult, if not impossible, to identify econometrically. Thus, the lack of conclusive empirical evidence does not contradict our model since its simulation is in line with a very weak link between firm size/growth and the wages of new hires. ${ }^{50}$ Rather, we view the high fit between the simulated averages of our model and the coefficients obtained in actual data as an out-of-sample check of the validity of our framework.

Conditional exporter wage premium. Columns (3) and (3') report an additional out-ofsample check. We compare the exporter status effect implied by the model with the one obtained in the data. For this exercise, we use the wage data for all workers (not just the new hires). ${ }^{51}$ As above, we simulate 230 samples of artificial data. We use the data to regress log residual wages on exporter status and productivity. We average across samples and find a coefficient of the exporter dummy that is equal to 0.022 . This is again very close to the coefficient measured in the real data.

Size distribution. Figure 3 plots the cross-sectional distribution of firm employment as a function of firm-level age and productivity. It focuses on a subset which includes the marginal producer $z_{D}^{*}$ and the marginal exporter $z_{X}^{*}$. Notice that the firm size distribution exhibits a discrete jump at the productivity cutoff $z_{X}^{*}$. By contrast, as a function of firm age, the size distribution is continuous. In our model, from the start of their existence, highly productive future exporters internalize that they will end up larger than non-exporters and they put on employment accordingly, even if they do not export yet. When they have reached the critical size (and age) of starting to export, foreign sales jump up and domestic sales fall, leaving overall sales (and employment) constant. This avoids the counterfactual prediction of the basic Melitz (2003) model where exporters and non-exporters are perfectly partitioned along the productivity dimension (e.g. Bernard et al., 2003). Impullitti et al. (2013) use the interaction between sunk

disappointing outcome is jointly due to the low number of observations and to the fact that a negative correlation between $\varepsilon_{i, j, t}$ and employment would bias $\iota_{1}$ towards zero. Additionally, since employment levels at adjacent years are highly correlated, multicollinearity in the regressions may inflate standard errors. We are grateful to a referee for pointing this out to us. Also, note that time variation in $E_{j, t}$ is low and that we do not have any start-ups in the sample.

${ }^{50} \mathrm{~A}$ proper test would require a different procedure based on data containing detailed information about gross jobs flows at the firm level, a task that we leave to further research.

${ }^{51}$ In the calibration, we have targeted the unconditional exporter wage effect. 


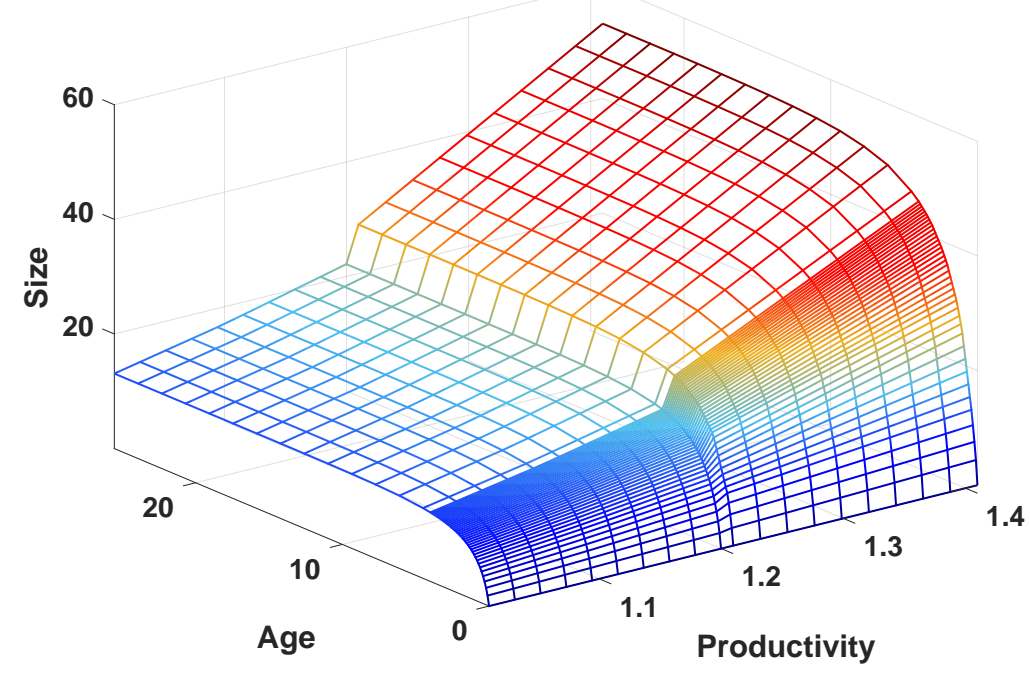

Figure 3: Firm size as a function of productivity and age

export costs and idiosyncratic uncertainty to explain the existence of highly productive nonexporters. Eaton, Kortum and Kramarz (2011) introduce firm and market specific heterogeneity in entry costs and demand. Fajgelbaum (2013) sets up an economy with frictions to job-tojob transitions and fixed investment costs into exporting and show that firms are born small, accumulate workers gradually and enter the export market only when they have reached a sufficient size. We complement Fajgelbaum's explanation by showing that a similar dynamic of firms entry into the export market can be generated by the combination of search frictions and convex adjustment costs without assuming on-the-job search.

The figure also shows that more productive firms grow faster. By equilibrium condition (14), this implies a higher vacancy filling rate. Thus directed search can explain the recent findings of Davis et al. (2013) according to which more productive firms fill their vacancies faster. ${ }^{52}$ By contrast, in models with random matching, firms achieve higher growth rates by posting more vacancies. Moreover, introducing screening in a random matching environment, as in Helpman et al. (2010), would deliver the counterfactual prediction that high wage openings are filled through a lengthier selection process.

Wage distribution. We have chosen not to target the overall wage variance in our calibration because, as explained in Section 2, it is not possible to isolate the 'pure' firm component of wage

\footnotetext{
${ }^{52}$ A similar result can be found in Kaas and Kircher (2015). Unfortunately, our data do not contain information on vacancies, so we cannot directly target the correlation between hiring wages and vacancy filling rates.
} 
dispersion in the data. Log wage variance due to the firm component in the decomposition of Table 1 is $2.9 \%$ on average in the period 1990-96 (Card et al., 2013). It is likely inflated by match effects and by rent sharing. Although the pure firm effect is the only source of inequality in our economy, the model does a good job in generating a sizable variance of log-wages of $1.03 \%$, thereby accounting for $36 \%$ of the residual wage dispersion attributable to firm fixedeffects in Card et al. (2013). In Table 6, we report the estimates of Card et al. (2013) for the periods 1990-96 and 2000-09 as - imperfect - reference points and compare them with the model predictions.

The wages of new hires fall with firm age because younger firms grow faster, and in our labor market with competitive search, firms foster growth by posting better compensations. Thus workers with more seniority earn higher wages, as commonly observed in the data. Notice that within-firm inequality cannot be obtained using random search as in, e.g., Cosar et al. (2016). In that model, firms pay their employees equally because all wages are renegotiated at every point in time and this firm-specific wage falls as the firm closes in to its desired size. The importance of within-firm wage dispersion is documented by, among others, Bloom et al. (2015) for US data, Mueller et al. (2015) for UK data and Helpman et al. (2013) for Brazilian data. As can be seen in Table 2, our German data confirm the presence of substantial pay differentials within firms and, as shown in Table (4), our model does a good job in replicating this fact.

\subsection{Equilibrium properties and policy evaluation}

Taking our calibration as the baseline, we evaluate whether trade, labor and product market reforms can explain the changes in German labor market outcomes documented above. We first feed the model the changes in parameters implied by each reform one by one, in order to isolate their effects. We then compute the combined effect of all reforms. The objective of this exercise is to understand and quantify the effects of the different reforms on the dynamics of total residual wage dispersion and on its between/within-firm decomposition.

Table 6, shows the changes in the main moments between the two periods and the effects of each reform predicted by our model. In columns (1) and (2), we report the key facts highlighted in Section 2. Comparing 1996 to 2009, the share of exports in total sales of exporters, the share

of exporting firms in the population, and the average size of exporters all increase, while the average size of exporters decreases. Moreover, the data show that the unemployment rate records a marked decline while wage dispersion due to the firm component increases substantially, and most of the increase is due to the between-firm component. 
Table 6: Impact of reforms under symmetry

\begin{tabular}{lccccccccc}
\hline \hline & $(1)$ & $(2)$ & $(3)$ & $(4)$ & \multicolumn{2}{c}{$(5)$} & $(6)$ & $(7)$ & $(8)$ \\
& Data & Model & \multicolumn{5}{c}{ Model (2009) } \\
Moments & 1996 & 2009 & 1996 & $\tau=1.3$ & $b=0.23$ & $A=3.8$ & $\sigma=5$ & Joint \\
\hline Median markup, \% & 30.0 & 25.0 & 30.0 & 30.0 & 30.0 & 30.0 & 25.0 & 25.0 \\
Exports share among exporters & 20.0 & 29.0 & 20.0 & 29.0 & 20.0 & 20.0 & 15.4 & 26.0 \\
Share of exporting firms, \% & 18.7 & 30.0 & 18.7 & 38.0 & 17.9 & 18.8 & 5.9 & 35.6 \\
Average firm size & 27.6 & 35.1 & 26.8 & 29.7 & 26.3 & 27.1 & 37.3 & 42.6 \\
Average size exporters & 96.6 & 89.6 & 99.7 & 64.9 & 100.0 & 101.6 & 396.5 & 104 \\
Unemployment rate & 9.9 & 7.8 & 9.9 & 10.1 & 9.1 & 9.2 & 13.4 & 12.1 \\
Total wage variance (residual), \% & 2.9 & 5.3 & 1.03 & 1.03 & 1.1 & 0.98 & 1.6 & 1.54 \\
Exporter wage premium, \% & 10.0 & 10.0 & 7.6 & 7.1 & 8.2 & 7.2 & 13.0 & 12.7 \\
Within-firm wage variance, \% total & 50.0 & 43.0 & 56 & 58.3 & 55.4 & 61.0 & 38.0 & 47.6 \\
\hline \hline
\end{tabular}

Notes. Baseline parameters reported in Table 4 with $\tau=1.53, b=0.35, A=3.46, \sigma=4.25$.

Trade liberalization. In column (4), we lower variable trade costs $\tau$ so as to match the increase in the share of revenues derived from exports. Since the mapping between the two variables does not depend on any other parameters aside from $\sigma$, we directly infer that $\tau$ needs to decrease from 1.58 to 1.3 in order to generate the observed increase in the share of exports in exporting firms' total sales from 20 to 29 percent. Keeping all the other parameters constant, we re-simulate the model and compare its outcome with the actual changes in the data.

Trade liberalization raises the share of exporting firms by increasing the survival cutoff $z_{D}^{*}$ and reducing the export cutoff $z_{X}^{*}$. It also raises the reservation wage $w_{r}$. These results are in line with the selection effect of the one-period model: the expansion in market size induced by trade liberalization increases the demand for labor, thereby raising workers' outside option and forcing less competitive firms out of the market. Moreover, lower variable trade costs allow the most productive domestic firms to start exporting. As a result of these selection effects, Table 6 shows that the model captures qualitatively and in some cases even quantitatively several changes found in the LIAB data.Moreover, the difference between the average exporter wage and the average non-exporter wage (the exporter wage premium) does not change much, which is in line with the data. Interestingly, although the key selection effects of trade are present, trade liberalization does not seem to affect neither the overall level of wage inequality nor its between/within break down. The latter in fact, slightly increases, which is at odd with the data.

Another feature of the comparative statics exercise is the prediction that unemployment increases slightly. In light of our discussion Section 4.4, this result suggests that the composition effect of trade liberalization prevails. The post-liberalization economy is populated by larger firms paying higher wages and offering longer queues, which result in a higher unemployment rate. The negligible increase in unemployment though, shows that the efficiency effect and the 
composition effect essentially offset each other.

Taking stock, feeding the model the observed increase in the export share explains most of the adjustments in firm size and export status. However, wage dispersion and its between/within firm decomposition remain almost flat. Hence, while trade goes a long way in explaining the selection effects observed in the data, it appears to be of little relevance for the observed increase in residual inequality. This suggests that other mechanisms are at work in our dynamic framework compared to its one-period presented in Section 4. One plausible explanation is that firms smooth the effect of trade-induced reallocations on wage dispersion. By contrast, in the one period model firms adjust immediately to the new post-liberalization optimal size, and this leads to a larger jump in the wage contract they offer.

Labor market deregulation. The first institutional change that we analyze is the reduction in unemployment benefits associated with the Hartz IV reform. The OECD estimates that the replacement rate in Germany was reduced by about 30\% from 2001 to 2009, which applied to our benchmark benefit gives $b=0.23 .{ }^{53}$ Lowering $b$ reduces the reservation wage $w_{r}$ as well as the two cutoffs $z_{D}^{*}$ and $z_{X}^{*}$. Intuitively, a reduction in benefits lowers workers' outside option, making survival easier for firms and allowing marginal non-exporters to enter the foreign market.

Column (5) of Table 6 reports the impact that unemployment benefits have on labor market outcomes. The reduction in unemployment benefits decreases unemployment by slightly less than one percentage point. ${ }^{54}$ The model also predicts that residual inequality increases with smaller $b$ : since the lower bound of the wage distribution is pinned down by the reservation wage $w_{r}$, a reduction in benefits shifts the support of the wage distribution to the left thereby making it more dispersed.

The Hartz III package of reforms focused on the Federal Employment Agency with the objective of increasing the efficiency of job search. Fahr and Sunde (2009) estimate the effects of this reform and argue that it has increased search efficiency by between 5 and $10 \%$. We model this by simulating the effects of an increase in $A$, from 3.46 to 3.8 ; see column (6). Not surprisingly, increasing matching efficiency lowers the intensity of search frictions, thereby reducing unemployment. The impact on inequality is counterfactual as better matching efficiency reduces wage dispersion. Improvements in the matching technology relax the trade off between wages and job filling rates. More productive firms resort less to wage incentives in order to

\footnotetext{
${ }^{53}$ One may argue that the acceleration of inequality dynamics started well before the Hartz IV reform was enacted; however, since wage bargaining is forward looking, expectations matter. Moreover, one can also view our reduction in $b$ as a result of lower trade union power.

${ }^{54}$ This is in line with the results in Launov and Waelde (2013). They estimate an equilibrium matching model with spell-dependent unemployment benefits and find that the Hartz IV reform reduced unemployment by 0.7 percentage points.
} 
raise their growth rates. Hence, the reforms aimed at improving the functioning of the public employment agency can explain part of the reduction in German unemployment but not the increase in inequality.

Product market deregulation. The other significant change over the period of interest relates to the ongoing process of European integration, most notably the Single Market Program (SMP henceforth) with its ambitious reforms of product market regulation. While the SMP presumably brought down trade costs between EU member states, it also led to deep domestic regulatory reform within each country. Indeed, the OECD index of product market regulation (PMR) intensity for Germany fell from 2.23 in 1998 to 1.4 in 2008, with two thirds of this change taking place by 2003. A similar pattern can be observed for Germany's major trade partners, particularly the large countries in continental Europe, while the UK and the US registered smaller changes since they had already low barriers in $1998 .{ }^{55}$ Griffith et al. (2004) and (2010) provide empirical evidence that the deregulation reforms carried out under the SMP in the early 1990s increased product market competition, as measured by a reduction in average sectorial profitability, in all major European economies. Using our firm level data we have computed the average and median markups for Germany in the period of interest. In Figure 2 we show that the markup, computed as profits share of revenues, has a median value of $30 \%$ in our benchmark year 1996, and it decreases to $28 \%$ in 2007 and to $25 \%$ in 2009 , a trend in line with the empirical evidence for other European countries.

Following Blanchard and Giavazzi (2003), we posit that product market reforms (encompassing trade liberalization) increase competition, thereby decreasing profit margins. A reduced form way to implement this is to experiment with an increase in the elasticity of substitution. The drop in markup observed in the data between 1996 and 2009 implies an increase in the elasticity of substitution $\sigma$, from 4.25 to 5 . Column (7) in Table 6 shows that, in spite of its relatively modest size, such a change has a significant impact on the economy. In particular, it increases both residual wage inequality and the share of inequality accounted for by the between firm channel. Overall residual inequality increases from $1.03 \%$ to $1.64 \%$, a $55 \%$ increase, accounting for a substantial share of the increase observed in the data where total wage variance due to the firm component increases from $2.9 \%$ in 1996 to $5.3 \%$ in 2009 , an $82 \%$ increase. Intuitively, a higher $\sigma$, and therefore higher demand elasticity increases the size premium of more productive firms, thereby increasing the dispersion of firm size. ${ }^{56}$ Since wage inequality in our economy

\footnotetext{
${ }^{55}$ The updated OECD Product Market Regulation data can be found at http://www.oecd.org/eco/growth/.

${ }^{56} \mathrm{~A}$ glance at the large increase in the difference between the average size of exporters and non exporters provides a rough but clear image of the change in size dispersion.
} 
is generated by dispersion in firm size, higher product market competition increases firm-size dispersion and wage inequality. Moreover, these adjustments imply that recruitment becomes more competitive, which intensifies search frictions and pushes up the rate of unemployment.

In addition to increasing overall inequality, product market competition has a stronger effect on wage dispersion between firms because it amplifies the differences in their hiring needs. This is why the decrease in markups lowers the share of inequality attributable to the within-firm component, matching most of the decline observed in the data. This result is in line with recent findings by Bloom et al. (2015). Focusing on a new matched employer-employee data set covering all US firms in the period 1976-2012 they find that most of the observed increase in inequality can be attributed to rising dispersion between firms in the average wage they pay.

To the best of our knowledge, our paper is the first to uncover this interesting link between demand elasticity, firm size and wage dispersion. Admittedly, the structure of our model economy with monopolistic competition and CES preference is too simple to allow a proper identification of which among the many reforms we consider had a major impact on product market competition, thereby shaping the evolution of firm size dispersion and wage inequality. Under this market structure, firms' market power cannot be affected by any change in the institutional environment. There is substantial empirical evidence that trade liberalization has pro-competitive effects via a reduction of markups at the sector and firm levels. ${ }^{57}$ In line with Krugman (1979), our model could be easily extended to embed a reduced-form representation of variable markups assuming that the elasticity of substitution is a function of firm size so that there would be pro-competitive gains from trade.

Hence, a key message of our analysis is that variable markups would tighten the link between trade liberalization and wage inequality. Unfortunately, modeling variable markups in open economies with firm heterogeneity and in general equilibrium is hard, even in a model with perfectly competitive labor markets. Melitz and Ottaviano (2008), offer a first step in this direction, setting up a partial equilibrium version of the Melitz model with variable markups obtained moving away from CES preferences. Recent contribution by Feenstra (2014) and Demidova (2016) have tried to extend the model to a general equilibrium setup. ${ }^{58}$ These considerations suggest that an important avenue for future research is to embed variable markups in our economy in order to carefully identify the effects of different policy changes on inequality, first among them the effect of trade liberalization.

\footnotetext{
${ }^{57}$ See Feenstra and Weinstein (2016) and De Loecker, Goldberg, Khandelwal, and Pavcnik (2016) for recent contributions.

${ }^{58}$ For a different approach focusing on an oligopolistic market structure see Atkeson and Burstein (2008) and Impullitti and Licandro (2017)
} 
Interactions between reforms. To take stock, trade liberalization can explain a substantial share of the adjustments in employment as well as in the cross-sectional distribution of firms characteristics. But its effect on residual inequality is rather marginal. Given that a similar conclusion holds for labor market reforms, the model singles out higher competition in domestic product markets as the main force behind the increase in residual inequality. Having determined the qualitative effects of each channel, we now assess whether their interaction can account for the changes observed in the data.

The results of this joint experiment is summarized in the last column of Table 6. Qualitatively, the combined policy changes generate responses in endogenous variables which are in line with the data, except for the unemployment rate which is predicted - counterfactually to increase as a consequence of fiercer product market competition. Quantitatively, the model successfully matches about half of the changes in moments as shown in Table 6. It works best for export shares of exporters, the average size of exporters, and the share of within-firm wage inequality. It predicts an increase of overall inequality by about 50\% (from 1.03 to 1.54\%), while the data see an increase by $83 \%$.

\subsection{Asymmetric model}

The comparative statics in our benchmark economy presented above was performed under the assumption of symmetric countries and symmetric reforms. While this is a plausible exercise for the trade and product market reforms which were undertaken simultaneously by the major German trade partners, Germany was rather isolated in its push towards labor market deregulation, to the extent that it has sometimes been accused of promoting beggar-thy-neighbor policies. In this section we extend the model to an asymmetric countries setting and study the effects of unilateral labor market reforms in Germany.

While the last years have seen the development of large-scale quantitative trade models with many countries, see Costinot and Rodriguez-Clare (2014), the stylized nature of these models and the absence of institutional detail allows calibration based on bilateral trade data only. Our setup is considerably more demanding, as we would require comparable micro-level data and institutional proxies for many countries. For this reason, we follow Cosar et al. (2016) or Helpman et al. (2017) and model Germany as a small open economy. 


\subsubsection{Small open economy}

This strategy has a long tradition both in the theoretical and quantitative trade literature; see Demidova and Rodriguez-Clare (2013) for a recent application in the context of the Melitz (2003) model. The idea is to assume that Germany is too small to influence foreign macroeconomic aggregates, such as income, the price level and the mass of firms, which are considered exogenous to changes in the home country. Empirically, this is a defendable assumption as Germany's share in global GDP is just about 4\%. Importantly, this setup does not preclude foreign firms to adjust their participation in exporting, and it also does not fix prices of individual product varieties.

More specifically, we assume that the rest of the world has the same demand system as Germany (i.e., the same elasticity $\sigma$ ) and that its firms are heterogeneous (with the same shape but possibly a different location parameter of the Pareto distribution). ${ }^{59}$ In contrast to the symmetric two-country model, we have to determine a foreign entry cutoff productivity $z_{x}^{*}$. To do this, we use the trade balance condition.

Denoting foreign variables by an asterisk, demand in the rest of the world is given by $q^{*}(z)=$ $p^{*}(z)^{-\sigma} Q^{*}$, where the aggregate demand shifter $Q^{*} \triangleq Y^{*} / M^{*}$ is treated parametrically by German firms and $P^{*}$ is used as numéraire. The revenue function for firm $z$ and size $\ell_{a}$ at age $a$ is

$$
R\left(\ell_{a}, \mathbb{I}_{a} ; z\right)=\left(z \ell_{a}\right)^{\frac{\sigma-1}{\sigma}}\left[P^{\sigma} Q+\mathbb{I}_{a}(z)(\tau)^{1-\sigma} Q^{*}\right]^{\frac{1}{\sigma}}
$$

for the home country, where $Q \triangleq Y / M$, and

$$
R^{*}\left(\ell_{a}^{*}, \mathbb{I}_{a} ; z\right)=\left(z \ell_{a}^{*}\right)^{\frac{\sigma-1}{\sigma}}\left[Q^{*}+\mathbb{I}_{a}(z)(\tau)^{1-\sigma} P^{\sigma} Q\right]^{\frac{1}{\sigma}}
$$

in the foreign country.

Since countries are asymmetric we allow for trade imbalances, which are pinned down by,

$$
\int_{z_{x}} R(z, \ell) M \mu(z) d z-\int_{z_{x}^{*}} R^{*}(z, \ell) M^{*} \mu^{*}(z) d z=B
$$

where $B$ is the trade balance. ${ }^{60}$ Finally, total production is $P Y=\mathcal{R}+B$, i.e., total revenues plus the trade balance. Hence the new version of the aggregate condition (19) is

$$
\frac{P Y-B}{M}=\left(1-\varrho^{*}\left(z_{x}^{*}\right) \frac{M^{*}}{M}\right) \int_{z_{D}^{*}}^{\infty}\left(\int_{0}^{\infty} R(z, \ell) \delta e^{-\delta a} d a\right) \mu(z) d z,
$$

\footnotetext{
${ }^{59}$ For more detail refer to Section A.10 in the Appendix.

${ }^{60}$ This equation holds implicitly in the symmetric two country world due to both countries satisfying their budget constraints.
} 
while the rest of the model remains unchanged.

\subsubsection{Quantitative analysis}

To facilitate the interpretation of the results, we stay as close as possible to the symmetric case for which we have successfully matched a number of German empirical moments. This anchors the calibration of the foreign economy. The small open economy assumption implies that we keep foreign variables constant as we conduct policy experiments in Germany. To restore equilibrium, the foreign export market cutoff $z_{x}^{*}$ and the terms of trade $P / P^{*}$ have to adjust. We proceed in several steps. ${ }^{61}$ First, we break the asymmetry in labor market institutions but keep the two regions equal sized and trade balanced. In our experiment, we start from full symmetry but alter Germany's institutions while holding the foreign ones constant. Second, we additionally allow for a German trade surplus $B$ of about $5 \%$ of GDP, the average magnitude observed for the years 1996 to 2009. Third, we introduce asymmetric country sizes. In the absence of a reliable measure for the number of varieties, we assume that Foreign has twice as many firms as Germany so that $M^{*} / M=2$.

Asymmetric labor market reforms. Table 7 reports the effects of labor market reforms in Germany when foreign institutions remain unchanged. Column (1) reports the model outcomes in 1996 under the symmetric setup which, by construction, also carries over to the small open economy world. Columns (2) to (4) maintain the balanced trade assumption and show the outcomes from (i) reducing unemployment benefits $b$ from 0.35 to 0.23 , (ii) increasing matching efficiency $A$ by $10 \%$, from 3.46 to 3.81, and (iii) increasing $\sigma$ to 5 while maintaining the changes in (2) and (3). Columns (5) to (7) repeat the same exercises but additionally impose a trade surplus of $5 \%$.

Lower $b$ increases the share of exporting firms only very slightly; accordingly, the average firm size of exporters falls from about 100 workers to 97 . Compared to the symmetric case, now, lower $b$ does induce some additional firms to export. This is in line with intuition: lower unemployment benefits reduce German wages, thereby improving competitiveness. However, this makes no discernible difference on aggregate outcomes such as the unemployment rate and inequality (which falls and rises, respectively, by about the same amount as in the symmetric case). If the trade surplus goes up to $5 \%$ of GDP, the share of exporters goes up strongly (from $18.8 \%$ to $21.3 \%$ ) and the average size of exporters falls to about 90 employees. Unemployment drops less, compared to the symmetric case, as queuing for a job in an exporting firm becomes

\footnotetext{
${ }^{61}$ The numerical procedure is described in the Technical Appendix.
} 
more attractive; the higher exporter wage premium bears witness to this. Wage inequality, in contrast, remains virtually unchanged.

Changing search efficiency in Germany, while keeping it constant in the rest of the world, lowers the share of exporting firms relative to the benchmark and raises the average size of exporters. In the symmetric case, those effects were much smaller (actually close to zero); see Table 6. Higher $A$ has an opposite effect to $b$ in terms of international competitiveness since it is associated with an increase in wages, in particular lower ones, so that residual inequality goes down. Adding a trade surplus of $5 \%$ to this scenario has similar qualitative implications as adding it to the Hartz IV reform scenario: unemployment goes up, but residual inequality remains the same.

Table 7: Impact of asymmetric labor market reforms

\begin{tabular}{|c|c|c|c|c|c|c|c|}
\hline \multirow[b]{3}{*}{ Moments } & \multirow[t]{2}{*}{ (1) } & $(2)$ & $(3)$ & $(4)$ & $(5)$ & $(6)$ & $(7)$ \\
\hline & & \multicolumn{3}{|c|}{ Balanced Trade } & \multicolumn{3}{|c|}{ Trade Surplus $=5 \%$} \\
\hline & Benchmark & $b=0.23$ & $A=3.8$ & Joint $^{\dagger}$ & $b=0.23$ & $A=3.8$ & Joint $^{\dagger}$ \\
\hline Share of exporting firms, $\%$ & 18.7 & 18.8 & 18.3 & 35.2 & 21.3 & 20.8 & 39.0 \\
\hline Average firm size & 26.8 & 26.3 & 27.1 & 42.7 & 26.9 & 27.5 & 43.4 \\
\hline Average size exporters & 99.7 & 96.5 & 103.6 & 105.2 & 90.1 & 96.0 & 98.0 \\
\hline Unemployment rate & 9.9 & 9.1 & 9.2 & 12.1 & 9.17 & 9.3 & 12.1 \\
\hline Total wage variance (residual), \% & 1.03 & 1.09 & 0.98 & 1.54 & 1.10 & 0.98 & 1.53 \\
\hline Exporter wage premium, $\%$ & 7.6 & 8.2 & 7.2 & 12.8 & 8.0 & 7.2 & 12.9 \\
\hline
\end{tabular}

Asymmetric market sizes. Next, we take into account the fact that the German economy is smaller than the rest of the world. More precisely, we assume that the (exogenous) mass of firms abroad is twice as high as the one in Germany. We recalibrate the parameters of the foreign economy so that the model generates the same benchmark values for endogenous variables in Germany as under symmetry, thereby making it possible to compare the results obtained under the two hypotheses. We find that trade flows are balanced when $P / P^{*}=0.85$. For trade to be balanced, the relative price index $P / P^{*}$ needs to be lower than one, otherwise the value of imports into Germany would be too high.

Table 8 shows the comparative statics under asymmetric market size. Labor market reforms have almost the same effects as in the symmetric economy in Table 6 ; the only remarkable difference is with respect to the share of exporters and their sizes. Table 8 also reports the effects of lowering variable trade costs (reciprocal liberalization). Since $M^{*}>M$, now, terms of trade have to fall to restore trade balance. The effects on the share of exporters and on average exporter size are magnified compared to the symmetric case, and the stronger expansion of the 
Table 8: Impact of reforms with asymmetric market sizes

\begin{tabular}{lcccccc}
\hline \hline & $(1)$ & $(2)$ & $(3)$ & $(4)$ & $(5)$ & $(6)$ \\
Moments & Benchmark & $b=0.23$ & $A=3.8$ & $\tau=1.3$ & Trade Surplus $+5 \%^{\text {Joint }^{\dagger}}$ \\
\hline Terms of trade $\left(\mathrm{P} / \mathrm{P}^{*}\right)$ & 0.85 & 0.86 & 0.86 & 0.84 & 0.84 & 0.86 \\
Share of exporting firms, $\%$ & 18.8 & 18.4 & 18.3 & 42.9 & 20.5 & 32.2 \\
Average firm size & 26.8 & 26.4 & 27.1 & 30.0 & 27.2 & 40.9 \\
Average size exporters & 99.8 & 98.2 & 103.5 & 59.8 & 95.1 & 108.6 \\
Unemployment rate & 9.9 & 9.1 & 9.2 & 10.1 & 9.9 & 12.0 \\
Total wage variance (residual), $\%$ & 1.03 & 1.10 & 0.98 & 1.03 & 1.03 & 1.54 \\
Exporter wage premium, $\%$ & 7.6 & 8.2 & 7.2 & 7.0 & 7.6 & 12.5 \\
\hline \hline Baseline par.: $\tau=1.53, b=0.35, A=3.46, \sigma=4.25, \mathrm{M}^{*} / \mathrm{M}=2 .{ }^{\dagger}$ Joint par.: $\tau=1.3, b=0.23, A=3.8, \sigma=5$, Trade Surplus $+5 \%$.
\end{tabular}

export sector leads to a relatively sharp decline in the exporter wage premium. However, asymmetric market size makes little difference regarding the effect of liberalization on unemployment or residual inequality. Intuitively, since both the benchmark and the asymmetric size model have been fed with trade shocks of similar magnitude, the aggregate impact of trade is not fundamentally affected by differences in country size. For the same reason, unilateral labor market reforms in Germany and multilateral trade and product market reforms have a joint impact on German unemployment and inequality that is similar to the one in the benchmark model.

\section{Conclusion}

We build a model where firm dynamics and directed search on the labor market produce wage dispersion among homogenous workers. We use it to explore the effects of trade, product, and labor market reforms on residual inequality and unemployment. A one-period version of the model can be solved in closed form and provides an analytical characterization of the mechanisms linking trade and inequality. It generates an inverted U-shape relationship between trade and inequality which hinges on the presence of an export wage premium: trade liberalization increases inequality when trade costs are high and few firms pay the premium, but it reduces it when trade costs are low and most firms pay the premium. The effect of trade on jobs is also ambiguous and strictly dependent on the shape of adjustment costs.

We use German matched employer-employees data to calibrate the dynamic model and explore its properties numerically. Going beyond trade, we also study the roles of labor and product market reforms. The main mechanisms linking trade and labor market outcomes highlighted in the one-period model continue to provide intuition. Moreover, the interaction between wage posting and firm growth explains important firm-level regularities recently highlighted in the empirical literature. First, firms increase their rate of growth by posting higher wages and filling their vacancies faster. Second, productivity distributions of exporters and non-exporters 
show partial overlap. Third, wage dispersion occurs both between and within firms.

Matching key statistics allows us to use the model for a quantitative assessment of the impact of trade and institutional reforms on the German labor market. Focusing on the period 19962007 we find that neither the massive increase in German trade openness, nor the main features of the Hartz labor market reforms, can explain the sharp increase in residual wage dispersion observed in the data. By contrast, higher competition in the product market, nested into the model as an increase in demand elasticity, has a strong effect on inequality, accounting for a large part of the increase in German wage dispersion. Interestingly, treating Germany asymmetrically from the rest of the world has implications for the share and the size of exporters, but does not affect the key effects of reforms on unemployment and inequality.

Our analysis suggests several directions for future research. One possible extension would analyze more deeply the role of smooth firm growth in shaping the trade-inequality nexus, by comparing dynamic models to their static counterparts. Secondly, since our results indicate that wage dispersion is highly responsive to changes in demand elasticity, introducing endogenous markups is likely to strengthen the quantitative link between trade and inequality. 


\section{References}

Acemoglu, Daron, and Robert Shimer, 1999, "Holdups and Efficiency with Search Frictions", International Economic Review 40: 827-928.

Acemoglu, Daron, 2003, "Patterns of Skill Premia", Review of Economic Studies 70(2): 199-230.

Amiti, Mary, and Donald Davis, 2011, "Trade, Firms, and Wages: Theory and Evidence", Review of Economic Studies 79: 1-36.

Autor, David, David Dorn, and Gordon Hanson, 2013, "The China Syndrome: Local Labor Market Effects of Import Competition in the United States", American Economic Review 103(6): 2121-2168.

Autor, David, David Dorn, Gordon Hanson, and Jae Song, 2014, "Trade Adjustment: Worker Level Evidence", Quarterly Journal of Economics 129(4): 1799-1860.

Bagger, Jesper and Rasmus Lentz, 2015, An Equilibrium Model of Wage Dispersion and Sorting, mimeo: University of Wisconsin-Maddison.

Baumgarten, Daniel, 2013, "Exporters and the Rise in Wage Inequality: Evidence from German Linked Employer-Employee Data", Journal of International Economics 90(1): 201-217.

Barth, Erling, Alex Bryson, James C. Davis, Richard Freeman, 2014, "It's Where You Work: Increases in Earnings Dispersion across Establishments and Individuals in the U.S.", NBER Working Paper No. 20447.

Bellon, Matthieu, 2016, "Trade liberalization and inequality: a dynamic model with firm and worker heterogeneity", Columbia University Working Paper.

Bernard, Andrew, Bradford Jensen, Jonathan Eaton, and Samuel Kortum, 2003, "Plants and Productivity in International Trade", American Economic Review 93(4): 1268-290.

Bernard, Andrew, Stephen Redding, and Peter Schott, 2007, "Comparative advantage and heterogeneous firms", Review of Economic Studies 74(1): 31-66.

Blanchard, Olivier, and Francesco Giavazzi, 2003, "Macroeconomic Effects of Regulation and Deregulation in Goods and Labor Markets", Quarterly Journal of Economics 118(3): 897-907.

Bloom, Nicholas, Fatih Guvenen, David Price, and Jae Song, 2015, "Firming up Inequality", mimeo Stanford. 
Blundell, Richard, and Ben Etheridge, 2010, "Consumption, Income and Earnings Inequality in Britain", Review of Economic Dynamics 13(1): 76-102.

Burstein, Ariel, and Andrew Atkeson, 2008, "Pricing-to-Market, Trade Costs, and International Relative Prices", American Economic Review, 98(5): 1998-203.

Card, David, Joerg Heining, and Patrick Kline, 2013, "Workplace Heterogeneity and the Rise of West German Wage Inequality", Quarterly Journal of Economics 128(3): 967-1015.

Coşar, Kerem, Nezih Guner, and James Tybout, 2016, "Firm Dynamics, Job Turnover, and Wage Distributions in an Open Economy", American Economic Review, 106(3): 625-63.

Costinot, Arnaud and Andrés Rodríguez-Clare, 2014, "Trade Theory with Numbers: Quantifying the Consequences of Globalization", in: Gopinath, Gita, Elhanan Helpman and Kenneth Rogoff (eds.), Handbook of International Economics, Volume 4 (Elsevier).

Dauth, Wolfgang, Sebastian Findeisen, and Jens Suedekum, 2014, "The Rise of the East and the Far East: German Labor Markets and Trade Integration ", Journal of the European Economic Association 12(6): 164-1675.

Davis, Donald, and James Harrigan, 2011, "Good Jobs, Bad Jobs, and Trade Liberalization", Journal of International Economic 84: 26-36.

Davis, Stephen, Jason Faberman, and John Haltiwanger, 2013, "The Establishment-Level Behavior of Vacancies and Hiring", Quarterly Journal of Economics 128 (2): 581-622.

De Loecker, Jan, Penny Goldberg, Amit Khandelwal, and Nina Pavcnik, 2016. "Prices, Markups and Trade Reform", Econometrica, forthcoming.

Demidova, Svetlana and Andrés Rodríguez-Clare, 2013, "The Simple Analytics of the Melitz Model in a Small Economy", Journal of International Economic 90(2): 266 - 272.

Demidova, Svetlana, 2016, "Trade Policies, Firm Heterogeneity, and Variable Markups", mimeo. Dustmann, Christian, Johannes Ludsteck, and Ute Schoenberg, 2009, "Revisiting the German Wage Structure", Quarterly Journal of Economics 124(2): 843-881.

Egger, Hartmut, and Udo Kreickemeier, 2009, "Firm Heterogeneity and the Labor Market Effects of Trade Liberalization", International Economic Review 50: 187-216. 
Egger, Hartmut, Peter Egger, and Udo Kreickemeier, 2013, "Trade, Wages, and Profits", European Economic Review 64: 332-350.

Eaton, Jonathan, Sam Kortum, and Francis Kramarz, 2011, "An Anatomy of International Trade: Evidence From French Firms", Econometrica, Vol. 79, No. 5, pp. 1453-1498.

Epifani, Paolo, and Gino Gancia, 2008, "The Skill Bias of World Trade," Economic Journal 118(530): 927-960.

Fahr, René, and Uwe Sunde, 2009, "Did the Hartz Reforms Speed Up Job the Matching Process? A Macroeconomic Evaluation Using Empirical Matching Functions", German Economic Review 10(3): 284-316.

Fajgelbaum, Pablo, 2013, "Labor Market Frictions, Firm Growth, and International Trade", NBER Working Paper 19492.

Feenstra, Robert, 2014, "Restoring the Product Variety and Pro-competitive Gains from Trade with Heterogeneous Firms and Bounded Productivity", NBER Working Paper No. 19833.

Feenstra, Robert, and David Weinstein, 2016, "Globalization, Competition, and U.S. Welfare, joint with David Weinstein", forthcoming, Journal of Political Economy.

Felbermayr, Gabriel, Julien Prat, and Hans-Jörg Schmerer, 2011, "Globalization and labor market outcomes: Wage bargaining, search frictions, and firm heterogeneity", Journal of Economic Theory 146: 39-73.

Felbermayr, Gabriel, Giammario Impullitti, and Julien Prat, 2014, "Firm Dynamics and Residual Inequality in Open Economies", CESifo Working Paper No. 4666.

Fuchs, Michaela, and Antje Weyh, 2010, "The Determinants of Job-Creation and Destruction: Plant-Level Evidence for Eastern and Western Germany", Empirica 111: 765-788.

Fuchs-Schuendeln, Nicole, Dirk Krueger, and Mathias Sommer, 2010, "Inequality Trends for Germany in the Last Two Decades: A Tale of Two Countries", Review of Economic Dynamics 13: $103-132$.

Garibaldi, Pietro, and Espen Moen, 2010, "Job to Job Movements in a Simple Search Model", American Economic Review 100(2): 343-47. 
Hall, Robert, and Alan Krueger, 2012, "Evidence on the Incidence of Wage Posting, Wage Bargaining, and on-the-Job Search", American Economic Journal: Macroeconomics 4(4): 5667.

Griffith, Rachel, Harrison, Rupert and Simpson, Helen, 2010, "Product market reforms and innovationin the EU", Scandinavian Journal of Economics, 112 (2): pp. 389-4 15

Harrigan, James, and Ariell Reshef, 2012, "Skill Biased Heterogeneous Firms, Trade Liberalization and the Skill Premium", Canadian Journal of Economics, forthcoming.

Hauptmann, Andreas, and Hans-Jörg Scherer, 2013, "Do Exporters Pay Fair-Wage Premiums", Economics Letters 121: 179-182.

Head, Keith, Thierry Mayer, and Matthias Thoenig, 2014, "Welfare and Trade Without Pareto", American Economic Review Papers and Proceedings, 104(5): 310-316.

Heathcote, Johnathan, Fabrizio Perri, and Giovanni Violante, 2010, "Unequal We Stand: An Empirical Analysis of Economic Inequality in the United States", Review of Economic Dynamics 13(1): $15-54$.

Helpman, Elhanan, Oleg Itskhoki, Marc-Andreas Muendler and Stephen J. Redding, 2017, "Trade and Inequality: From Theory to Estimation," Review of Economics Studies, 84(1): 357405.

Helpman, Elhanan, and Oleg Itskhoki, 2010, "Labor Market Rigidities, Trade and Unemployment", Review of Economic Studies 77(3): 1100-1137.

Helpman, Elhanan, Oleg Itskhoki, and Stephen Redding, 2010, "Inequality and Unemployment in a Global Economy", Econometrica 78(4): 1239-1283.

Hertweck, Matthias, and Oliver Sigrist, 2012, "The Aggregate Effects of the Hartz Reforms in Germany", Working Paper 2012-38, University of Konstanz.

Hornstein, Andreas, Per Krusell, and Gianluca Violante, 2011, "Frictional Wage Dispersion in Search Models: A Quantitative Assessment ", American Economic Review 101(7): 2873-2898.

Impullitti, Giammario, Alfonso Irarrazabal, and Luca David Opromolla, 2013, "A Theory of Entry into and Exit from Exports Markets", Journal of International Economics 90(1): 75-90. Impullitti, Giammario, and Omar Licandro, 2017, "Trade, Selection and Innovation: the Competition Channel", Economic Journal, forthcoming. 
Jacobi, Lena, and Kluve, Jochen, 2007, "Before and after the Hartz reforms: The performance of active labour market policy in Germany", Zeitschrift für ArbeitsmarktForschung - Journal for Labour Market Research 40(1): 45-64.

Jappelli, Tullio, and Luigi Pistaferri, 2010, "Does Consumption Inequality Track Income Inequality in Italy?", Review of Economic Dynamics 13(1): 133-153.

Kaas, Leo, and Philipp Kircher, 2015, "Efficient Firm Dynamics in a Frictional Labor Market", American Economic Review 105(10): 3030-60.

Krebs, Tom, and Martin Scheffel, 2013, "Macroeconomic Evaluation of Labor Market Reform in Germany", mimeo.

Kohlbrecher, Britta, Christian Merkl, and Daniela Nordmeyer, 2013, "The Matching Function: A Selection-Based Interpretation", LASER Discussion Papers - Paper No. 70.

Koske, Isabell, Isabelle Wanner, Rosa Bitette, Omar Barbiero, 2015, "The 2013 update of the OECD's database on product market regulation: Policy insights for OECD and non-OECD countries", OECD Economics Department Working Papers, No. 1200.

Launov, Andrei, and Klaus Waelde, 2013, "Estimating Incentive and Welfare Effects of NonStationary Unemployment Benefits", International Economic Review 54(4): 1159-1198.

Launov, Andrei, and Klaus Waelde, 2016, "The Employment Effect of Reforming a Public Employment Agency", European Economic Review 84: 140-164.

Manning, Alan, 2006, "A generalised model of monopsony", Economic Journal 116: 84-100.

Martin, John, 1996, "Measures of Replacement Rates for the Purpose of International Comparisons: A Note", OECD Economic Studies, No, 26.

Merz, Monika, and Eran Yashiv, 2007, "Labor and the Market Value of the Firm", American Economic Review 97: 1419-1431.

Moen, Espen, 1997, "Competitive Search Equilibrium", Journal of Political Economy 105(2): $385-411$.

Mueller, Holger, Ouimet, Page, and Elena Simintzi, 2015, "Wage Inequality and Firm Growth", NBER Working Paper No. 20876.

OECD, 2011, "Divided We Stand: Why Inequality Keeps Rising", OECD Publishing, Paris. 
Roberts, Mark, and James Tybout, 1997, "What Makes Exports Boom?", in Directions in Development Series, The World Bank, 1997.

Shimer, Robert, 2010, Labor Markets and Business Cycle,. Princeton University Press.

Torres, Sonia, Pedro Portugal, John Addison, and Paulo Guimaraes, 2013, "The Sources of Wage Variation: A Three-Way High-Dimensional Fixed Effects Regression Model", IZA Discussion Paper 7276.

Wolf, Anita, Isabelle Wanner, Tomasz Kozluk, and Giuseppe Nicoletti, 2009, "Ten years of product market reform in OECD countries - insights from a revised PMR indicator", OECD Economics Department Working Paper No. 695.

Woodcock, Simon, 2008, "Wage Differentials in the Presence of Unobserved Worker, Firm, and Match Heterogeneity", Labour Economics 15(4): 771-793.

Xing, Chunbing, and Shi Li, 2012, "Residual wage inequality in urban China, 1995-2007", China Economic Review 23(2): 205-222.

Yeaple, Stephen, 2005, "A Simple Model of Firm Heterogeneity, International Trade, and Wages", Journal of International Economics, 65(1): 1-20. 


\section{A Proofs}

\section{A.1 Proof of Proposition 2}

The only dynamic component of the optimality conditions is $\partial \Psi\left(\ell_{a}, \mathbb{I}\right) / \partial \ell_{a}$. Directly differentiating its expression in (11) yields

$$
(r+\delta+\chi) \frac{\partial \Psi\left(\ell_{a}, \ell ; z\right)}{\partial \ell_{a}}=R_{1}\left(\ell_{a}, \mathbb{I} ; z\right)+\frac{\partial^{2} \Psi\left(\ell_{a}, \mathbb{I} ; z\right)}{\partial \ell_{a}^{2}}\left[q\left(\theta_{a}\right) v_{a}-\chi \ell_{a}\right]
$$

where we add the number of the independent variable as a subscript to denote its partial derivative. The expression above makes clear that $\partial \Psi\left(\ell_{a}, \mathbb{I}\right) / \partial \ell_{a}$ is the shadow value of labor since it is equal to the discounted sum of marginal output. The term on the right hand side can be expressed as ${ }^{62}$

$$
\begin{aligned}
\frac{\partial^{2} \Psi\left(\ell_{a}, \mathbb{I} ; z\right)}{\partial \ell_{a}^{2}}\left[q\left(\theta_{a}\right) v_{a}-\chi \ell_{a}\right] & =\frac{\partial^{2} \Psi\left(\ell_{a}, \mathbb{I} ; z\right)}{\partial \ell_{a}^{2}} \dot{\ell}_{a}=\frac{d}{d a}\left(\frac{\partial \Psi\left(\ell_{a}, \mathbb{I} ; z\right)}{\partial \ell_{a}}\right)=\frac{d}{d a}\left(\frac{C^{\prime}\left(v_{a}\right)}{q\left(\theta_{a}\right)}+\frac{w\left(\theta_{a}\right)}{r+\delta+\chi}\right) \\
& =\frac{C^{\prime \prime}\left(v_{a}\right) \dot{v}_{a} q\left(\theta_{a}\right)-C^{\prime}\left(v_{a}\right) q^{\prime}\left(\theta_{a}\right) \dot{\theta}_{a}}{q\left(\theta_{a}\right)^{2}}+\frac{w^{\prime}\left(\theta_{a}\right) \dot{\theta}_{a}}{r+\delta+\chi} .
\end{aligned}
$$

Reinserting this equality into the previous equation, we obtain

$$
(r+\delta+\chi)\left[\frac{C^{\prime}\left(v_{a}\right)}{q\left(\theta_{a}\right)}+\frac{w\left(\theta_{a}\right)}{r+\delta+\chi}\right]-\frac{C^{\prime \prime}\left(v_{a}\right) \dot{v}_{a} q\left(\theta_{a}\right)-C^{\prime}\left(v_{a}\right) q^{\prime}\left(\theta_{a}\right) \dot{\theta}_{a}}{q\left(\theta_{a}\right)^{2}}-\frac{w^{\prime}\left(\theta_{a}\right) \dot{\theta}_{a}}{r+\delta+\chi}=R_{1}\left(\ell_{a}, \mathbb{I} ; z\right) .
$$

The dynamics condition is too intricate to be analyzed at this level of generality. This is why we impose the additional Assumptions A1 and A2. When recruitment costs are isoelastic, i.e., $C(v)=v^{\alpha}$, (14) is equivalent to $v_{a}^{\alpha-1}=(1-\eta) \rho /\left(\eta \alpha \theta_{a}\right)$ and the dynamic equation (40) reads

$$
(r+\delta+\chi) \frac{\alpha v_{a}^{\alpha-1}}{q\left(\theta_{a}\right)}+w\left(\theta_{a}\right)-\frac{\alpha(\alpha-1) v_{a}^{\alpha-2} \dot{v}_{a} q\left(\theta_{a}\right)-\alpha v_{a}^{\alpha-1} q^{\prime}\left(\theta_{a}\right) \dot{\theta}_{a}}{q\left(\theta_{a}\right)^{2}}-\frac{w^{\prime}\left(\theta_{a}\right) \dot{\theta}_{a}}{r+\delta+\chi}=R_{1}\left(\ell_{a}, \mathbb{I} ; z\right)
$$

Assumption A2 allows us to simplify this equation further by expressing analytically the slope $\dot{v}_{a}$ of the vacancy schedule with respect to age. When the matching function is Cobb-Douglas, i.e., $q(\theta)=A \theta^{-\eta}$,

$$
\dot{v}_{a}=-\frac{\dot{\theta}_{a} \theta_{a}^{-\frac{\alpha}{\alpha-1}}}{\alpha-1}\left[\left(\frac{1}{\eta}-1\right) \frac{\rho}{\alpha}\right]^{\frac{1}{\alpha-1}}
$$

and so

$$
\frac{\alpha v_{a}^{\alpha-1}}{q\left(\theta_{a}\right)}\left[r+\delta+\chi-(\alpha-1) \frac{\dot{v}_{a}}{v_{a}}+\frac{q^{\prime}\left(\theta_{a}\right) \dot{\theta}_{a}}{q\left(\theta_{a}\right)}\right]=\left(\frac{1}{\eta}-1\right) \frac{\rho}{\theta_{a} q\left(\theta_{a}\right)}\left[r+\delta+\chi+\frac{\dot{\theta}_{a}}{\theta_{a}}(1-\eta)\right] .
$$

Reinserting (42) into (41) and substituting out $w^{\prime}\left(\theta_{a}\right)$, we finally obtain

$$
\frac{1}{\theta_{a} q\left(\theta_{a}\right)}\left(r+\delta+\chi+\frac{\dot{\theta}_{a}}{\theta_{a}}(1-\eta)\right)=\frac{\eta}{\rho}\left[R_{1}\left(\ell_{a}, \mathbb{I} ; z\right)-w_{r}\right] .
$$

In order to solve this equation, we use the following change of variable $\vartheta_{a} \triangleq\left[\theta_{a} q\left(\theta_{a}\right)\right]^{-1}=A^{-1} \theta_{a}^{\eta-1}$ so that

$$
\dot{\vartheta}_{a}=(\eta-1) A^{-1} \theta_{a}^{\eta-2} \dot{\theta}_{a}=\frac{1}{\theta_{a} q\left(\theta_{a}\right)} \frac{\dot{\theta}_{a}}{\theta_{a}}(\eta-1) .
$$

\footnotetext{
${ }^{62}$ The third equality follows from (12).
} 
Thus (43) is equivalent to

$$
\vartheta_{a}(r+\delta+\chi)-\dot{\vartheta}_{a}=\frac{\eta}{\rho}\left[R_{1}\left(\ell_{a}, \mathbb{I} ; z\right)-w_{r}\right]
$$

We wish to express (44) as an ODE in $\ell_{a}$ only. Straightforward algebra yields

$$
\dot{\ell}_{a}+\chi \ell_{a}=q\left(\theta_{a}\right) v_{a}=q\left(\theta_{a}\right)\left[\frac{1}{\theta_{a}}\left(\frac{1}{\eta}-1\right) \frac{\rho}{\alpha}\right]^{\frac{1}{\alpha-1}}=\vartheta_{a}^{\frac{\eta+1 /(\alpha-1)}{1-\eta}} \underbrace{A^{1+\frac{\eta+1 /(\alpha-1)}{1-\eta}}\left[\left(\frac{1}{\eta}-1\right) \frac{\rho}{\alpha}\right]^{\frac{1}{\alpha-1}}}_{\triangleq \xi_{0}} .
$$

In order to obtain $\dot{\vartheta}_{a}$, we differentiate this expression with respect to time

$$
\dot{\vartheta}_{a}=\frac{1-\eta}{\eta+1 /(\alpha-1)}\left(\frac{\dot{\ell}_{a}+\chi \ell_{a}}{\xi_{0}}\right)^{\frac{1-\eta}{\eta+1 /(\alpha-1)}} \frac{\ddot{\ell}_{a}+\chi \dot{\ell}_{a}}{\dot{\ell}_{a}+\chi \ell_{a}},
$$

and replace it into (44) to finally derive the law of motion (16) for employment. It obeys a highly non linear second order ODE. The employment profile of any given firm can therefore be pinned down using a starting and terminal conditions. First, given that startups have no labor force, we can set $\ell_{0}=0 .{ }^{63}$ The second condition ensures that employment converges smoothly to its optimal value in the long run, so that both $\dot{\ell}_{a}$ and $\ddot{\ell}_{a}$ approach zero as time goes to infinity. Eliminating $\dot{\ell}_{a}$ and $\ddot{\ell}_{a}$ from (16), we find that the asymptotic level of employment $\bar{\ell}(z) \triangleq \lim _{a \rightarrow \infty} \ell_{a}(z)$ is given by the unique solution to (17). Finally the smooth-pasting condition ensures that the employment schedule is everywhere differentiable, including the employment level $\ell^{X}(z)$ at which domestic firms start exporting. If the smooth-pasting condition were violated, there would be a kink at $\ell^{X}(z)$. But this cannot be optimal because adjustment costs are convex, implying that firms could save on recruitment costs by smoothing their convergence path. ${ }^{64}$

\section{A.2 Derivation of equation (25)}

Lemma 1 For a given value of search $W$ and average productivity $\tilde{z}$, the equilibrium locus $\theta(z)$ reads

$$
\theta(z)=\left(\frac{\sigma}{\sigma-1} \frac{W}{A \eta}\right)^{\frac{1}{1-\eta}} \tilde{z}^{-\frac{1}{1-\eta} \frac{\beta}{\sigma-1}} z^{\zeta \frac{\sigma-1}{\sigma}}\left[1+\mathbb{I}(z) \tau^{1-\sigma}\right]^{\frac{\zeta}{\sigma}}
$$

where $\beta>0$ and $\zeta<0$ are combinations of parameters defined in (53) and (52), respectively.

Equation (5) implies that marginal revenue are proportional to the domestic price which, combined with our normalization, yields

$$
R_{1}(\ell, \mathbb{I} ; \tilde{z})=\frac{\sigma-1}{\sigma} p_{D}(\tilde{z}) \tilde{z}=\frac{\sigma-1}{\sigma} \tilde{z}
$$

\footnotetext{
${ }^{63}$ When the revenues function $R\left(\ell_{a}, \mathbb{I}\right)$ is isoelastic, as in Melitz's (2003) model, marginal revenues diverge to infinity as $\ell$ goes to zero. This implies that the ODE (16) has a singularity at $\ell=0$. Yet it is well behaved for any arbitrarily small initial size. Hence, in the simulation, we follow Garibaldi and Moen (2010) and circumvent this technical difficulty by assuming that $\ell_{0}=\varepsilon$. Letting $\varepsilon$ go to zero shows that, for sufficiently small $\varepsilon$ s, the optimal recruitment schedule is not significantly affected by the choice of $\varepsilon$

${ }^{64}$ Smooth-pasting is a standard optimality condition in firm entry models, explored in details in Dixit and Pindyck (1994) and applied to entry into and exit from the export market in Impullitti, et al. (2013).
} 
Using this identity and the functional forms in Assumptions 1 and 2, one can use the first-order condition $R_{1}(\ell, \mathbb{I} ; z) q^{\prime}(\theta)=-W / \theta^{2}$ to solve for the tightness associated with $\tilde{z}$

$$
\tilde{\theta}=\left(\frac{\sigma}{\sigma-1} \frac{W}{A \eta \tilde{z}}\right)^{\frac{1}{1-\eta}} .
$$

Similarly, reinserting our functional forms into equation (24), one obtains a closed form solution for $v$ as a function of $\theta$

$$
v(z)=\left(\frac{1-\eta}{\eta \alpha} \frac{W}{\theta(z)}\right)^{\frac{1}{\alpha-1}} .
$$

We now explain how posted wages can be derived for all productivity levels. First, note that marginal revenues are related in the following fashion

$$
\frac{R_{1}(\ell, \mathbb{I} ; z)}{R_{1}(\tilde{\ell}, 0 ; \tilde{z})}=\left(\frac{z}{\tilde{z}}\right)^{\frac{\sigma-1}{\sigma}}\left[1+\mathbb{I}(z) \tau^{1-\sigma}\right]^{1 / \sigma}\left(\frac{\tilde{\ell}}{\ell(z)}\right)^{1 / \sigma}=\left(\frac{\tilde{\theta}}{\theta(z)}\right)^{1-\eta}
$$

The second equality results from the first order condition $R_{1}(\ell, \mathbb{I} ; z) q^{\prime}(\theta)=-W / \theta^{2}$, which-under our parametric assumptions-simplifies to $R_{1}(\ell, \mathbb{I} ; z)=W /\left(\eta A \theta^{1-\eta}\right)$. Since $\ell=q(\theta) v$, one can solve for the employment levels using equation (49) and substitute them out of equation (50) to obtain

$$
\frac{z}{\tilde{z}}=\left[1+\mathbb{I}(z) \tau^{1-\sigma}\right]^{\frac{1}{1-\sigma}}\left(\frac{\theta(z)}{\tilde{\theta}}\right)^{\zeta^{-1} \frac{\sigma}{\sigma-1}},
$$

where

$$
\zeta^{-1} \triangleq-\left[1-\eta+\frac{1}{\sigma}\left(\frac{1}{\alpha-1}+\eta\right)\right]<0 .
$$

Tightness is inversely related to productivity as the exponent on the right-hand side of (51) is unambiguously negative. Observe also that the relationship depends on the export status of the firm. If a firm with productivity $z$ decides to export, the indicator function $\mathbb{I}(z)$ switches from zero to one which lowers $\theta(z)$. As expected, everything else equal, the decision to sell on the foreign market leads to an increase in optimal employment. And, to accommodate its expansion, the firm decide to post a higher wage.

The equilibrium tightness is obtained plugging (48) into (51), with

$$
\beta \triangleq-\zeta \frac{\sigma-1}{\sigma} \frac{\alpha}{\alpha-1}>0
$$

The exponents of both $z$ and $\tilde{z}$ in (46) are negative. To derive the exponent of $\tilde{z}$, one replaces (48) into (51). This yields the expression in (46) but with the following exponent for $\tilde{z}$

$$
-\left(\frac{1}{1-\eta}+\zeta \frac{\sigma-1}{\sigma}\right)=-\frac{1}{1-\eta}\left[1+\zeta \frac{\sigma-1}{\sigma}(1-\eta)\right]=-\frac{1}{1-\eta}\left[-\zeta \frac{1}{\sigma} \frac{\alpha}{\alpha-1}\right] .
$$

Replacing the definitions of $\zeta$ and of $\beta$ into the expression above yields the exponent of $z$ and $\tilde{z}$ in (46). Since the exponent of $z$ in (46) is negative, firms with a higher productivity recruit in tighter markets (lower $\theta$ ) and post higher wages. Furthermore, more productive firms post more vacancies and employ more workers in equilibrium. A higher productivity of the representative firm $(\tilde{z})$ shifts the $\theta(z)$ locus up, thereby leading to higher wages for all $z$. Finally, replacing the results of the Lemma into (22) and taking logarithms ${ }^{65}$ we obtain the wage profile $(25)$.

\footnotetext{
${ }^{65}$ We have made use of $1+\zeta[(\sigma-1) / \sigma](1-\eta)=\beta /(\sigma-1)$.
} 


\section{A.3 Derivation of equation (26)}

Equation (26) is a direct consequence of the Lemma below.

Lemma 2 (Profits) For given aggregates $W$ and $\tilde{z}$, operating profits are log-linear in $z$ as

$$
\pi(z ; W)+f+\mathbb{I}(z) f_{X}=K W^{-\frac{\eta}{1-\eta}\left(\frac{\alpha}{\alpha-1}\right)} \tilde{z}^{\gamma} z^{\beta}\left[1+\mathbb{I}(z) \tau^{1-\sigma}\right]^{\frac{\beta}{\sigma-1}},
$$

where the constants $K>0$ and $\gamma>0$ are defined in (62) and (61). The productivity $\tilde{z}$ of the representative firm is given by

$$
\tilde{z}=\left[\frac{1}{1+\varrho} \int_{z_{D}^{*}}^{\infty} z^{\beta}\left[1+\mathbb{I}(z) \tau^{1-\sigma}\right]^{\frac{\beta}{\sigma-1}} \mu(z) d z\right]^{\frac{1}{\beta}} .
$$

The expression for $\tilde{z}$ follows from the normalization of the aggregate price index $P=1$. Recognizing that $p_{X}(z)=\tau^{1-\sigma} p_{D}(z)$ and that the mass of domestically available varieties $M$ is related to the mass of domestically produced varieties $M_{D}$ by $M=M_{D}+\varrho M_{D}$, since $\varrho M_{D}$ measures the mass of imported varieties, we obtain

$$
\begin{aligned}
P & =\left[\frac{1}{M} \int_{\omega \in \Omega} p(\omega)^{1-\sigma} d \omega\right]^{\frac{1}{1-\sigma}}=\left[\frac{M_{D}}{M} \int_{z_{D}^{*}}^{\infty} p_{D}(z)^{1-\sigma}\left[1+\mathbb{I}(z) \tau^{1-\sigma}\right] \mu(z) d z\right]^{\frac{1}{1-\sigma}} \\
& =\left[\frac{1}{1+\varrho} \int_{z_{D}^{*}}^{\infty} p_{D}(z)^{1-\sigma}\left[1+\mathbb{I}(z) \tau^{1-\sigma}\right] \mu(z) d z\right]^{\frac{1}{1-\sigma}} .
\end{aligned}
$$

The normalization $P=1$ implies that

$$
1+\varrho=\int_{z_{D}^{*}}^{\infty} p_{D}(z)^{1-\sigma}\left[1+\mathbb{I}(z) \tau^{1-\sigma}\right] \mu(z) d z .
$$

We use (50) to substitute domestic prices out as

$$
\frac{R_{1}(\ell, \mathbb{I}(z) ; z)}{R_{1}(\tilde{\ell}, 0 ; \tilde{z})}=\frac{p_{D}(z) z}{\tilde{z}}=\left(\frac{\tilde{\theta}}{\theta}\right)^{1-\eta}
$$

from which one can make use of equation (51) to express the distribution of producer prices as a function of $z$

$$
p_{D}(z)=\frac{\tilde{z}}{z}\left(\frac{\tilde{\theta}}{\theta}\right)^{1-\eta}=\left(\frac{\tilde{z}}{z}\right)^{1+\zeta \frac{\sigma-1}{\sigma}(1-\eta)}\left[1+\mathbb{I}(z) \tau^{1-\sigma}\right]^{-\frac{\zeta}{\sigma}(1-\eta)} .
$$

Let $\lambda=\zeta[(\sigma-1) / \sigma](1-\eta)+1$, we now show that $\lambda=\beta /(\sigma-1)$. Using the definition of $\zeta$, note that

$$
\lambda=\frac{\alpha}{(\alpha-1) \sigma\left[\frac{1}{\sigma}\left(\frac{1}{\alpha-1}+\eta\right)+\sigma(1-\eta)\right]}=-\frac{\zeta}{\sigma} \frac{\alpha}{\alpha-1}=\frac{\beta}{\sigma-1} .
$$

Replacing the exponent of $\tilde{z} / z$ in (57) with $\lambda=\beta /(\sigma-1)$ and plugging the price equation into (56), we obtain (28).

In order to establish the proportionality of profits, we exploit the fact that demand functions are such that $R(z)=\left[1+\mathbb{I}(z) \tau^{1-\sigma}\right] R_{D}(z)$ as well as $R_{D}(z)=(z \ell / \tilde{z} \ell)^{(\sigma-1) / \sigma} R_{D}(\tilde{z})$. Replacing theses two equalities into (23) we obtain

$$
\pi(z ; W)=\left[1+\mathbb{I}(z) \tau^{1-\sigma}\right]\left[\frac{z \ell_{D}(z)}{\tilde{z} \ell_{D}(\tilde{z})}\right]^{\frac{\sigma-1}{\sigma}} \tilde{z} \ell_{D}(\tilde{z})-\frac{v(z)}{\theta(z)} W-v(z)^{\alpha}-f-\mathbb{I}(z) f_{X},
$$


where we have suppressed the dependence of $\mathbb{I}, \ell_{D}, v$ and $\theta$ on $W$ and $\tilde{z}$ to avoid notational clutter. Using Lemma 1 , it is possible to simplify each components of $\pi(z ; W)$. Starting with revenues, we observe that

$$
\begin{aligned}
\frac{z \ell_{D}(z)}{\tilde{z} \ell_{D}(\tilde{z})} & =\frac{z}{\tilde{z}}\left(\frac{1}{1+\mathbb{I}(z) \tau^{1-\sigma}}\right) \frac{\ell(z)}{\ell(\tilde{z})}=\frac{z}{\tilde{z}}\left(\frac{1}{1+\mathbb{I}(z) \tau^{1-\sigma}}\right)\left(\frac{\theta}{\tilde{\theta}}\right)^{\frac{1}{1-\alpha}-\eta} \\
& =\left(\frac{z}{\tilde{z}}\right)^{1+\zeta \frac{\sigma-1}{\sigma}\left[\frac{1}{1-\alpha}-\eta\right]}\left(\frac{1}{1+\mathbb{I}(z) \tau^{1-\sigma}}\right)^{1-\zeta \frac{1}{\sigma}\left[\frac{1}{1-\alpha}-\eta\right]}
\end{aligned}
$$

while

$$
\tilde{z} l_{D}(\tilde{z})=\tilde{z} A \tilde{\theta}^{\frac{1}{1-\alpha}-\eta}\left(\frac{1-\eta}{c \alpha \eta} W\right)^{\frac{1}{\alpha-1}}=\tilde{z}^{1+\frac{1}{\eta-1}\left(\frac{1}{1-\alpha}-\eta\right)} W^{-\frac{\eta}{1-\eta} \frac{\alpha}{\alpha-1}} K_{1}
$$

where

$$
K_{1} \triangleq\left(\frac{1}{\eta}\right)^{-\frac{\eta}{1-\eta} \frac{\alpha}{\alpha-1}}\left(\frac{\sigma}{A(\sigma-1)}\right)^{\frac{1}{1-\eta}\left(\frac{1}{1-\alpha}-\eta\right)} A\left(\frac{1-\eta}{\alpha}\right)^{\frac{1}{\alpha-1}}
$$

We can therefore rewrite revenues as

$$
\left(1+\mathbb{I}(z) \tau^{1-\sigma}\right)\left[\frac{z \ell_{D}(z)}{\tilde{z} \ell_{D}(\tilde{z})}\right]^{\frac{\sigma-1}{\sigma}} \tilde{z} l_{D}(\tilde{z})=K_{1} W^{-\frac{\eta}{1-\eta} \frac{\alpha}{\alpha-1}} \tilde{z}^{\gamma} z^{\beta}\left[1+\mathbb{I}(z) \tau^{1-\sigma}\right]^{\frac{\beta}{\sigma-1}}
$$

where

$$
\beta=\frac{\sigma-1}{\sigma} \zeta \frac{\alpha}{1-\alpha}=\left(\frac{\sigma-1}{\sigma}\right)^{2} \zeta\left(\frac{1}{1-\alpha}-\eta\right)+\frac{\sigma-1}{\sigma}>0 .
$$

The sign of $\beta$ follows from $\zeta<0$ and $\alpha>1$. The exponent of $\tilde{z}$ is

$$
\gamma \triangleq\left(\frac{1}{\alpha-1}+\eta\right)\left[\frac{1}{1-\eta}+\left(\frac{\sigma-1}{\sigma}\right)^{2} \zeta\right]+\frac{1}{\sigma}=\frac{\alpha}{\alpha-1} \frac{1}{1-\eta}-\beta>0 .
$$

The last equality holds because $((\sigma-1) / \sigma) \zeta(1 /(1-\alpha)-\eta)+1=(\sigma /(\sigma-1)) \beta$. To see that $\gamma$ is positive, observe that this holds true if $(\sigma /(\sigma-1))(1 /(1-\eta))+\zeta>0$. Replacing the definition of $\zeta$ given in (52) and imposing $\alpha>1$ shows that the last inequality is indeed satisfied. Focusing now on the wage bill, we obtain

$$
\begin{aligned}
\frac{v(z)}{\theta(z)} & =\left(\frac{1-\eta}{\alpha \eta} W\right)^{\frac{1}{\alpha-1}} \theta(z)^{\frac{\alpha}{1-\alpha}}=\left(\frac{1-\eta}{\alpha \eta} W\right)^{\frac{1}{\alpha-1}}\left[\left(\frac{z}{\tilde{z}}\left(1+\mathbb{I}(z) \tau^{1-\sigma}\right)^{\frac{1}{\sigma-1}}\right)^{\zeta \frac{\sigma-1}{\sigma}} \tilde{\theta}\right]^{\frac{\alpha}{1-\alpha}} \\
& =\left(\frac{1-\eta}{\alpha \eta} W\right)^{\frac{1}{\alpha-1}} \tilde{z}^{\gamma} z^{\beta}\left(1+\mathbb{I}(z) \tau^{1-\sigma}\right)^{\frac{\beta}{\sigma-1}}
\end{aligned}
$$

Finally, turning our attention to the expression for recruitment costs, we find that

$$
v(z)^{\alpha}=\left(\frac{1-\eta}{c \alpha \eta} W\right)^{\frac{\alpha}{\alpha-1}} \theta(z)^{\frac{\alpha}{1-\alpha}}=\left(\frac{1-\eta}{c \alpha \eta} W\right)^{\frac{\alpha}{\alpha-1}} \tilde{\theta}^{\frac{\alpha}{1-\alpha}}\left(\frac{z}{\tilde{z}}\right)^{\zeta \frac{\sigma-1}{\sigma} \frac{\alpha}{1-\alpha}}\left(1+\mathbb{I}(z) \tau^{1-\sigma}\right)^{\zeta \frac{1}{\sigma} \frac{\alpha}{1-\alpha}}
$$

Hence, adding all the terms above yields

$$
\pi(z ; \tilde{z}, W)=K W^{-\frac{\eta}{1-\eta}\left(\frac{\alpha}{\alpha-1}\right)} \tilde{z}^{\gamma} z^{\beta}\left[1+\mathbb{I}(z ; W, \tilde{z}) \tau^{1-\sigma}\right]^{\frac{\beta}{\sigma-1}}-f-\mathbb{I}(z ; W, \tilde{z}) f_{X} .
$$

The constant $K$ reads

$$
K \triangleq K_{1}-\left[\left(\frac{1-\eta}{\alpha \eta}\right)^{\frac{1}{\alpha-1}}+\left(\frac{1-\eta}{\alpha \eta}\right)^{\frac{\alpha}{\alpha-1}}\right]\left(A \eta \frac{\sigma-1}{\sigma}\right)^{-\frac{1}{1-\eta} \frac{\alpha}{1-\alpha}},
$$


where $K_{1}$ is defined in equation (59).

\section{A.4 Derivation of the free entry condition (30)}

The free entry condition ensures that entry occurs until expected profits are exactly identical to the entry $\operatorname{costs} f_{E}$, hence

$$
E[\pi(z)]=\frac{f_{E}}{1-G\left(z_{D}^{*}\right)} .
$$

The expectation operator $E[\cdot]$ aggregates over levels of $z$ that are consistent with positive profits, i.e.,

$$
E[\pi(z)]=\frac{\int_{z_{D}^{*}}^{\infty} \pi(z) d G(z)}{1-G\left(z_{D}^{*}\right)}=\int_{z_{D}^{*}}^{\infty} \pi(z) \mu(z) d z .
$$

In order to use condition (63), we need to relate expected profits $E[\pi(z)]$ to the profits $\tilde{\pi}$ of the representative firm. The definition in (64) and the proportionality of profits established in Lemma 2 ensure that

$$
E[\pi(z)]+f+\varrho f_{X}=[\tilde{\pi}+f] \int_{z_{D}^{*}}^{\infty}\left(\frac{z}{\tilde{z}}\right)^{\beta}\left[1+\mathbb{I}(z) \tau^{1-\sigma}\right]^{\frac{\beta}{\sigma-1}} \mu(z) d z .
$$

But we know from the definition of $\tilde{z}$ in (28) that the integral on the right hand side is equal to $1+\varrho$, which implies in turn that

$$
E[\pi(z)]+f+\varrho f_{X}=[\tilde{\pi}+f](1+\varrho) .
$$

Equation (65) provides us with the desired mapping between expected profits $E[\pi(z)]$ and $\tilde{\pi}$. Accordingly, we can substitute $\tilde{\pi}$ out of (63) to obtain the free entry condition

$$
(F E): \tilde{\pi}=\frac{1}{1+\varrho}\left[\frac{f_{E}}{1-G\left(z_{D}^{*}\right)}+\varrho\left(f_{X}-f\right)\right] .
$$

Using the definition of $\varrho$, expression (30) follows.

\section{A.5 Proof of Proposition 3}

Derivative of $\tilde{z}$ with respect to $z_{D}^{*}$. Denote $\partial z_{X}^{*} / \partial z_{D}^{*} \equiv k$, where we know $k>1$ from (29). We rewrite expression (28) as

$$
\begin{aligned}
\tilde{z}^{\beta}= & \frac{1}{2-G\left(z_{D}^{*}\right)-G\left(z_{X}^{*}\right)} \int_{z_{D}^{*}}^{\infty} z^{\beta}\left[1+\mathbb{I}(z) \tau^{1-\sigma}\right]^{\beta /(\sigma-1)} g(z) d z, \\
\frac{\partial \tilde{z}^{\beta}}{\partial z_{D}^{*}}= & \frac{g\left(z_{D}^{*}\right)+g\left(z_{X}^{*}\right) k}{\left[2-G\left(z_{D}^{*}\right)-G\left(z_{X}^{*}\right)\right]^{2}} \int_{z_{D}^{*}}^{\infty} z^{\beta}\left[1+\mathbb{I}(z) \tau^{1-\sigma}\right]^{\beta /(\sigma-1)} g(z) d z \\
& -\frac{1}{2-G\left(z_{D}^{*}\right)-G\left(z_{X}^{*}\right)} z_{D}^{* \beta} g\left(z_{D}^{*}\right), \\
\frac{\partial \tilde{z}^{\beta}}{\partial z_{D}^{*}} \frac{z_{D}^{*}}{\tilde{z}^{\beta}}= & \frac{g\left(z_{D}^{*}\right) z_{D}^{*}}{2-G\left(z_{D}^{*}\right)-G\left(z_{X}^{*}\right)}\left[1+\frac{g\left(z_{X}^{*}\right)}{g\left(z_{D}^{*}\right)} k-\left(\frac{z_{D}^{*}}{\tilde{z}}\right)^{\beta}\right] \\
\simeq & \frac{G\left(z_{D}^{*}\right)}{2-G\left(z_{D}^{*}\right)-G\left(z_{X}^{*}\right)}\left[1+\frac{g\left(z_{X}^{*}\right)}{g\left(z_{D}^{*}\right)} k-\left(\frac{z_{D}^{*}}{\tilde{z}}\right)^{\beta}\right], \\
\frac{\partial \tilde{z}^{\beta}}{\partial z_{D}^{*}} \frac{z_{D}^{*}}{\tilde{z}^{\beta}} & 0 \Longleftrightarrow\left(1+\frac{g\left(z_{X}^{*}\right)}{g\left(z_{D}^{*}\right)} k\right)\left(\frac{\tilde{z}}{z_{D}^{*}}\right)^{\beta}>1,
\end{aligned}
$$

which is always true since the representative firm has higher productivity than the marginal producer, $\tilde{z}>z_{D}^{*}$, and $\partial z_{X}^{*} / \partial z_{D}^{*}>1$. For the same initial $z_{D}^{*}$, an increase of $z_{D}^{*}$ has a stronger effect on $\tilde{z}$ in our 
model than in the Melitz model (where $\beta$ is replaced by $\sigma-1$ ). Also note that

$$
\frac{\partial \tilde{z}^{\beta}}{\partial \tau} \frac{\tau}{\tilde{z}^{\beta}}=-\beta \frac{\tau^{1-\sigma}}{1+\tau^{1-\sigma}} \Longleftrightarrow \frac{\partial \tilde{z}}{\partial \tau} \frac{\tau}{\tilde{z}}=-\frac{\tau^{1-\sigma}}{1+\tau^{1-\sigma}} .
$$

Slope of free entry condition. We have

$$
\frac{\partial \tilde{\pi}}{\partial z_{D}^{*}}=\frac{-g\left(z_{X}^{*}\right)\left(f_{X}-f\right) k\left[2-G\left(z_{D}^{*}\right)-G\left(z_{X}^{*}\right)\right]+\left[f_{E}+\left[1-G\left(z_{X}^{*}\right)\right]\left(f_{X}-f\right)\right]\left[g\left(z_{D}^{*}\right)+g\left(z_{X}^{*}\right) k\right]}{\left[2-G\left(z_{D}^{*}\right)-G\left(z_{X}^{*}\right)\right]^{2}} .
$$

Then, $\partial \tilde{\pi} / \partial z_{D}^{*}>0$ is equivalent to

$$
\left[f_{E}+\left[1-G\left(z_{X}^{*}\right)\right]\left(f_{X}-f\right)\right]\left[g\left(z_{D}^{*}\right)+g\left(z_{X}^{*}\right) k\right]>g\left(z_{X}^{*}\right)\left(f_{X}-f\right) k\left[2-G\left(z_{D}^{*}\right)-G\left(z_{X}^{*}\right)\right],
$$

or

$$
\frac{\tilde{\pi}}{\left[\left(f_{X}-f\right)-\tilde{\pi}\right]}>\frac{g\left(z_{X}^{*}\right)}{g\left(z_{D}^{*}\right)} k .
$$

Using the expression for $\bar{\pi}$ from (30), one can show that, under the sufficient condition $f_{X}<f_{E}$,

$$
\begin{aligned}
\left(f_{X}-f\right)-\tilde{\pi} & =\left(f_{X}-f\right)-\frac{f_{E}+\left[1-G\left(z_{X}^{*}\right)\right]\left(f_{X}-f\right)}{2-G\left(z_{D}^{*}\right)-G\left(z_{X}^{*}\right)}<0 \\
& \Longleftrightarrow f_{X}<\frac{f_{E}+\left[1-G\left(z_{X}^{*}\right)\right]\left(f_{X}-f\right)}{2-G\left(z_{D}^{*}\right)-G\left(z_{X}^{*}\right)}+f=\frac{f_{E}+\left[1-G\left(z_{X}^{*}\right)\right] f_{X}+\left[1-G\left(z_{D}^{*}\right)\right] f}{2-G\left(z_{D}^{*}\right)-G\left(z_{X}^{*}\right)} .
\end{aligned}
$$

The condition is equivalent to

$$
f_{X}<\frac{f_{E}}{1-G\left(z_{D}^{*}\right)}+f
$$

which always holds if $f_{X}<f_{E}$. Moreover,

$$
\left.\frac{\partial \tilde{\pi}}{\partial z_{D}^{*}} \frac{z_{D}^{*}}{\tilde{\pi}}\right|_{F E}=\frac{\left[g\left(z_{D}^{*}\right)+g\left(k z_{D}^{*}\right) k\right] z_{D}^{*}}{2-G\left(z_{D}^{*}\right)-G\left(z_{X}^{*}\right)} .
$$

Slope of zero cutoff profit condition. The ZCP is identical to the one derived by Melitz (2003) for the case of a closed economy. Totally differentiating with respect to $z_{D}^{*}$, one obtains

$$
\begin{aligned}
\left.\frac{\partial \tilde{\pi}}{\partial z_{D}^{*}} \frac{z_{D}^{*}}{\tilde{\pi}}\right|_{Z P C} & =-\frac{\beta}{1-\left(z_{D}^{*} / \tilde{z}\right)^{\beta}}\left(1-\frac{\partial \tilde{z}}{\partial z_{D}^{*}} \frac{z_{D}^{*}}{\tilde{z}}\right) \\
& =-\frac{1}{1-\left(z_{D}^{*} / \tilde{z}\right)^{\beta}}\left(\beta-\frac{g\left(z_{D}^{*}\right) z_{D}^{*}}{2-G\left(z_{D}^{*}\right)-G\left(z_{X}^{*}\right)}\left[1-\left(z_{D}^{*} / \tilde{z}\right)^{\beta}+\frac{g\left(z_{X}^{*}\right) k}{g\left(z_{D}^{*}\right)}\right]\right) .
\end{aligned}
$$

Melitz (2003) shows that for standard families of distribution functions, this expression is non-positive. For given $z_{D}^{*}$, we obtain

$$
\left.\frac{\partial \tilde{\pi}}{\partial \tilde{z}} \frac{\tilde{z}}{\tilde{\pi}}\right|_{Z P C}=\frac{\beta}{1-\left(z_{D}^{*} / \tilde{z}\right)^{\beta}},
$$

which is positive when $\beta>1$ since $1-\left(z_{D}^{*} / \tilde{z}\right)^{\beta}>0$. In terms of fundamental parameters, the restriction $\beta>1$ is met if $\sigma>1+\alpha$. To see this, we employ the definition of $\beta$

$$
\beta=\frac{(\sigma-1) \alpha}{(\alpha-1)[(1-\eta) \sigma+\eta]+1} .
$$

It is easy to show that $\beta>1 \Longleftrightarrow[1+\eta(\alpha-1)](\sigma-1)>\alpha$. Since $1+\eta(\alpha-1)>1$, we have $\sigma>$ $1+\alpha \Longrightarrow \beta>1$. 


\section{A.6 Derivation of equation (33)}

The aggregate level of employment is by definition equal to

$$
L=M_{D} \int_{z_{D}^{*}}^{\infty} \ell(z) \mu(z) d z=M_{D} A\left(\frac{1-\eta}{\alpha \eta} W\right)^{\frac{1}{\alpha-1}} \int_{z_{D}^{*}}^{\infty} \theta(z)^{-\left(\eta+\frac{1}{\alpha-1}\right)} \mu(z) d z .
$$

To simplify this expression, we have to derive the mass of domestic firms $M_{D}$. Given that a firm with productivity $z$ recruits his workers from a pool of unemployed workers with mass $s(z)=\ell(z) /[\theta(z) q(\theta(z))]$, integrating over all levels of productivity yields

$$
S=M_{D} \int_{z_{D}^{*}}^{\infty}\left[\frac{\ell(z)}{\theta(z) q(\theta(z))}\right] \mu(z) d z=M_{D}\left(\frac{1-\eta}{\alpha \eta} W\right)^{\frac{1}{\alpha-1}} \int_{z_{D}^{*}}^{\infty} \theta(z)^{\frac{\alpha}{1-\alpha}} \mu(z) d z,
$$

where $S$ is the mass of job seekers. Lemma 1 allows us to simplify the integral

$$
\begin{aligned}
\int_{z_{D}^{*}}^{\infty} \theta(z)^{\frac{\alpha}{1-\alpha}} d \mu(z) & =\int_{z_{D}^{*}}^{\infty}\left[\tilde{\theta}\left(\frac{z}{\tilde{z}}\right)^{\zeta \frac{\sigma-1}{\sigma}}\left[1+\mathbb{I}(z) \tau^{1-\sigma}\right]^{\frac{\zeta}{\sigma}}\right]^{\frac{\alpha}{1-\alpha}} \mu(z) d z \\
& =\tilde{\theta}^{\frac{\alpha}{1-\alpha}} \int_{z_{D}^{*}}^{\infty}\left(\frac{z}{\tilde{z}}\right)^{\beta}\left[1+\mathbb{I}(z) \tau^{1-\sigma}\right]^{\frac{\beta}{\sigma-1}} \mu(z) d z .
\end{aligned}
$$

But we know from (28) that the integral on the right hand side equals $1+\varrho$, which implies in turn that

$$
\int_{z_{D}^{*}}^{\infty} \theta(z)^{\frac{\alpha}{1-\alpha}} \mu(z) d z=\tilde{\theta}^{\frac{\alpha}{1-\alpha}}(1+\varrho) .
$$

Reinserting this equality into (68) and setting $S=1$, we find that

$$
M_{D}=\left(\frac{1-\eta}{\alpha \eta} W\right)^{\frac{1}{1-\alpha}} \frac{\tilde{\theta}^{\frac{\alpha}{\alpha-1}}}{1+\varrho} .
$$

Substituting $M_{D}$ in (67), we finally get

$$
L=\frac{A}{1+\varrho} \tilde{\theta}^{\frac{\alpha}{\alpha-1}} \int_{z_{D}^{*}}^{\infty} \theta(z)^{-\left(\eta+\frac{1}{\alpha-1}\right)} \mu(z) d z,
$$

Finally, Lemma 1 allows us to substitute out the vacancy-unemployment ratios

$$
L=A \tilde{\theta}^{1-\eta} \frac{\int_{z_{D}^{*}}^{\infty} z^{-\left(\eta+\frac{1}{\alpha-1}\right) \zeta \frac{\sigma-1}{\sigma}}\left[1+\mathbb{I}(z) \tau^{1-\sigma}\right]^{-\frac{\zeta}{\sigma}\left(\eta+\frac{1}{\alpha-1}\right)} \mu(z) d z}{(1+\varrho) \tilde{z}^{-\left(\eta+\frac{1}{\alpha-1}\right) \zeta \frac{\sigma-1}{\sigma}}} .
$$

The exponents can be simplified using the definition of $\beta$ in (60) to obtain (33) with $\bar{z}$ being given by

$$
\bar{z} \triangleq\left[\frac{1}{1+\varrho} \int_{z_{D}^{*}}^{\infty} z^{\beta \frac{\sigma}{\sigma-1}-1}\left[1+\mathbb{I}(z) \tau^{1-\sigma}\right]^{\frac{1}{\sigma-1}\left(\beta \frac{\sigma}{\sigma-1}-1\right)} \mu(z) d z\right]^{\frac{1}{\beta \frac{\sigma}{\sigma-1}-1}} .
$$




\section{A.7 Wage distribution when $G(z)$ is Pareto}

Let $\mu_{X}(z)$ and $\mu_{D}(z)$ denote the distribution of productivity among exporters and domestic producers, respectively. When $G(z)$ is Pareto we have by definition

$$
\mu_{X}(z)=\frac{g(z)}{1-G\left(z_{X}\right)}=\kappa z_{X}^{* \kappa} z^{-\kappa-1}, \text { and } \mu_{D}(z)=\frac{g(z)}{G\left(z_{X}\right)-G\left(z_{D}\right)}=\frac{\kappa z_{D}^{* \kappa} z^{-\kappa-1}}{1-\left(\frac{z_{D}^{*}}{z_{X}^{*}}\right)^{\kappa}} .
$$

The distribution of wages follows weighting the densities above by firm sizes. Starting with exporters, one obtains

$$
g_{X}^{w}(z)=\frac{\int_{z_{X}^{*}}^{z(w)} \ell(x) \mu_{X}(x) d x}{\int_{z_{X}^{*}}^{\infty} \ell(x) \mu_{X}(x) d x}=\frac{\int_{z_{X}^{*}}^{z(w)} x^{\beta \frac{\alpha-1}{\alpha}\left(\eta+\frac{1}{\alpha-1}\right)-\kappa-1} d x}{\int_{z_{X}^{*}}^{\infty} x^{\beta \frac{\alpha-1}{\alpha}-\kappa-1} d x}=1-\left(\frac{z(w)}{z_{X}^{*}}\right)^{\beta \frac{\alpha-1}{\alpha}\left(\eta+\frac{1}{\alpha-1}\right)-\kappa},
$$

where, with some slight abuse of notation, $z(w)$ is the inverse function for $w(z)$. To write the previous expression in terms of wages, we use the proportionality relationship

$$
\frac{w(z)}{w\left(z_{X}^{*}\right)}=\left(\frac{z}{z_{X}^{*}}\right)^{1-\frac{\beta}{\sigma-1}} \Rightarrow \frac{z(w)}{z_{X}^{*}}=\left(\frac{w}{w\left(z_{X}^{*}\right)}\right)^{\frac{\sigma-1}{\sigma-1-\beta}} .
$$

Reinserting this identity in the previous equation yields a Pareto distribution with shape parameter $\kappa_{w}=(\sigma-1)\left[\kappa-\beta \alpha^{-1}(\alpha-1)(\eta+1 /(\alpha-1))\right] /(\sigma-1-\beta)$. The wage distribution among domestic producers can be derived in a similar fashion. Skipping intermediate steps, one gets

$$
g_{D}(z)=\frac{\int_{z_{D}^{*}}^{z} \ell(x) \mu_{D}(x) d x}{\int_{z_{D}^{*}}^{z_{X}^{*}} \ell(x) \mu_{D}(x) d x}=\frac{1-\left(\frac{z}{z_{D}^{*}}\right)^{\beta \frac{\alpha-1}{\alpha}\left(\eta+\frac{1}{\alpha-1}\right)-\kappa}}{1-\left(\frac{z_{X}^{*}}{z_{D}^{*}}\right)^{\beta \frac{\alpha-1}{\alpha}\left(\eta+\frac{1}{\alpha-1}\right)-\kappa}} .
$$

Once productivity $z$ have been replaced by wages, $g_{D}^{w}(w)$ becomes equivalent to a truncated Pareto distribution with shape parameter $\kappa_{w}$.

\section{A.8 Proof of Proposition 4}

We start by showing that the $F E$ condition shifts down with $\Delta \tau<0$. To see this, note that $\partial z_{X}^{*} /\left.\partial \tau\right|_{z_{D}^{*}=\text { const. }}>$ 0 , and differentiate the $F E$ condition with respect to $\tau$ for given $z_{D}^{*}$,

$$
\frac{\partial \tilde{\pi}_{F E}}{\partial \tau}=\frac{-\left(f_{X}-f\right) g\left(z_{X}^{*}\right) \frac{\partial z_{X}^{*}}{\partial \tau}\left[2-G\left(z_{D}^{*}\right)-G\left(z_{X}^{*}\right)\right]+\left\{f_{E}+\left[1-G\left(z_{X}^{*}\right)\right]\left(f_{X}-f\right)\right\} g\left(z_{X}^{*}\right) \frac{\partial z_{X}^{*}}{\partial \tau}}{\left\{2-G\left(z_{D}^{*}\right)-G\left[z_{X}^{*}\left(z_{D}^{*}\right)\right]\right\}^{2}},
$$

where all derivatives are understood as relating to fixed $z_{D}^{*}$. This implies

$$
\frac{\partial \tilde{\pi}_{F E}}{\partial \tau}>0 \Leftrightarrow\left\{f_{E}-\left(f_{X}-f\right)\left[1-G\left(z_{D}^{*}\right)\right]\right\} g\left(z_{X}^{*}\right) \frac{z_{X}^{*}}{\partial \tau}>0 \Leftrightarrow\left\{f_{E}-\left(f_{X}-f\right)\left[1-G\left(z_{D}^{*}\right)\right]\right\}>0 .
$$

The last inequality is satisfied under the sufficient condition $f_{E}>f_{X}$, which has been employed in proof of Proposition 3. Bringing the $Z C P$ condition into the picture, product market equilibrium $\pi(\tilde{z})_{Z P C}=$ $\pi(\tilde{z})_{F E}$ is characterized by

$$
f\left[\left(\frac{\tilde{z}\left(z_{D}^{*}\right)}{z_{D}^{*}}\right)^{\beta}-1\right]=\frac{f_{E}+\left\{1-G\left[z_{X}^{*}\left(z_{D}^{*}\right)\right]\right\}\left(f_{X}-f\right)}{2-G\left(z_{D}^{*}\right)-G\left[z_{X}^{*}\left(z_{D}^{*}\right)\right]} .
$$


Totally differentiating the equilibrium condition and using the notation $\hat{x}=d x / x$, we obtain

$$
-\left[\frac{\beta}{1-\left(z_{D}^{*} / \tilde{z}\right)^{\beta}}+\frac{\left[g\left(z_{D}^{*}\right)+g\left(k z_{D}^{*}\right) k\right] z_{D}^{*}}{2-G\left(z_{D}^{*}\right)-G\left(z_{X}^{*}\right)}\right] \hat{z}_{D}^{*}=\frac{\beta}{1-\left(z_{D}^{*} / \tilde{z}\right)^{\beta}} \frac{\tau^{1-\sigma}}{1+\tau^{1-\sigma}} \hat{\tau} .
$$

We have already shown in the proof of Proposition 3 that $z_{D}^{*}$ is decreasing in $\tau$ when $\beta>1$. So, if the sufficient condition $\beta>1$ holds, $\hat{z}_{D}^{*} / \hat{\tau}<0$ and trade liberalization (lower $\tau$ ) indeed increases $z_{D}^{*}$. We still have to prove that $\tilde{z}$ is increasing in $z_{D}^{*}$. Reinserting the Pareto distribution into the definition of $\tilde{z}$, we obtain

$$
\begin{aligned}
\tilde{z}^{\beta} & =\frac{1}{1+\varrho} \int_{z_{D}^{*}}^{\infty} z^{\beta}\left[1+\mathbb{I}(z) \tau^{1-\sigma}\right]^{\frac{\beta}{\sigma-1}} \kappa z_{D}^{* \kappa} z^{-\kappa-1} d z \\
& =\frac{z_{D}^{* \kappa}}{1+\varrho} \frac{\kappa}{\kappa-\beta}\left[z_{X}^{* \beta-\kappa}\left(\left[1+\tau^{1-\sigma}\right]^{\frac{\beta}{\sigma-1}}-1\right)+z_{D}^{* \beta-\kappa}\right] .
\end{aligned}
$$

But we know from equation (29) that

$$
\left[1+\tau^{1-\sigma}\right]^{\frac{\beta}{\sigma-1}}-1=\frac{f_{X}}{f}\left(\frac{z_{D}^{*}}{z_{X}^{*}}\right)^{\beta},
$$

while the share of exporters $\varrho=\left(z_{D}^{*} / z_{X}^{*}\right)^{\kappa}$. We can therefore rewrite the equality above as

$$
\tilde{z}^{\beta}=\frac{\kappa}{\kappa-\beta} z_{D}^{* \beta}\left[\frac{1+\varrho\left(\frac{f_{X}}{f}\right)}{1+\varrho}\right] .
$$

Given that $\varrho$ is increasing in $z_{D}^{*}$, we indeed have $\tilde{z}$ increasing in $z_{D}^{*}$ whenever $f_{X}>f$.

\section{A.9 Aggregate employment $L$ when $G(z)$ is Pareto}

With the Pareto assumption, equation (33) can be stated as $L=\tilde{\theta} q(\tilde{\theta}) \Lambda$ where

$$
\Lambda=\left(\frac{\left[1+\tau^{1-\sigma}\right]^{\frac{\beta}{\sigma-1}}}{2} \kappa\right)^{\frac{1}{\beta}-\frac{1}{\sigma-1}} \frac{[\kappa-\beta]^{\frac{\sigma}{\sigma-1}-\frac{1}{\beta}}}{\kappa-\beta \frac{\sigma}{\sigma-1}+1}
$$

To understand the mapping between $\tilde{z}$ and $\tilde{\theta}$, it is helpful to combine the expressions of $\tilde{\theta}$ in (46) and of $W$ in (31) to obtain

$$
\tilde{\theta} q(\tilde{\theta})=\tilde{\theta}^{1-\eta}=\frac{\sigma}{\sigma-1} \frac{W}{A \eta \tilde{z}}=\frac{\sigma}{(\sigma-1) A \eta}\left[\frac{K}{f}\left(\frac{z_{D}^{*}}{\tilde{z}}\right)^{\beta}\right]^{\frac{1-\eta}{\eta} \frac{\alpha-1}{\alpha}} \tilde{z}^{\frac{1}{\eta}-1} .
$$

When $G(z)$ is Pareto and all firms export, the ratio $\left(z_{D}^{*} / \tilde{z}\right)$ is constant. Hence the elasticity of $\tilde{\theta}$ with respect to $\tilde{z}$ is also constant and equal to $1 / \eta>0$.

\section{A.10 Asymmetric countries}

In our small open economy setup we assume the foreign aggregate demand shifter $Q^{*}$ and the foreign mass of firms $M^{*}$ as given. Since the domestic price index is not equal to one anymore the demand for 
each good in the home market is

$$
q(z)={\frac{p(\omega)}{M P^{1-\sigma}}}^{-\sigma} R=\left(\frac{p(\omega)}{P}\right)^{-\sigma} Q
$$

while in the foreign market it is

$$
q^{*}(z)=p^{*}(\omega)^{-\sigma} \frac{Y^{*}}{M^{*}}=p^{*}(\omega)^{-\sigma} Q^{*} .
$$

Revenues are only slightly different now and given by

$$
R(z, \ell)=(z \ell)^{\frac{\sigma-1}{\sigma}}\left[P^{\sigma} Q+\mathbb{I}_{a}(z) \tau^{1-\sigma} Q^{*}\right]^{\frac{1}{\sigma}}
$$

Labor market description for Home is as before. The export cutoff $\ell_{x}$ is now given by

$$
\ell_{X}(z)=\frac{1}{z}\left(\frac{f_{x}}{\left(P^{\sigma} Q+\left(\tau^{*}\right)^{1-\sigma} Q^{*}\right)^{\frac{1}{\sigma}}-\left(P^{\sigma} Q\right)^{\frac{1}{\sigma}}}\right)^{\frac{\sigma}{\sigma-1}}
$$

Foreign firms participate in the export business if their labor productivity exceeds the exporting threshold $z_{x}^{*}$, which is determined in the same fashion as the one for home firms. The size threshold for exporting for foreign firms is

$$
\ell_{X}^{*}(z)=\frac{1}{z}\left(\frac{f_{x}}{\left(Q^{*}+(\tau)^{1-\sigma} P^{\sigma} Q\right)^{\frac{1}{\sigma}}-Q^{* \frac{1}{\sigma}}}\right)^{\frac{\sigma}{\sigma-1}}
$$

and the cutoff $z_{X}^{*}$ is determined by the condition, $z_{X}^{*}=\inf \left\{z: \bar{\ell}^{*}(z) \geq \ell_{X}^{*}(z)\right\}$, according to which the marginal exporter is the least productive firm reaching the export threshold size $\ell_{X}^{*}(z)$. Where the steady state level of firm size $\bar{\ell}^{*}(z)$ is determined by

$$
\left(\frac{\chi^{\ell^{*}}(z)}{\xi_{0}}\right)^{\xi_{1}}=\frac{\eta}{\rho}\left[\frac{R_{1}^{*}\left[\bar{\ell}^{*}(z), \mathbb{I}\left(\bar{\ell}^{*}(z), z\right) ; z\right]-w_{r}^{*}}{r^{*}+\delta+\chi}\right] .
$$

We need to introduce a new equilibrium condition: the balance of trade condition,

$$
\begin{aligned}
\int_{z_{x}} R(z, \ell) M \mu(z) d z-\int_{z_{X}^{*}} R^{*}(z, \ell) M^{*} \mu^{*}(z) d z & =B \\
\int_{z_{X}}(z \ell)^{\frac{\sigma-1}{\sigma}}\left[\tau^{1-\sigma} Q^{*}\right]^{\frac{1}{\sigma}} M \mu(z) d z-\int_{z_{X}^{*}}(z \ell)^{\frac{\sigma-1}{\sigma}}\left[\tau^{1-\sigma} P^{\sigma} Q\right]^{\frac{1}{\sigma}} M^{*} \mu^{*}(z) d z & =B
\end{aligned}
$$

where $B$ is the trade balance. In order to derive aggregate output note that

$$
\begin{aligned}
\mathcal{R} & =\int R(\omega) d \omega=\int\left[P^{\sigma} Q+\mathbb{I}_{a}(\omega) \tau^{1-\sigma} Q^{*}\right]^{\frac{1}{\sigma}}(z(\omega) \ell(\omega))^{\frac{\sigma-1}{\sigma}} d \omega \\
P Y-B & =\left(M-\varrho^{*} M^{*}\right) \int\left(P^{\sigma} Q+\mathbb{I}_{a}(\omega) \tau^{1-\sigma} Q^{*}\right)^{\frac{1}{\sigma}}(z \ell(z))^{\frac{\sigma-1}{\sigma}} \mu(z) d z .
\end{aligned}
$$

where the third equality follows from $M_{D}=M-\varrho^{*} M^{*}$. Total production is $P Y=\mathcal{R}+B$, total revenues plus the trade balance which, rearranged, gives (39). The rest of the model is structurally similar to the benchmark economy and the derivation is straightforward.

The way we set up the small open economy version of the model has the nice feature that the only endogenous variable we need to compute for the foreign country is the export cutoff $z_{X}^{*}$. Once we account 
for the changes above the equilibrium of the model is as follows: the home country firm-size dynamics is given by (16) and a similar set of differential equations for the foreign country. Steady-state firm size for home country is given (17) but now you need to add one for the foreign country (70) above. Moreover, we need to take the foreign interest rate $r^{*}$ as given and also the foreign reservation wage $w_{r}^{*}$ as given. The equilibrium is computed in the following way. Given $Q$ and $w_{r}\left(r^{*}\right.$ and $\left.w_{r}^{*}\right)$ use the differential equations to solve for the size dynamics of both domestic and foreign firms. Then the cutoff conditions $\Pi\left(0,0 ; z_{D}\right)=0, z_{X}=\inf \left\{z: \bar{\ell}(z) \geq \ell_{X}(z)\right\}$ and $z_{X}^{*}=\inf \left\{z: \bar{\ell}^{*}(z) \geq \ell_{X}^{*}(z)\right\}$, together export conditions give us the home cutoffs $z_{D}$ and $z_{X}$ and the foreign export cutoff $z_{X}^{*}$. The free entry condition (same as in the paper), the aggregate output (73), and $S+L=1$, to determine $Q, w_{r}$ and $M$. Finally, $B$ is pinned down by (71) which yields the domestic price index $P$.

\section{B Data Appendix}

\section{B.1 The SIAB data base}

The Sample of Integrated Labour Market Biographies (Stichprobe der integrierten Arbeitsmarktbiographien - SIAB) is a $2 \%$ sample of the population of the Integrated Employment Biographies (IEB) of the Institute for Employment Research (Institut für Arbeitsmarktund Berufsforschung - IAB) ${ }^{66}$ The IEB comprises all workers in Germany subject to social security. The major excluded groups are civil servants and self-employed. The data is process-produced from administrative sources such as the notification process by which firms are legally obliged to register workers to the Federal Employment Agency and report any changes in wage or employment structure. The current version of the SIAB contains employment histories of 1,659,024 individuals, documented in 40,501,525 data records. The SIAB comprises data reaching as far back as 1975, and it is organized by spells (worker-plant matches).

Amongst other things, the data provides unique identifiers for persons and establishments (which allows the computation of plant fixed-effects), information about the gross daily pay, the occupation of the worker, socio-demographic characteristics such as year of birth, sex, citizenship, school education, and so on, basic characteristics of the employing establishment such as industry code (five digit), number of (full) employees and median gross daily pay, and so on.

Generally, the data comprised in the SIAB can be considered to be very reliable. This is particularly true for information collected not exclusively for statistical purposes: for instance, the data on remuneration are used by the German Statutory Pension Insurance to calculate pension claims. The educational variable is less reliable because an incorrect information there neither hurts the employer nor the employee. However, well-established procedures are available to cleanse the education variable to make it more accurate (Fitzenberger et al., 2006). Additional issues arise with regard to the industry classification which has changed several times; but industry classifications can be harmonized following the proposal of Card et al. (2013) at the two-digit level.

Finally, a very important issue with the data relates to the top-coding of the wage variable. Daily wages are right-censored at the maximum level on which Social Security contributions are based. Following Dustmann et al. (2009) and Card et al. (2013), we use Tobit regressions to impute wages above the cut-off level. For each year we run a separate regression using age, age squared, tenure, tenure squared, gender, foreign nationality as well as a full set of industry dummies. Missing wages are replaced by predicted values from the Tobit model.

\section{B.2 The LIAB data base}

The LIAB data base is a linked employer-employee data base provided by the Institute of Labor market Research (IAB) ${ }^{67}$ Its core is the so called IAB establishment panel, which provides plant-level information. Based on a unique establishment identifier, the IAB merges the information of the universe of socially secured employees at the plant level to the establishment data. The establishment panel is a

\footnotetext{
${ }^{66}$ A comprehensive introduction to the SIAB data set is provided by Dorner et al. (2010).

${ }^{67} \mathrm{~A}$ comprehensive introduction to the LIAB data set is provided by Alda et al. (2005).
} 
yearly survey which includes establishments with at least one employee covered by social security. The sample is drawn following the principle of optimum stratification. These stratification cells are also used in the weighting and extrapolation of the sample. The survey is conducted by interviewers from TNS Infratest Sozialforschung. About 4300 establishments from Western Germany participate in the survey. The response rate of units that have been interviewed repeatedly is over $80 \%$. We use the cross-sectional version of the data set for the years 1996 to 2007.

One problem with the plant-level data is its lack of representativeness. However, the IAB represents sampling weights which can be employed to reconstruct a representative sample of German plants. The plant-level information is very rich; it covers details about the plants' industrial relations, information about the structure of its work-force, and, quite important for our purposes, on total revenue and on the export share of the plant. It has information on the total wage bill and on the age of the establishment, as well as on establishment size and industry.

\section{B.3 Aggregate data}

We report a measure of residual inequality that is attributable to establishment effects. We obtain this information by multiplying the standard deviation of log raw wages by the share of variance explained by establishment effects as estimated by Card et al. (2013). Raw inequality is $0.40 \log$ points in 1996, while the share of total wage variation in 1996 is 0.205 . In 2007 the estimates are 0.526 and 0.21 , respectively.

The trade openness measure is based on a value added metric rather than on the usual ratio of gross trade over GDP. In the presence of an internationally fragmented value chain, gross exports (the value of exports at the border as declared to customs) overestimates the value added content of domestic production aimed for foreign consumption. The reason is that export of some country increasingly include foreign inputs. Similarly, a country's imports may include a non-trivial measure of its own value added. To compute the domestic value added content of exports and the foreign value added content of imports, one requires a matrix of input-output tables for the entire world. the Word Input-Output Data (WIOD) consortium has produced such matrices for the years 1995 to 2009; it is available under www.wiod.org. Details of calculations are provided by Aichele et al. (2013).

In Germany, the outsourcing trend has been strong over the last 15 years. From 1995 to 2007, the VAX ratio (value added exports divided by gross exports) has fallen from 74 to $66 \%$. A similar trend is observable for imports. Hence, adjusting gross data for their value added content leads to a sizeable reduction of the measured openness. Nonetheless, it remains true that openness has increased very strongly from 1996 to 2007 in Germany.

\section{References}

- Aichele, Rahel, Gabriel Felbermayr and Inga Heiland, 2013, "The Value-Added Content of International Trade: New Data, New Perspectives", ifo Schnelldienst 66(05), 29-41 (in German).

- Alda, Holger, Stefan Bender, and Hermann Gartner, 2005, "The linked employer-employee dataset created from the IAB establishment panel and the process-produced data of the IAB (LIAB)", Schmollers Jahrbuch 125(2): 327-336.

- Dorner, Matthias, Jörg Heining, Peter Jacobebbinghaus and Stefan Seth, 2010, "Sample of Integrated Labour Market Biographies (SIAB) 1975-2008", FDZ-Methodenreport 09/2010, Institute for Employment Reseach, Nuremberg.

- Fitzenberger, Bernd, Aderonke Osikominu, and Robert Völter, 2006, "Imputation Rules to Improve the Education Variable in the IAB Employment Subsample", Schmollers Jahrbuch 126(3): 405436 . 